九州大学学術情報リポジトリ

Kyushu University Institutional Repository

The Halictine Bees of Sri Lanka and the Vicinity III. Sudila (Hymenoptera, Halictidae) Part 1

Sakagami, Shoichi

Ebmer, Andreas W.

Tadauchi, 0samu

https://doi.org/10.5109/2600

出版情報: ESAKIA. 36，pp.143-189，1996-01-31. Entomological Laboratory，Faculty of Agriculture, Kyushu University バージョン :

権利関係 : 


\title{
The Halictine Bees of Sri Lanka and the Vicinity III. Sudila (Hymenoptera, Halictidae) Part 11), 2)
}

\author{
Shôichi F. SAKAGAMI \\ Ainosato, 1-6, 2-2-610, Kitaku, Sapporo, 002 Japan \\ Andreas W. EBMER \\ Kirchenstrasse 9, A-4048, Puchenau, Austria \\ and \\ Osamu TADAUCHI \\ Entomological Laboratory, Faculty of Agriculture, \\ Kyushu University, Fukuoka, 8 12-8 1 Japan
}

\begin{abstract}
The halictine genus Sudila (Cameron, 1898), mainly characterized by the male gigantism, is reinterpreted as a subgenus of Lasioglossum Curtis with 6 species: bidentatum, alphenum, aulacophorum, knndiense (all Sri Lanka, males of 2 last species are first described), jacobsoni (Java), and paralphenum sp. nov. (S. India), mainly characterized by singular metepisternal tubercle (absent in paralphenum) and well dentate male inner tibial spur (jacobsoni, male unknown), all confined to the mountains of S. Asia. This part 1 gives features common to these species and taxonomic and chorologic notes on each species.
\end{abstract}

Key words: Hymenoptera; Halictidae; Sudila; new species; male gigantism; South Asia.

\section{Introduction}

As the 3rd report of "The halictine bees of Sri Lanka and the vicinity (I: Sakagami \& Ebmer, 1987; II: Sakagami, 1991). This paper deals with Sudila, a singular halictine taxon confined to the mountans of S. Asia, particularly of Sri Lanka. This taxon was first described as a halictine genus with 3 species, all from Sri Lanka (Cameron, 1898), mainly by the male cephalic gigantism. However, this feature cannot be considered generic, because

1) Contribution from the Entomological Laboratory, Faculty of Agriculture, Kyushu University, Fukuoka (Ser. 4, No. 95).

2) Reprint request to 0 . Tadauchi 
it is now known in various halictine taxa independently (Ebmer \& Sakagami, 1994), and a continuous polymorphism is obtained in closely studied species, e.g. Lasioglossum (Evylaeus) ohei Hirashima \& Sakagami (Sakagami et al., 1966). Certainly the gigantism attains a bizarre level in Sudilabidentata, but even here small males are more normal (Fig. 1).

Instead, S. bidentatu is characterized by unusual mesepistemal tubercle (weak to obsolete in males, Figs. 3-4) not seen in any other known halictines. Further, the inner spur of the male hind tibia is distinctly dentate (Fig. 2), nevertheless edentate in most halictines (exception: Nesohalictus, but the teeth are far less developed, Sakagami, 1991). By the possession of one or both of these 2 features, Sudila can be distinguished from any other halictines, and regarded as a subgenus of the enormous genus Lasioglossum as detailed later.

\section{Material and methods}

Most studied specimens are those collected by the members of "The biosystematic studies of the insects of Sri Lanka" directed by Dr. Karl V. Krombein, Smithsonian Institution, Washington, D. C., whose names are alphabetically abbreviated in "Specimens examined" as follows: DR (Davis \& Rowe), DW (D. W. Balasooriya), GF (G. F. Hevel), KVK (K. V. Krombein), LJ (L. Jayawicrema), LW (L. Weeratunge), MJ (M. Jayaweera), OS (0. S. Flint, Jr.), PA (Panawatta), PB (P. B. Karunaratne), PF (P. Fernando), RE (R. E. Diets), SK (S. Karunaratne), SS (S. Siriwardane), TG (T. Gunawardane), TW (T. Wijesinhe), VK (V. Kulaselare). For other specimens the collectors are cited as given in the attached labels.

District names in Sri Lanka are abbreviated as Kandy (= Kan. Distr.), Nuwara Eliya (= NE. Distr.), Galle (= Gal. Distr.), Kegalla (= Keg. Distr.), Ratnapura (= Rat. Distr.) and Budulla (= Bad. Distr.).

Terminology mainly follows Eickwort (1969) and Sakagami \& Tadauchi (1995). Some abbreviations: $\mathrm{PP}=$ punctures, IS $=$ interspaces between punctures (IS $0.5=1 / 2$ of the diameter of punctures), $\mathrm{F} n=$ flagellomere $n, \mathrm{~T} n, \mathrm{~S} n=$ metasomal tergum and sternum $n$. Tables 1 and 2 show some measured values in the studied species each measured part shown with abbreviation.

\section{Diagnosis of the subgenus Sudila (Cameron, 1898)}

The genus Sudila Cameron (1898) was erected for the reception of S.bidentata (male), S. fuscipennis (male) and S. ceylonica (female). The type species was designated as S. bidentatu by Sandhouse (1943). Sudila fuscipennis and S. ceylonica are the junior synonyms of S. bidentata(Blüthgen, 1931). Sudila was originally distinguished from Halictus (including Lasioglossum in the present usage) by the absence of propodeal enclosure, the presence of longitudinal furrows on mesoscutum in females, but particularly by the gigantic macrocephalism in males. These 3 features are, however, insufficient to distinguish Sudila from Halictus s. lat. (with Lasioglosswn). The absence of well delimited propodeal enclosure is widespread in many species of the subgenus Evylaeus of the genus Lasioglossum, especially in the group called carinaless Evylaeus with propodeal dorsum not separated from the vertical shield by the distinct transverse carina (Sakagami \& Tadauchi, 199.5). The presence of median furrow and parapsidal furrows is common to all halictines, 

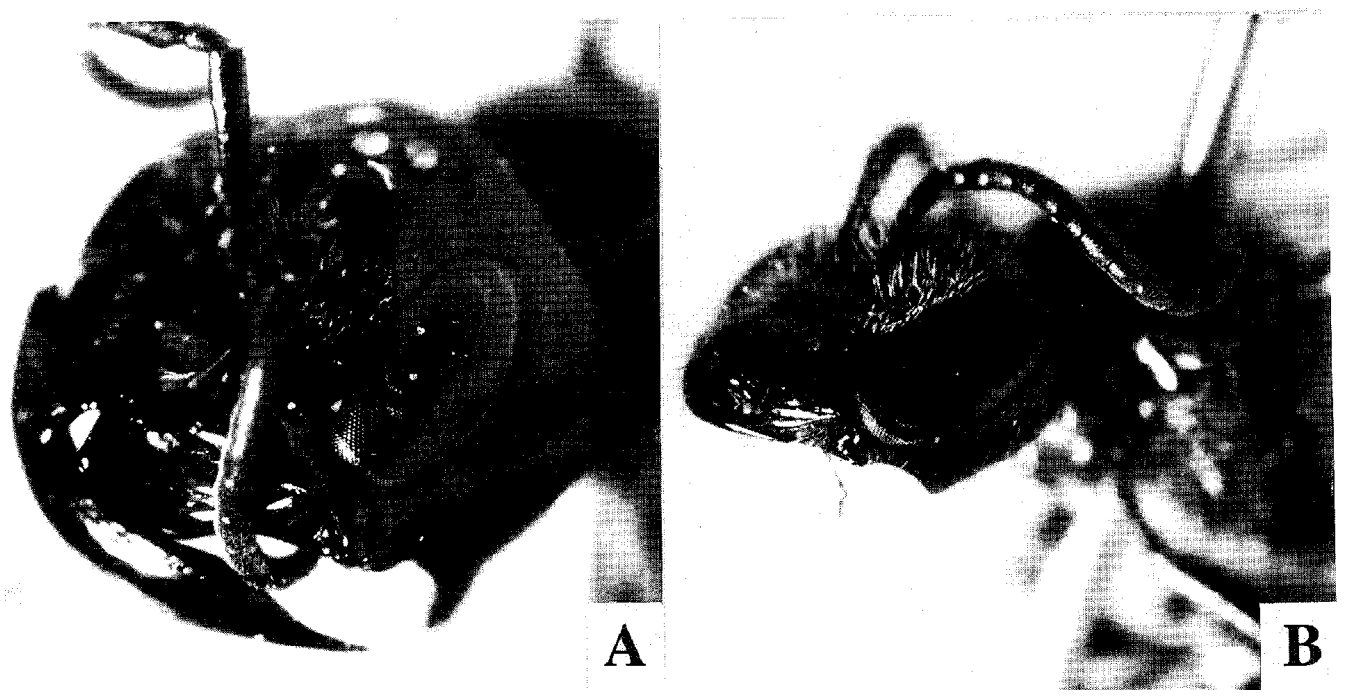

Fig. 1. Head seen oblique-laterally of large (A) and small (B) males of L.(S.) bidentatum.
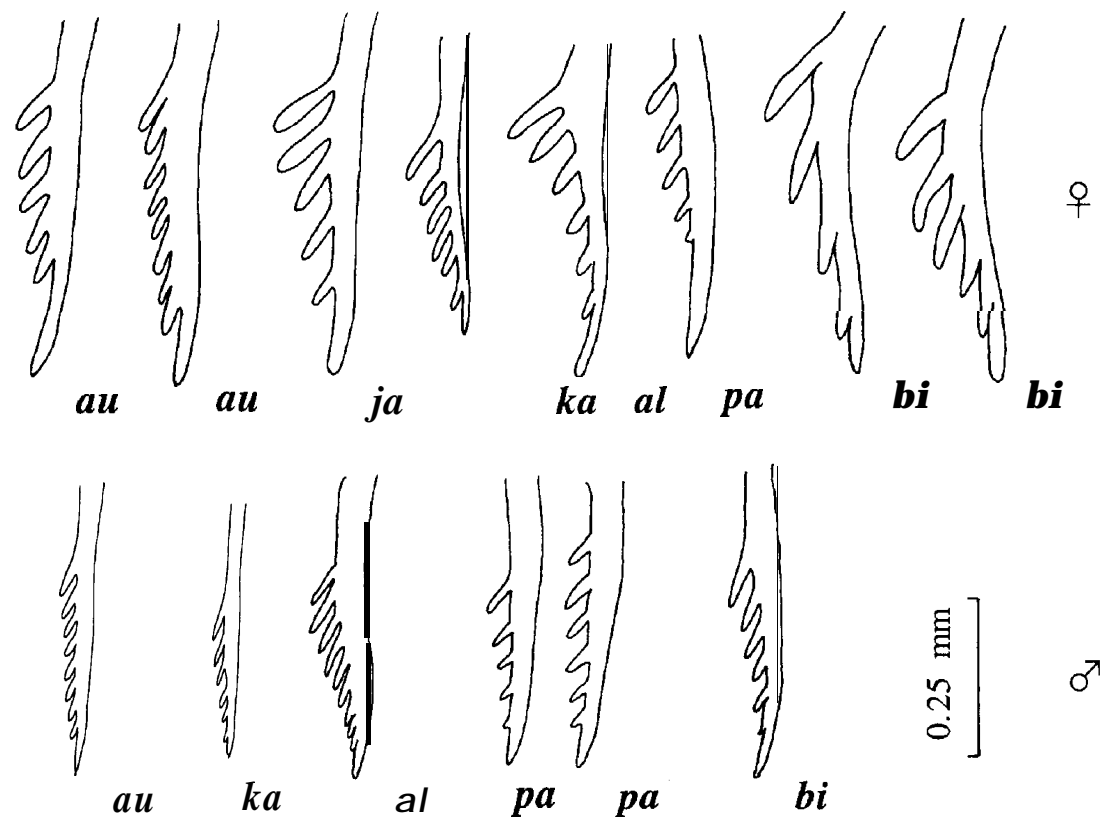

Fig. 2. Inner hind tibial spur of female (top) and male (bottom) of Sudila (au, ja, ka, al, $p a$, bi = aulacophorum, jacobsoni, kandiense, alphenum, paralphenum, bidentatum, these abbreviations are subsequently used in figures and texts). Two extremes are given in $a u$ and bi female (jacobsoni male is unknown).

even if their distinctiveness varies specifically. Possibly due to the poor magnification of microscope and dim light in his time, Cameron perceived these lines more conspicuous in S. bidentata with poorly haired mesoscutum. As explained in Introduction and also later in the 
male cephalic gigantism (Part 2), which was considered the most conspicuous generic feature by Cameron, evolved in several halictine lines independently. It can not be regarded as diagnostic to Sudila.

Ceylonicola Friese (1918), a junior synonym of Sudila, includes 3 species, C. atra the type species designated by Sandhouse, 1943), C. rubriventris and C. submicans, all described simultaneously. The first 2 are junior synonyms of S. bidentata and C. submicans that of S. alphenum Cameron, 1897 (Blüthgen, 1926). Friese characterized Ceylonicola by the nearly hairless and smooth body, resembling that of Prosopis (= Hylaeus). The poor pubescence, particularly of $S$. bidentata, is certainly remarkable, but it alone may not validate the erection of an independent supraspecific taxon.

On the other hand, as mentioned in Introduction, both S. bidentata and alphena, and the 4 other Sudila species, are distinguished from the other Lasioglossum s. lat. by the presence of mesepisternal tubercle and the developed dentition of the inner hind spur of the male hind tibia, although the distinction is not clearly categorical as mentioned below:

\begin{tabular}{lcccc}
\hline Species & Distribution & $\begin{array}{c}\text { Inner hind tibia1 spur } \\
\text { dentate in male }\end{array}$ & \multicolumn{2}{c}{$\begin{array}{c}\text { Presence of } \\
\text { mesepistemal }\end{array}$} \\
\cline { 3 - 5 } & & & tubercle \\
\hline jacobsoni & Java & male unknown & + & male \\
paralphenum & S.India & + & - & $?$ \\
aulacophorum & Sri Lanka & + & + & + \\
kandiense & Sri Lanka & + & + & + \\
alphenum & Sri Lanka & + & + & + \\
bidentatum & Sri Lanka & + & + & $\pm \sim-$ \\
\hline
\end{tabular}

The absence of mesepistemal tubercle in paralphenum and its poor development in the male of $L$. (S.) bidentatum are regarded to suggest the secondary degeneration as discussed in the 'Phylogenetic notes' (Part 2).

The taxonomic position of Sudila is not yet solved, as our knowledge on the supraspecific classification of the tribe Halictini is still insufficient. Except Wamcke (1973, 1975) it is now widely accepted to recognize 2 major groups in this tribe by the presence (Lasioglossum Curtis) or the absence (Halictus Latreille and some other genera, Michener, 1978) of the weakening of fore wing veins $1 r-m$ and $2 r-m$ (or tc-2, $t c-3$; Michener, 1965; McGinley, 1986; Ebmer, 1987a). We do not accept the possible new or revived formation of veins suggested by Wamcke (1973). Sudila, defined by the above 2 features and some others, such as more or less sparse pilosity, the absence of coarse surface sculpture, reduced male ventral retrose lobe, etc., is placed in Lasioglossum s. lat. by the wing venation.

Figure 5 shows the venation of the area of submarginal cells of the fore wing in Halictus rubicundus (A), Lasiogfossum (Lasioglossum) leucozonium (B), L. (Evyfaeus) calceatum (C) and L. (Sudila) bidentatum (D) (all in females). In Halictus $l r-m$ and $2 r-m$ are as strong as Rs-a and Rs-b, although often slightly narrower, and M-b is as wide as M-a. In Lasioglossum s. str. (and its palaeotropic counterparts Ctenonomia and Nesohalictus), $1 \mathrm{r}-\mathrm{m}$ is often slightly narrower than Rs-b, and $2 r-m$ distinctly narrower than $l r-m$, although the contour is usually not faint. M-b is narrower than M-a but not becoming faint. In Evylaeus 


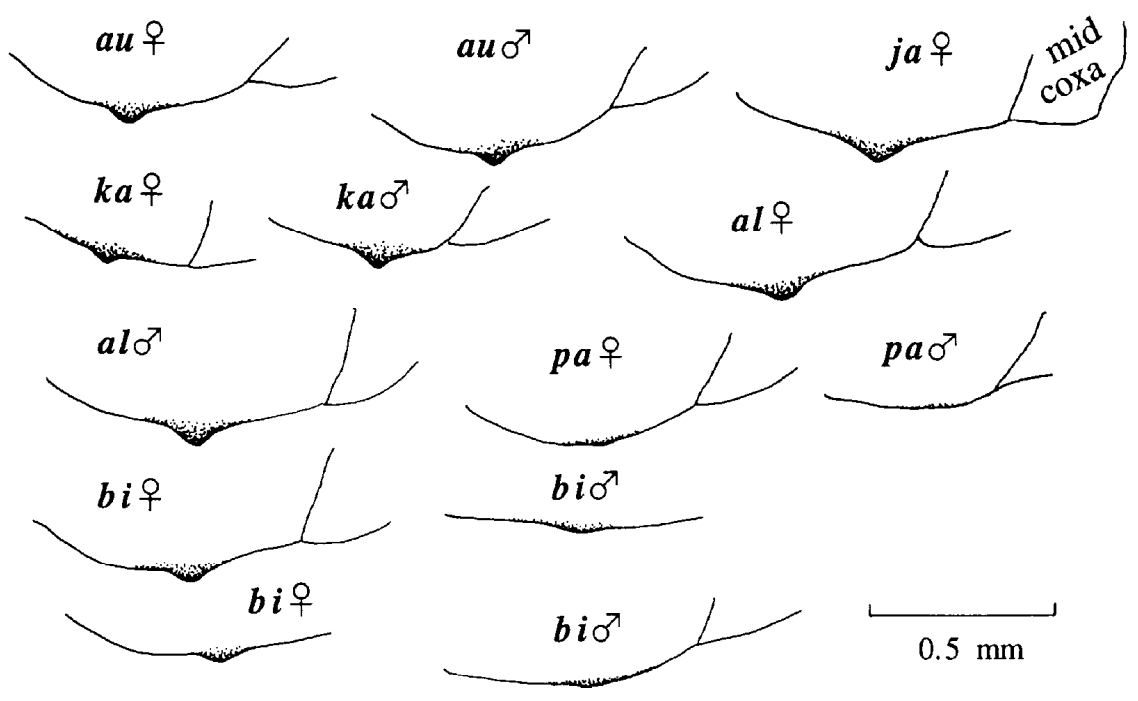

Fig. 3. Mesepistemal tubercle in 6 Sudifa species seen laterally. Species codes as in Fig. 2. Two extremes are shown in L.aulacophorum (female) and L. bidentatum (female and male).

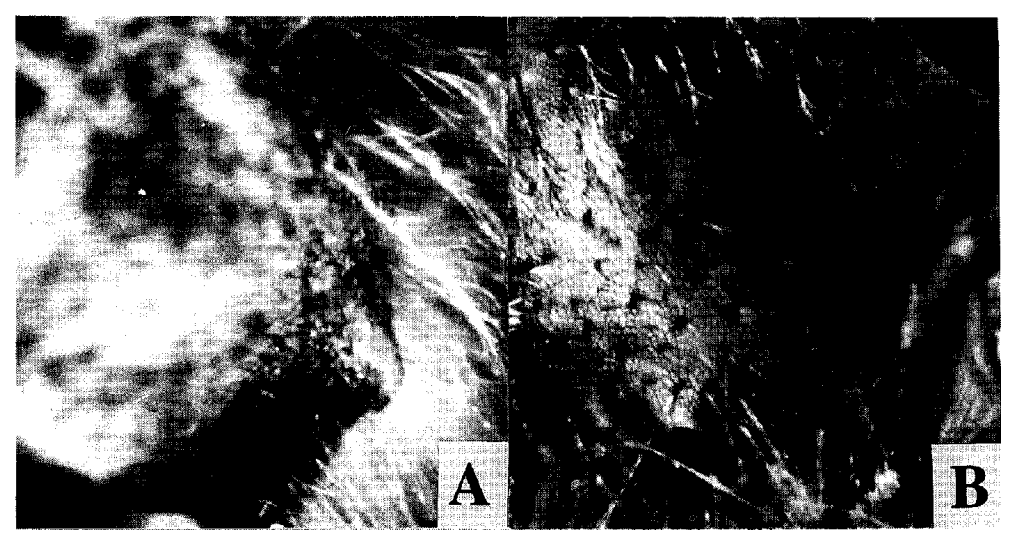

Fig. 4. Mesepistemal tubercle of L. alphenum (A) and bidentatum (B), both females.

lr-m, $2 r-m$ and M-b are all narrower and often more or less faint, though not completely disappears as in some nearctic "Dialictus". Although involving some boundary cases, particularly in males, the veins forming submarginal cells of the 3 big taxa,Halictus s. lat., Lasioglossum s. str., and Evylaeus, are stably different from each other (Fig. 5).

In Sudifa the widths of $l r-m$ and $2 r-m$ behave similarly, both narrower than Rs-b and slightly narrower than Rs-a, M-a is narrowing apicad and M-b as narrow as $2 r-m$. Thus these veins behave as in Evylaeus (though less faint), not differentially as in Lasioglossum (and its palaeotropic counterpart, Ctenonomia). To synonymize Sudifa with Evylaeus for the similar venation should, however, evoke a nomenclatorial confusion, resulting in the replacement of 
Evylaeus (Robertson, 1902), a huge, well known and biologically important taxon, by the earlier-named Sudila (Cameron, 1898), a small, little known taxon. Following Ebmer (1987a), we regard Sudila as an aberrant subgenus of the genus Lasioglossum.

There seems to occur a slight sexual difference in the weakening of veins, more in females than in males in Sudila, but not so clearly as in many other groups of Lasioglossum. In all 6 Sudila species, $1 r-m$ is interrupted near the both ends in both sexes. This appears also in other supraspecific taxa of Lasioglossum, but may be less consistently.*

\section{Features common to the species of Sudila}

The present state of the taxonomy of the Indomalayan halictines does not still permit to give the description of the supraspecific taxa as did by McGinley (1986) in his revision of the New World Lasioglossum s. str. Instead, we enumerate below the features common to the 6 Sudila species. Some of these may vary interspecifically in other genera or subgenera whereas some others may be constant throughout various genera.

Female. Color: Basically black but with metallic tint in 2 species and sometimes with orange-tinted metasoma in L. bidentatum. Flagella frontally, tegulae, some parts of mesoand metasoma and legs dark brown to brown. Mandible apically chestnut brown. Metasomal terga apically not tending semitransparent. Wings transparent with slight or no infuscation. Stigma and veins dark to blackish brown.

Pilosity: Sparse to very sparse. Surface hidden completely only by tomenta on pronotum, on and around pronotal lobe, on metanotum anteriorly (very poor in $L$. paralphenum) and, if present, by basitergal tomenta and tergal postmarginal fimbriae. Hairs generally whitish, often tending pale yellow on some parts. As in many halictines, dark tergal setae gradually longer and denser on posterior terga. Hairs on vertex erect, simple, on face above mostly simple, semierect; denser and more plumose on circumalveolar and paraocular areas, though neither tomented nor hiding surface. Supraclypeus and clypeus sparsely haired. Genal hairs simple and erect, with sparse and fine tomental hairs not hiding the surface. Eye virtually glabrous. Mesoscutum without peripheral tomental zone. Femoral scopa of the common Lasioglossum type. $\mathrm{T}_{1}$ without basilateral patch. Sternal scopa with hairs semierect, simple but some ones poorly plumose.

Structure: Head: About as long as wide except L. kundiense. Supraorbital line passing the middle of mid-ocellus. Both outer and inner orbits distinctly convergent below. Lateral ocellus not attaining vertex. Seen dorsally, tapering postward, lateral ocelli behind jointed with linear impression, OOD and OOcD slightly to distinctly longer than IOD, occiput not carinate. Seen laterally, gena either slightly wider or narrower than eye, neither swollen nor angulate. Malar space very narrow to linear. Hypostoma mat with dense striation.

\footnotetext{
* We do not enter here the Evylaeus-Dialictus problem (or black-green metallic problem), but we can not agree with the opinion prevailing in some North American specialists (except Michener, 1979, 1993), to put many if not all metallic green Evylaeus in Dialictus. The old world metallic "Evylaeus" include several very different groups, some of which seemingly close to the nearctic counterparts but some others not, just as somewhat comparable to $L$. (Sudila) alphenum (cf. Ebmer, 1987a).
} 


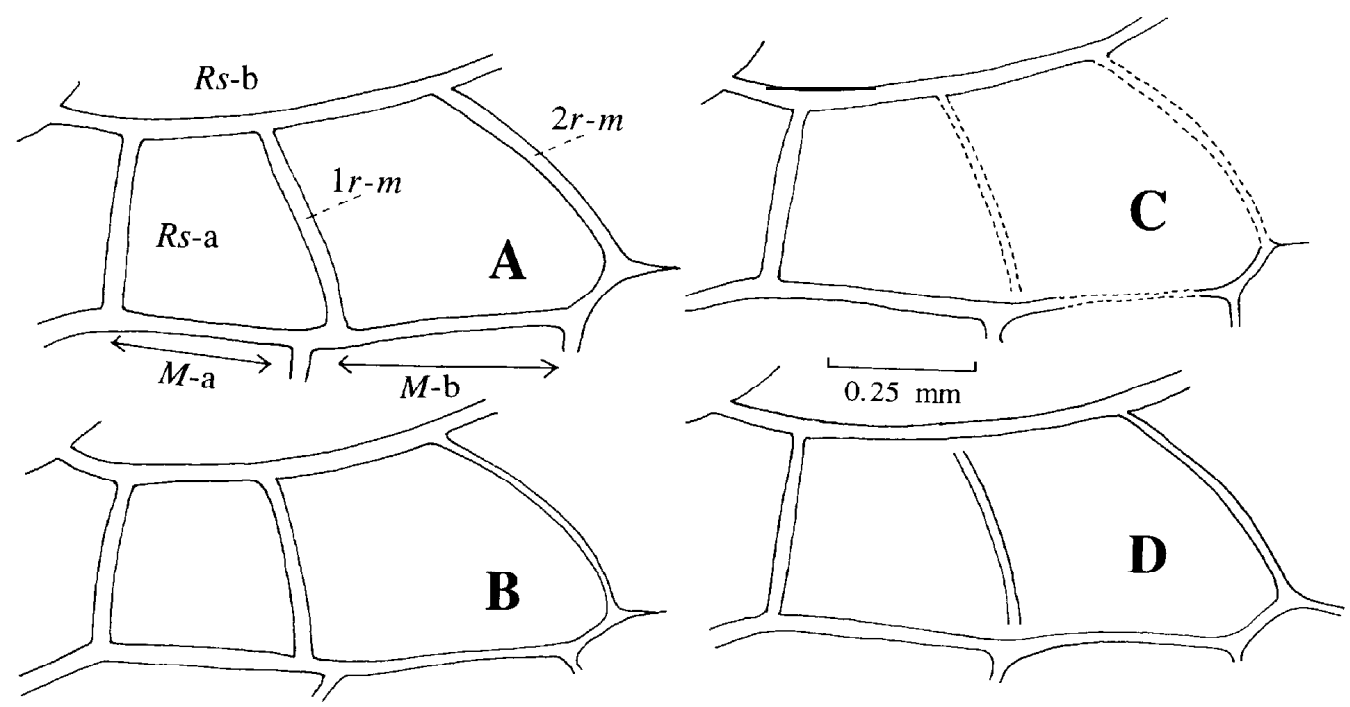

Fig. 5. Venation in the area of 2 nd and 3rd submarginal cells in 3 major halictine groups and Sudila. A: Halictus (Halictus) rubicundus (Christ); B: Lasioglossum (Lasioglossum) leucozonium (Schrank); C: L. (Evylaeus) calceatum (Scopoli); D: L. (Sudila) alphenum. Venation was semischematically drawn on the figure of $L$. alphenum.

Supraclypeus evenly rounded and mildly protuberant. Frontal carina distinct, upward exceeding line of maximum inner orbital distance, above replaced by fine, linear sulcus. Facial sculpture variable but never coarsely punctate. Clypeus as high as supraclypeus; median longitudinal sulcation (McGinley, 1986) absent; basally granular and dully shining; apically smoother and shiner with ill-outlined longitudinal furrows and coarse and illdefined punctures, often elongate in outline; clypeal tooth mild but distinct. Epistomal angle roundly rectangular. Labrum (Fig. 6 A) with basal tubercle mild; apical part triangular, distal-lateral projection absent, apical process acute with marginal bristles slightly curved apically. Mandible (Fig. 6 C) bidentate; as in many other Lasioglossum, preapical tooth distinct, neither broad nor rounded, with distinct sinus between it and rustellum (Michener, 1986; Michener and Fraser, 1978). Mouthparts (Fig. 6 B) of the usual halictine type, glossa mildly pointed apically and maxillary palpi relatively but not unusually long. Scape attaining or exceeding lateral ocellus (Figs. 10 A, D, 14 A, 18 A, B), basal flagellomeres $2-n$ wider than long (Fig. 7, left).

Mesosoma: Pronotum dorsally concave, lateral angle obtuse and apex, not or (in bidentatum) slightly projecting (Fig. 29); dorsal ridge subcarinate; lateral ridge above very flat or mildly convex, not continuing downward. Mesoscutum anteriorly mildly projecting and hiding the median part of pronotum, rather transverse than bilobed; anterior margin roundly truncate, the vertical part not separated with carina from disc; median and parapsidal lines distinct, the area along median line slightly depressed anteriorly; sculpture variable but never coarsely punctate or reticulate, surface more or less granular, not typically smooth and shiny. Scutellum flat, medially not or very weakly depressed. Hypoepimeron dimly smooth and shining, finely and densely punctured. Mesepisternum 

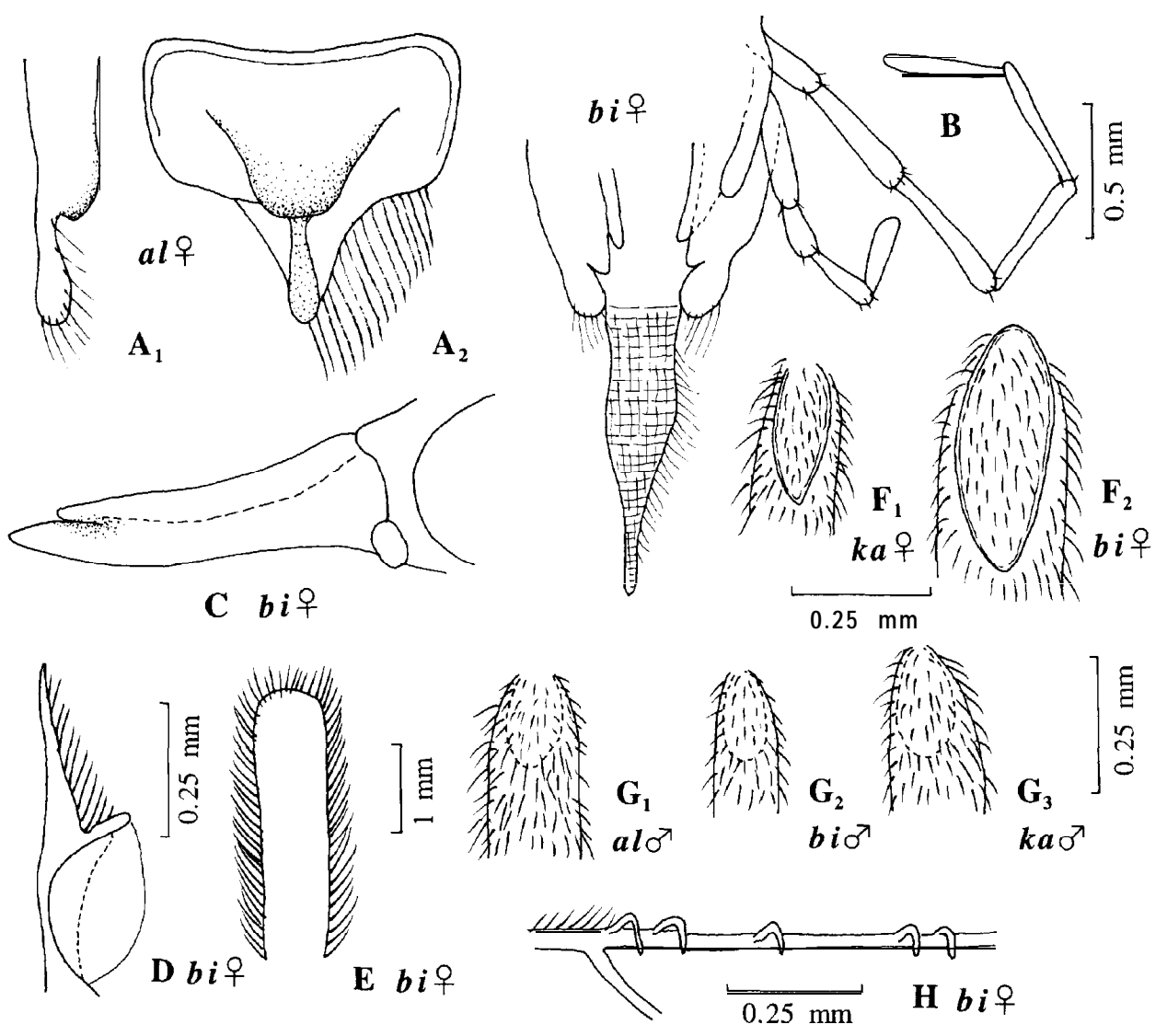

Fig. 6. Some common features in females of Sudila spp. (A-F2 and H) and basitibial plate in males $\left(\mathrm{G}_{1}-\mathrm{G}_{3}\right)$. AI, $\mathrm{A}_{2}$ : : Frontal and lateral views of labrum; B: Mouthparts; C: Mandible (left); D: Strigilis; E: Fore basitarsal comb; F: Basitibial plate (left); H: Hamuli (right).

finely granular except for paralphenum, above with weak transverse reticula-striation, below, except for paralphenum, with a mild but characteristic tubercle (Figs. 3, 4). Propodeal dorsum relatively long, with ratio to mesoscutellum $=1: 1.09-0.86$, posterior half more or less concave, tapering postward and more or less sloping down; medioapically simple, without V-shaped depression; apical margin not carinate, medially roundly but distinctly flexed downward (Fig. 11), laterally gradually sloping down; sculpture variable but without strong longitudinal or anastomosing ridges; shield with lateral carina upward attaining its $2 / 3$ height. Tegula of normal size, anteriobasally finely and densely punctate, the rest smooth and shiny.

Fore wing with veins $1 r-m, 2 r-m$ and M-b narrower than Rs-a and M-a, sometimes faint (Fig. 5). Hamuli arranged in 2-1-2 (Fig. $6 \mathrm{H}$ ). Fore basitarsal comb entire (Fig. $6 \mathrm{E}$ ). Strigilis of the common Lasioglossum type (Fig. 6 D); velum convex, malus as long as velum; outer margin edentate. Anterior basitarsal comb complete (Fig. 6E). Basitibial plate elongate oval, apically pointed (Fig. 6 F1, F2); margin distinctly carinate; surface with fine, rather sparse hairs. Inner hind tibial spur with several distinct, round-tipped teeth (Fig. 2). 

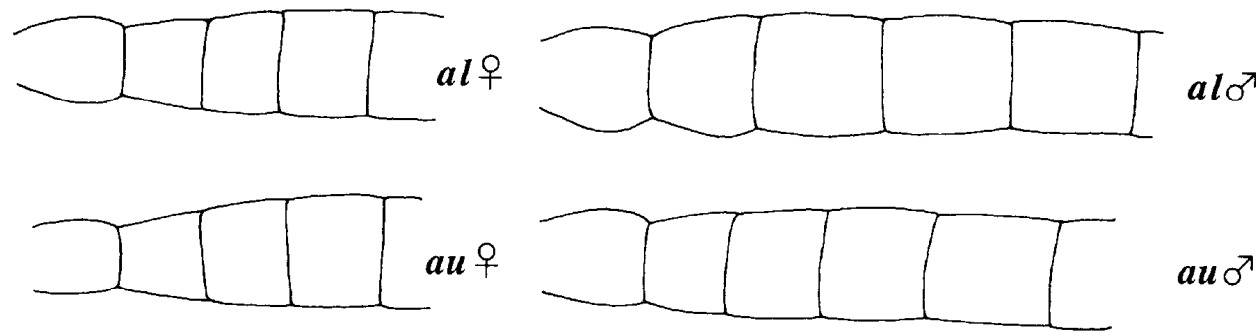

$a u \sigma^{7}$
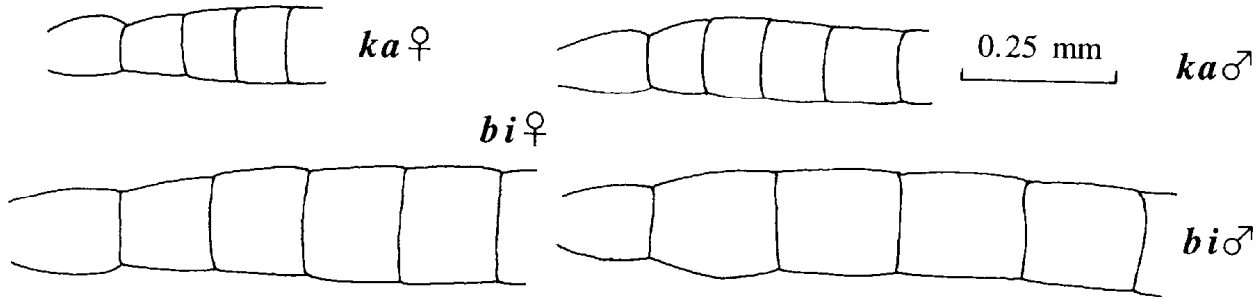

$b i \sigma^{7}$
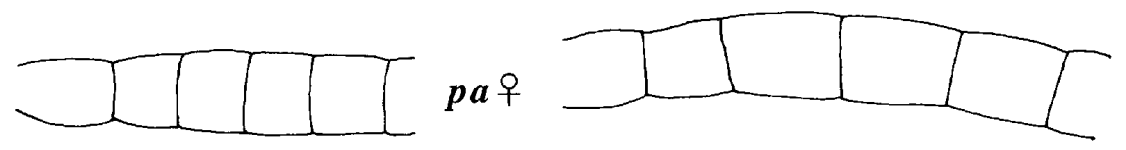

$p a \sigma^{\top}$

Fig. 7. Basal flagellomeres of Sudila species, female (left) and male (right).

Metasoma: Elongate oval. Postmarginal areas of terga not much depressed. Lateral edge of T2 (McGinley, 1986) without concavity; posterior part straightforwards tapering or mildly outcurving. $\mathrm{T}_{1}$ fine and sparsely punctate on disc, seen nearly smooth; PMA striated; other terga gradually more granular, with extension of striation forwards, but still dimly shining.

Male. Differences from female are numbered below (in some sex-linked items, the absence of difference is mentioned). 1- Color as in female, legs not particularly paler. Yellow marks on clypeus below, labrum, mandible and legs absent. 2- Pilosity essentially as in female. Unlike in many other halictines, facial tomentum not much denser than in female. Sternal hairs sparser and shorter, consisting of simple semiappressed hairs directing obliquely. 3- Head similar to female in L. aulacophorum and L. kandiense (Figs. 12, 16), whereas exhibiting sexual dimorphism in L. alphenum, L. paralphenum and particularly in L. bidentatrtm (Figs. 21, 27, 30, 31). 4- Apicolateral clypeal tooth absent as in other Lasioglossum s. lat. 5- Mandible edentate, simple and small in L. aulacophorum and kandiense, sickle-like in L. paralphenum, alphenum and particularly in L. bidentatum with size-linked polymorphism (Figs. 1, 32-34). 6- Antenna longer but not much long as in some other groups. Scape shorter but relatively longer than in some other groups, though not exceeding lateral ocellus (Figs. 12, 16, 21, 27, 30, 31). Flagellomeres not conspicuously longer than in female (Fig. 7). 7-Labrum variable (Figs. 12D, 22 G, H) but without developed apical process as in female (Fig. 6 A). 8- Wing veins as in female, not much stronger as in many other halictines. 9- Hamuli arranged as in female (Fig. $6 \mathrm{H}$ ). 10Basitibial plate represented by oval area with short hairs, not outlined with carina (Fig. $6 \mathrm{G}$ ). 11 - Unlike in most halictines, inner hind tibial spur with distinct teeth though shorter than in 
female (Fig. 2). 12- Metasoma slightly but not conspicuously cylindrical. 13- Metasomal tergum 7 with preapical pygidial plate as in other groups of Halictini (Eickwort, 1969a). 14- Visible metasomal sterna not modified (Fig. 12 E). 15- s7 with median process relatively short, triangular, Ss with apical margin only mildly outcurved (Figs. 12, 17, 22, 28). 16- Gonobase distinctly narrower than gonocoxite, the latter not following gonobasal contour (Figs. 13, 17, 23, 28). 17- Gonostylus small, short, with dense, fine setae, above with long bristles (Figs. 13, 17, 23, 28, 35). 18- Ventral retrose lobe small to very small, not much elongate (Figs. 13, 17, 23, 28, 35).

\section{Morphometric characters}

Tables 1 and 2 present the values of morphometric characters in female and male of each Sudila species. The characters are abbreviated as explained in methods. The significant interspecific differences can be estimated by the presence or absence of overlap of $\pm \mathrm{SD}$ between any 2 species. Figure 8 shows the size difference in both sexes of 6 species by comparing the relationship between body length (BL) and wing length (WL). The both characters, particularly BL, are affected by the conditions of measured specimens (flexing, curling, twisting, etc.), but general trends are clear. Except for L. kandiense (female, male) represented by a few specimens, the variation range does not much differ among $L$. aulacophorum (female, male), paralphenum (female, male), alphenum (female), and bidentutum (female), whereas distinctly larger in ulphenum (male) and particularly in bidentatum (male). These trends are more exaggerated in the relationships $\mathrm{HW} / \mathrm{HL}$ and HW/WD in Fig. 9, where the male cephalic polymorphism intervenes strongly, the variation range in L. bidentatum distinctly deviates from those in other species-sex combinations and probably those in many other halictine groups.

Table 3 presents the coefficients of variation (CV) in 4 species, L. bidentutrrm, alphenum, parulphenum and uulucophorum. In males of the first 2 species the variability may not follow the normal distribution in many characters, but CV could be used as an approximation. A glance at the table, $\mathrm{CV}$ of male are much higher than those of female in L. bidentutum, and are similar but less conspicuously in L. alphenum. This is particularly clear in cephalic characters, reflecting male gigantism in these 2 species.

Table 4 shows some important ratios between 2 metric characters. Here again the variation range is larger in the males of L. bidentutum and ulphenrtm affected by cephalic polymorphism, but some cases show the proper taxonomic values, e. $g$., larger HL and shorter PDL in L. kandiense.

The number and arrangement of hamuli were 2-1-2 (Fig. $6 \mathrm{H}$ ) in all examined specimens (uulacophorum, 9 females 5 males; jacobsoni, 1 female; kundiense, 2 females 1 male; purulphenum, 13 females 3 males; ulphenrtm, 10 females 19 males; bidentutum, 10 females 15 males; except 1 purulphenum female with 2-1-3.

\section{Descriptions and records of Sudila species}

Each item of the species description is numbered below, which are common throughout all species, except for $L$. jacobsoni and L. purulphenum sp. nov., each described synoptically with close species, L. aulacophorum and L. ulphenrtm, respectively. Unless mentioned, the male is similar to the conspecific female in the respective feature. 


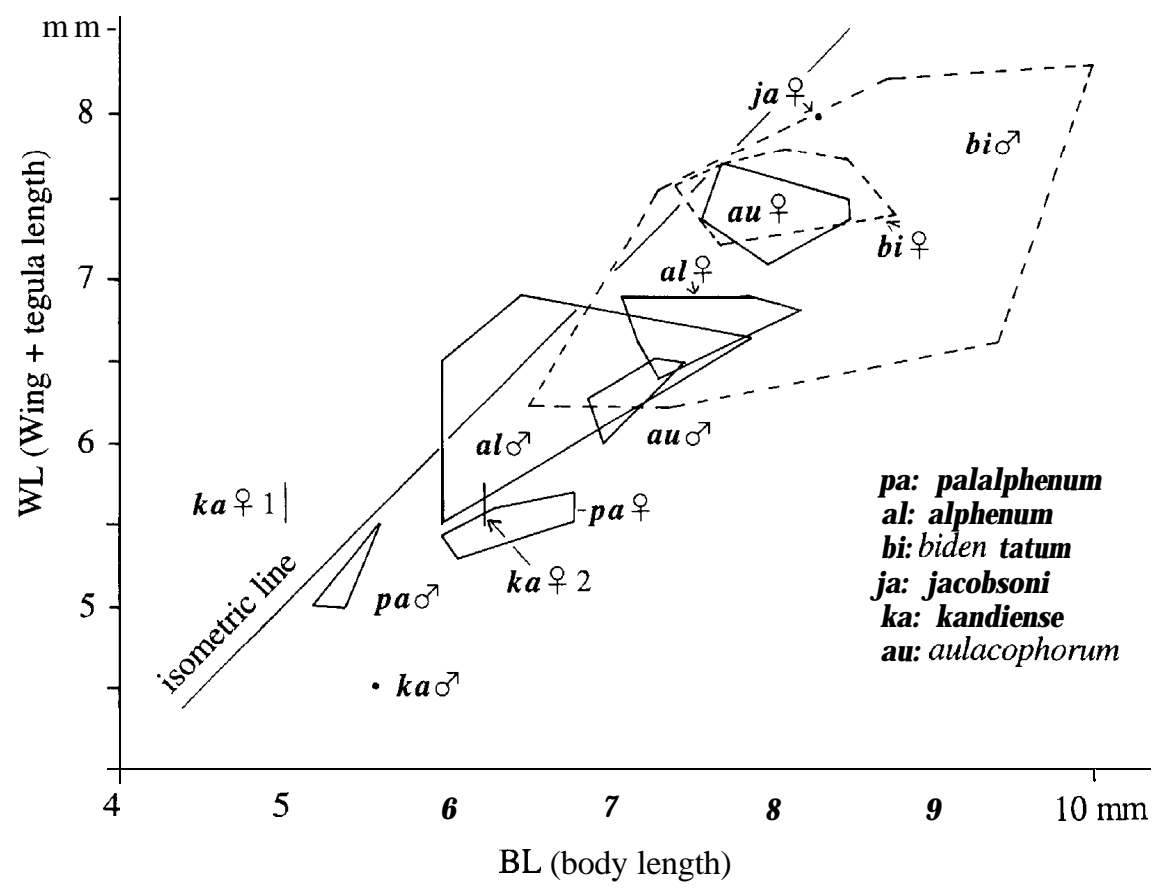

Fig. 8. Body length-wing length relation in Sudila species ( $N$ of specimens measured in Tables 1 and 2). Both females of L. kandiense had wings folded (= ka female 1), actual length probably as given by ka female 2).

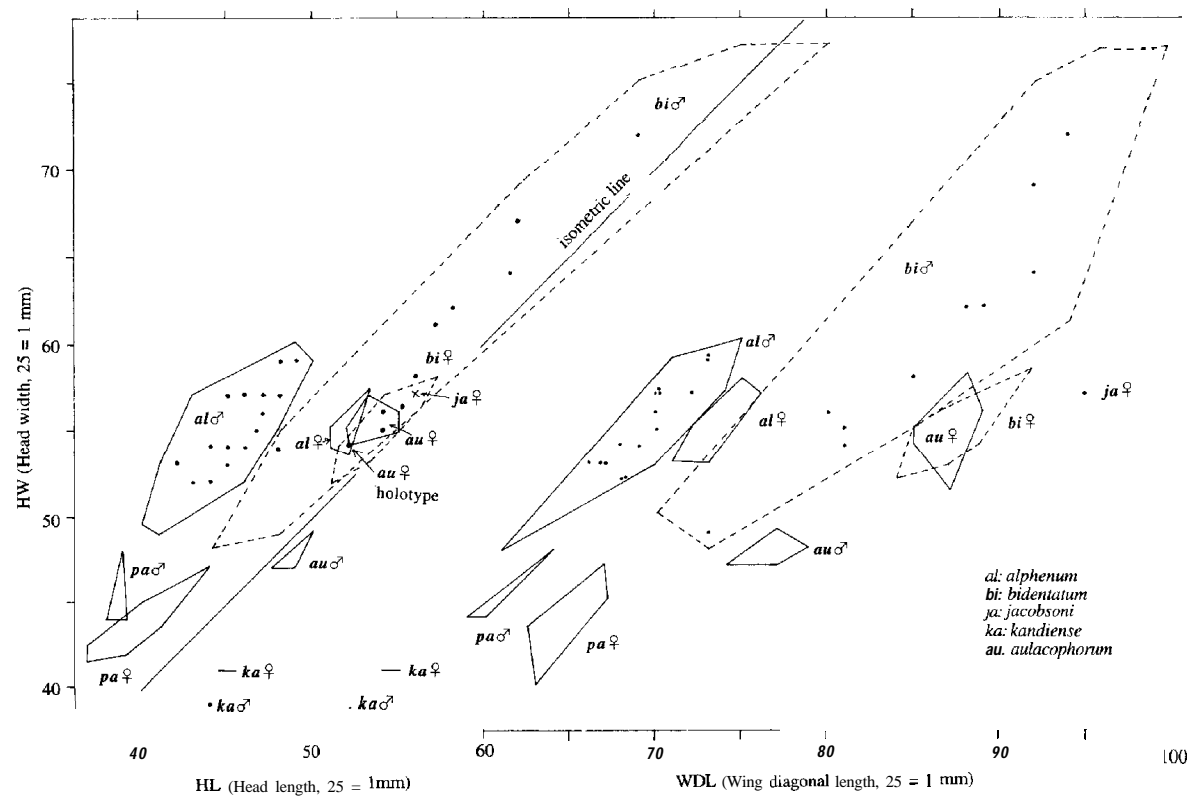

Fig. 9. Head width (HW) - Head length (HL) - Wing diagonal length (WDL) relation in Sudila ( $\mathbf{N}$ of specimens measured in Tables 1 and 2). Only the specimens of alphenum and bidentatum are individually dotted. 


\section{A. Species in which male gigantism is not confirmed}

\section{Lasioglossum (Sudila) aulacophorum (Strand, 1913)}

(Figs. 2, 3, 7, 8, 9, 10, 11, 12, 13, 19, 29, 36)

Halictus aulacophorus Strand, 1913, Arch. Naturgesch., 79A: 137 [female, Hatton, Ceylon, type in Deuts. Entom. Inst., Eberswalde]; Blüthgen 1926, Zool. Jb. Syst., 51: 538 [redescription].

Diagnosis: This and next species differ from the other 4 species by the relatively dense vestiture, especially on propodeal side, and by the sculpture coarser, especially on mesoscutum and propodeal dorsum (Figs. 10, 1 1), although the latter finer in $\mathbf{L}$. aulacophorum than in L. jacobsoni. Mesepistemal tubercle distinct. Male head normal, not gigantic. Ventral retrose lobe of male genitalia extremely small.

Description: Female. 1- Medium sized, BL 7.6-8.5 mm, WL 7.1-7.7 mm (Fig. 8). 2$\mathrm{MsW}$ and MtW rather wide relative to HW. 3- Body black without metallic tint. Tegula pale brown. Metasoma not tending reddish. 4- Hairs sparse but partly denser than in other consubgeners except L. jacobsoni. Tomental hairs white. Other hairs pale yellow to pale yellow brown, with some deep brown hairs on clypeus and supraclypeus in some specimens. Otherwise without admixing of dark hairs on head and mesosoma. 5- Hairs on head (Fig. 10 A) $200-250 \mu$ on vertex, face and paraocular area. Supraclypeus medially almost glabrous, peripheral hairs $\pm 150 \mu$. Genal hairs slightly denser than in other consubgeners except L. jacobsoni, anteriorly simple, $150 \mu$, posteriorly $200 \mu$ or more, distinctly plumose. 6- Mesosomal hairs as in L. jacobsoni, generally denser than in other consubgeners. Longer mesoscutal hairs $\pm 200 \mu$, partly poorly plumose, shorter ones $100 \mu$, simple, semierect. Hairs on mesoscutellum and metanotum postlaterally 300-325 $\mu$, metanotal tomentum confined to anterior $1 / 3$ but distinct. 7- Propodeal side apically lined with yellowish tomentum, above with dense, erect plumose hairs $(275 \mu)$, issuing from immediately below the lateral slope of dorsum (Fig. 19 B), downward gradually replaced by hairs sparser, longer $(375 \mu)$ and simple or poorly plumose, which attaining mesad near lateral margin of propodeal shield. Shield covered with thick tomentum and dense, erect, plumose hairs (325 $\mu$ ). 8- Hairs on metasomal dorsum predominantly yellow brown, sparse but slightly denser than in other consubgeners except L. jacobsoni. 9- $\mathrm{T}_{1}$ on slope, besides erect, poorly plumose hairs, with small inconspicuous sublateral patch of short appressed hairs; disc laterally with sparse, outward-directing appressed hairs; postmarginal hairs absent; dorsolateral comer with sparse submarginal hairs. 10- T2 with narrow, interrupted basilateral patch; discal hairs sparse but denser $>T_{\text {ı }}$. Laterapically with relatively dense postmarginal hairs, but simple, not forming white marginal fimbria as in L. kandiense. 11-T3,4 as on T2 but basal patch absent (at least hidden by $\mathrm{T}_{n-1}$ ). Hairs gradually denser; postmarginal hairs more extending mesad though not forming white fimbria. 12- Head seen frontally slightly shorter than wide (Fig. 10A). HW : HL = $1: 0.96$ (1: 0.97 in holotype), UOD slightly longer than LOD. 13- Seen frontally (Fig. 10 A) vertex mildly convex, lateral ocellus distant from vertex less than own short axis; seen laterally (Fig. 10 A) postward not much raised, OOD and OOcD about as long as IOD and VOD distinctly shorter. 14- Seen laterally gena distinctly narrower than eye; $\mathrm{EW}: \mathrm{GW}=1: 0.71$; above finely and sparsely punctured; IS $=\varnothing \mathrm{P}$, smooth and shiny. Malar space linear. 15- Postocellar area granular with weak, small PP ( $\mathrm{P}=12-15 \mu, \mathrm{IS}= \pm 1 . \mathrm{O}$ ). Ocellocular area, face and upper paraocular area homogeneously and finely punctured $(\phi \mathrm{P}= \pm 20 \mu$, IS linear), seen from some 


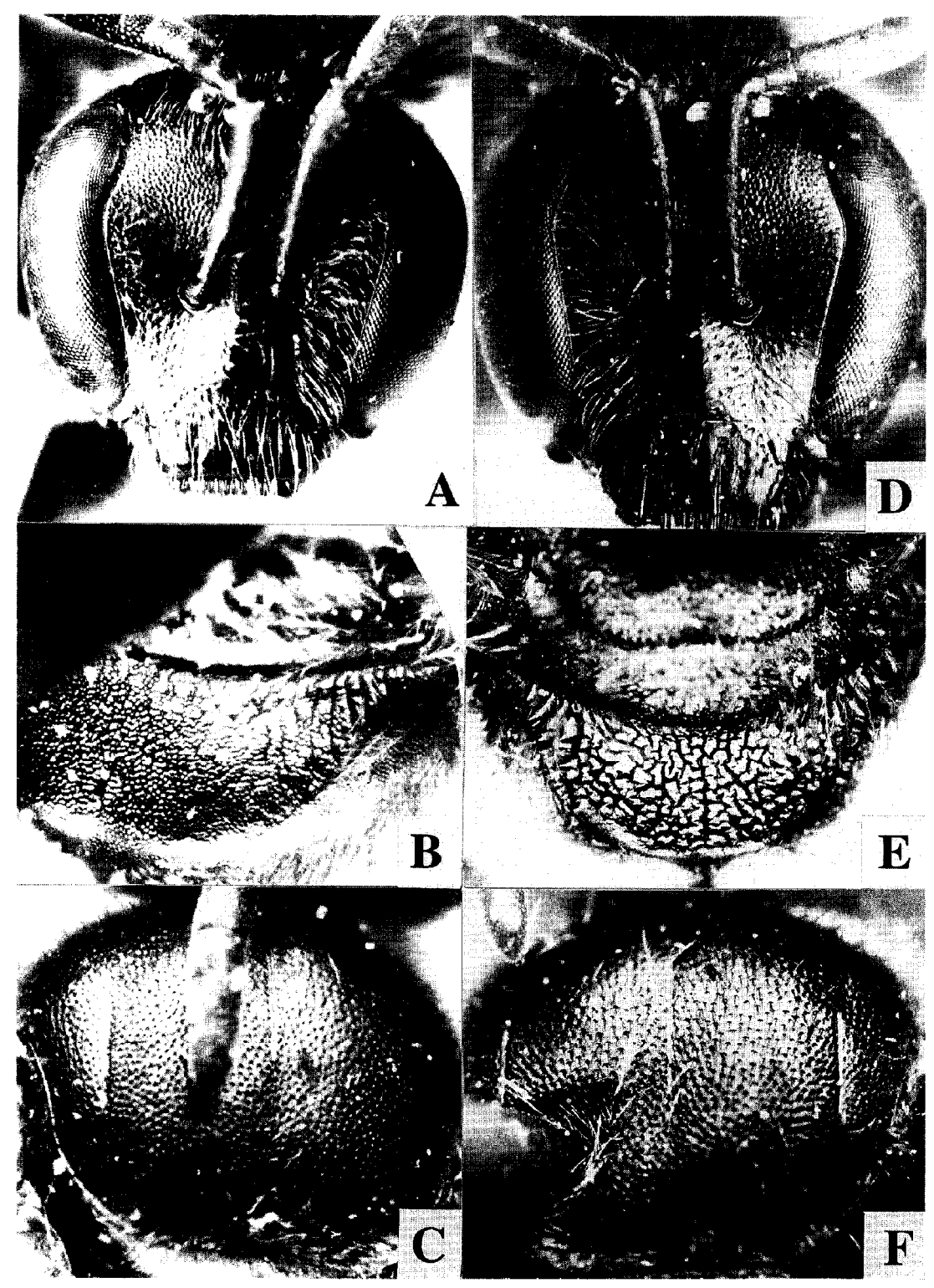

Fig. 10. Lasioglossum (Sudila) aulacophontm (A-C) and L. (S.) jacobsoni (D-F), both holotypes (female). A, D: Head seen frontally; B, E: Propodeal dorsum; C, F: Mesoscutum.

direction as if microreticulate. Epistomal lobe with PP coarser ( $\phi$ P 20-25 $\mu$ ) and sparser; IS 1.0-I .5, coarsely coriaceous and dully shining. 16- Supraclypeus more raised than in other consubgeners except L. jacobsoni, peripherally sculptured as on paraocular area, medially smooth and shiny with fine, very sparse punctures. 18-Scape exceeding mid ocellus (Fig. 10 A). 19- Pronotal lateral angle obtuse, apex not projecting and outer margin nearly straight (Fig. 29 A). 20- Mesoscutum medially with fine PP ( $\phi$ P 20-25 $\mu$ ) as on face 
(Fig.10 C), IS linear and granular; anteriorly PP sparser, IS granular and seen obliquely striate. Mesoscutellum sometimes weakly bigibbous, sculptured as on mesoscutum but PP on submedian elevation sometimes sparser with IS smooth and shiny. 21- Hypoepimeron finely punctured with IS smooth and shiny, more contrasting to coarser mesepisternal sculpture than in other consubgeners except L. jacobsoni. Mesepisternum homogeneously tessellate, superimposed with coarser striation. Mesepistemal tubercle distinct (Fig. 3). 22Propodeal dorsum nearly as long as scutellum. PDL : MTL : MCL $=1: 0.69: 1.03$; fairly concave, postlateral margin roundly rectangular (Fig. $10 \mathrm{~B}$ ), posterior margin demarcated with narrower depression; surface finely and homogeneously granulo-microareolate (Figs. $11 \mathrm{~A}, 19 \mathrm{~B}$ ), each areola seen as if tessellate; on basal half and laterally superimposed with fine, anastomosing ridges (Figs. $10 \mathrm{~B}, 11 \mathrm{~A}$ ). Shield granular, lateral carina above attaining to $2 / 3$ height. 23- Teeth of inner hind tibial spur fine and numerous (Fig. 2) (No. of teeth in 9 females: 5,7 x 5, 8, 9, 10).

Male (new to science): 1- Distinctly smaller than female (Fig. 8). BL 6.9-7.5 mm, WL 6.0-6.5 mm. 2-MsW and MtW rather wide relative to HW. 3 to 4-Supraclypeal and clypeal hairs paler. 5- Hairs on vertex longer, to $300 \mu$; circum-alveolar hairs denser though not hiding surface. 6- Mesosomal hairs as in female, relatively denser than in other consubgeners. Pleural hairs tending more distinctly plumose. Mesoscutal hairs shorter; long erect hairs $\pm 150 \mu$; short, semiappressed ones $\pm 75 \mu$.7 - Hairs of propodeal dorsum laterally above slightly sparser. 8 to 11 - Tergal hairs sparser. Sternal hairs moderately dense, all directing obliquely-postward, submarginal hairs to $175 \mu$, marginal hairs present but hidden by longer ones. 12- Seen frontally head as long as wide (Fig. 12 A). HW : HL = $1: 1.02$. UOD distinctly longer than LOD. 13- Seen frontally vertex more convex than in female; lateral ocellus distant from vertex less than $1 / 2$ own short axis (Fig. 12 A). Seen laterally vertex not much raised posteriorly (Fig. $12 \mathrm{~B}$ ). OOcD nearly as long as IOD and OOD nearly as long as VOD. 14- Seen laterally gena sculptured as in female, distinctly narrower than eye (Fig. 12 B). EW : GW = 1:0.66. Malar space linear. 17- Clypeal proportion $\fallingdotseq$ female. 18-Scape attaining mid ocellus (Fig. 12 A). Basal flagellomeres relatively short. $F_{1}$ below not outcurved (Fig. 7). $F_{2} L: F_{2} W=1: 1.14$. Labrum flat, transverse, apical margin straight with homogeneous bristles (Fig. 12 D). Mandible normally short and slender (Fig. 12 C). 19 to 22- Mesoscutal and -scutellar sculpture weaker, IS seen more smooth and shiny; $\emptyset \mathrm{P}$ shorter, hence PP seen sparser. Mesepisternal striation more superficial. Mesepistemal tubercle and venation as in female (Figs. 3, 5). PDL : MTL:MCL = $1: 0.52$ : 0.88. 23- Mid trochanter and mid femur below not angulate (similar to Fig. $22 \mathrm{~F}$ ). Teeth of inner hind tibial spur shorter but denser, $10 \pm 0.6$ (in 5 females, $n=9(1), \pm 10(1), 10$ (2), 11 (1) (Fig. 2). 24- S7 (Fig. 12 F) with median process short, triangular, tip not acutely pointed, seemingly fused with Ss, of which posterior margin mildly outcurved with fine setae. 25 (Fig. 13 B) - Gonobase short, about 1/2 of the own width. Gonocoxite slender, outer apical comer widely rounded, inner apical angle round and mildly projecting, inner margin mildly concave, dorsal contour flat. Volsella small. Penis valve dorsoventrally wide, dorsal surface with abundant bristles. Gonostylus small, relatively slender; ventral retrose lobe slender, unusually small (Fig. $13 \mathrm{C}$ ); hairs relatively sparser than in the other consubgeners (Fig. $13 \mathrm{C}$ ).

Specimens examined (Fig. 36): all from Sri Lanka. Holotype female, Hatton, at Foot of Peak Adams, Ceylon, 17. vii. 1899 (W. Horn) (Deutsch. Ent. Inst., Eberswalde); [NE. Distr.]: 5 females (1 female "malaise"), Hakagala Nat. Reserve, 6-7. ii. 1979 (KVK, PB, TW, 

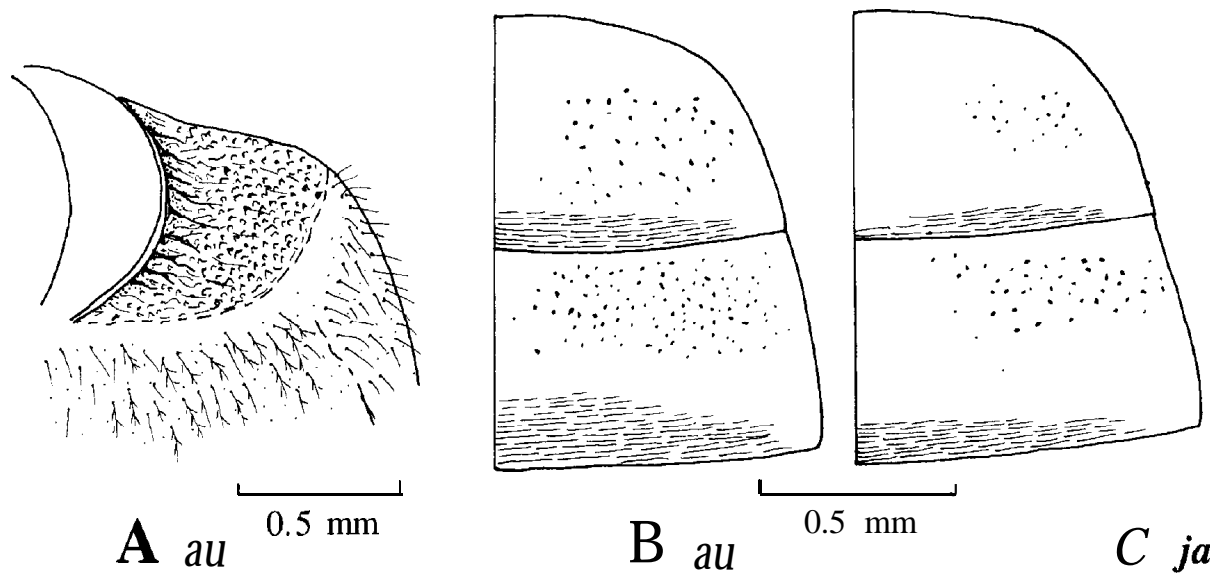

Fig. 11. Lasioglossum (Sudila) aulacophorum (A, B) and L. (S) jacobsoni (C), female. A: Propodeal dorsum seen obliquely; B, C: Sculpture on metasomal terga 1 and 2.

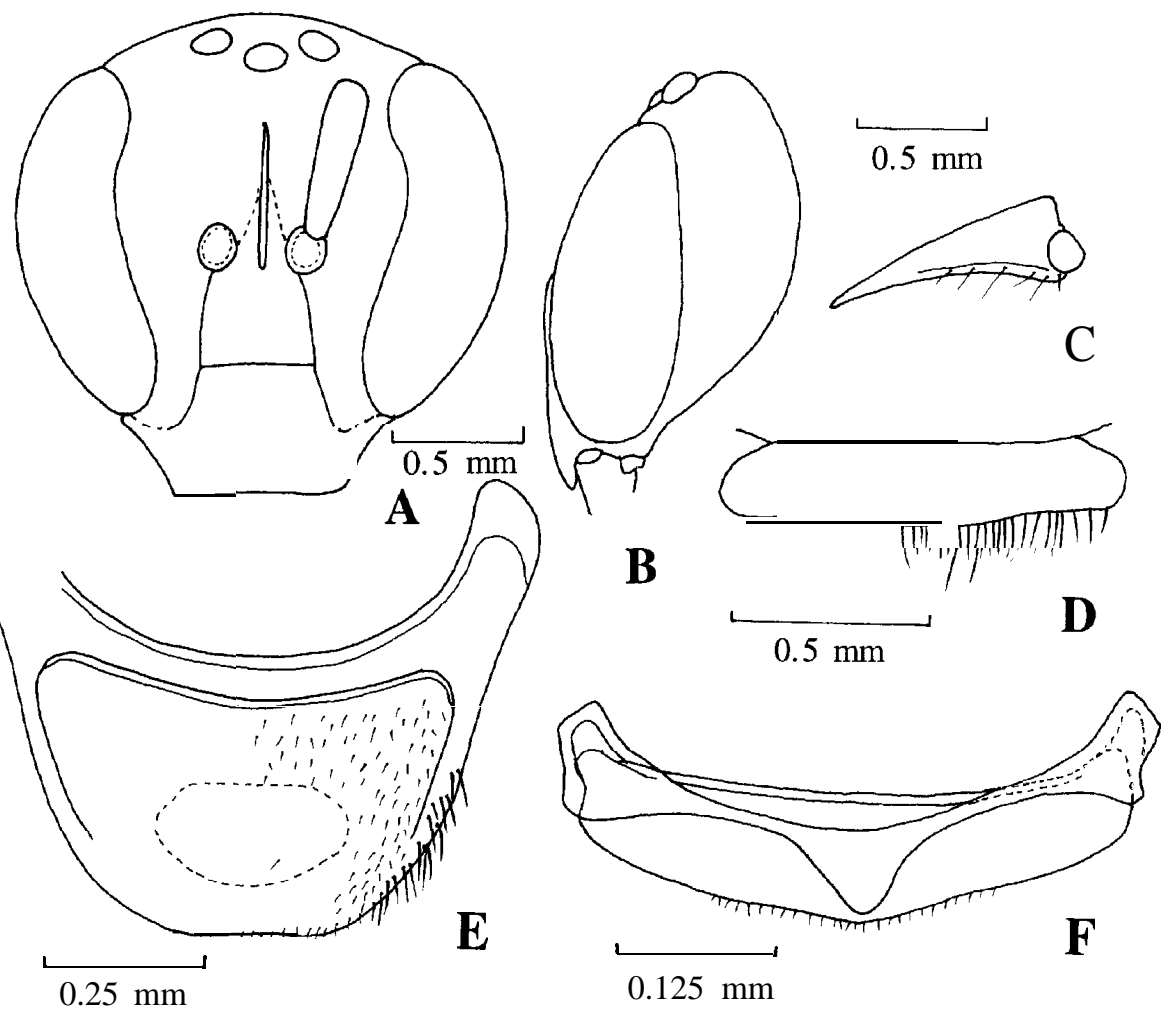

Fig. 12. Lasioglossum (Sudila) aulacophorum, male. A, B: Head seen frontally and laterally; C: Left mandible; D: Labrum; E: Metasomal sternum 6; F: Sterna 7 and 8. 


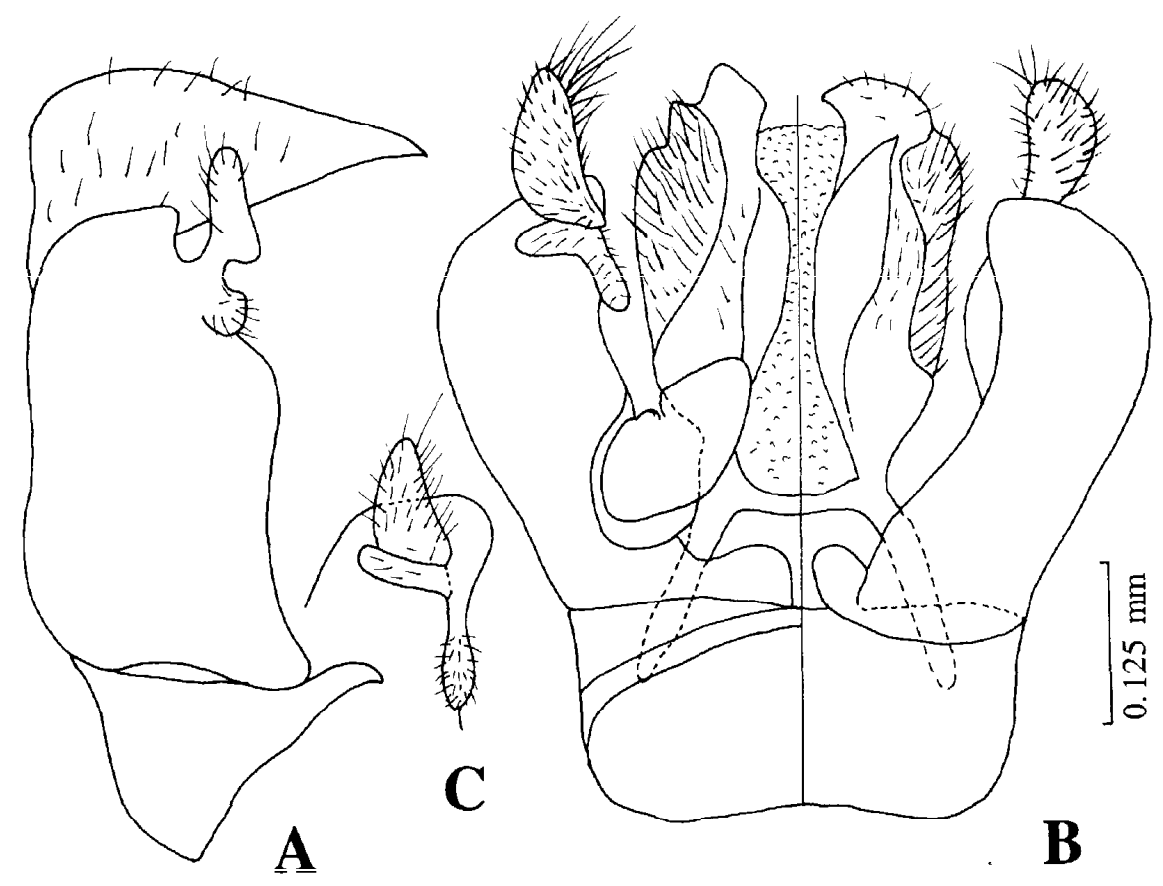

Fig. 13. Lasiogiossum (Sudila) aulacophorum, male genitalia. A: Right lateral view; B: Ventral (left) and dorsal views; C: Gonostylus and ventral retrose lobe seen obliqueventrally.

SS, TG); 1 male, Hakagala Sanctuary, 23-24. iv. 1981 (KVK, TW, LW); 1 male, Lovers Leap Creek, 7000 ft, 15. iii. 1973 (Baumann \& Cross); [Bad. Distr.]: 2 females, Ohiya, 5500 ft, 1. vi. 1976 (KVK, SK, DW); [Kan. Distr.]: 1 female, Adams Peak Trail, $4.5 \mathrm{mi}$ W Makeliya, 1530 m, 19-21. x. 1977 (KVK, TW, MJ, PA); 1 female 1 male, Adams Peak Trail, 4.5 mi W Makeliya, 1600-1700 m, 13. vi. 1978 (KVK, PB, TW, VK, LJ).

The holotype female is smaller ( $\mathrm{HW} / \mathrm{HL}=54 / 51$ against the mean of the other female, $55.9 \pm 1.0 / 53.7 \pm 1.0,25=1 \mathrm{~mm}$ ), and paler-tinted than other females, scape dark brown, flagella brown, mesosomal sides and metasomal terga distinctly brown tinted and legs rather concolorously brown (in other females basal parts to tibia of fore and mid legs and entire hind femora dark brown, stigma brown, veins pale brown. Further, the boundary between median part and lateral slope of propodeal dorsum more demarcated. Otherwise no essential difference from other specimens.

Blüthgen (1926) placed $H$. aulacophorus in the group of $H$. leucozonitus Schrank and $H$. costulatus Kriechbaumer (in the recent system both classified in Lasioglossum s. str.). He also thought $H$. aulacophorus as very similar to $H$. trichiosulus Strand from Taiwan and the latter species related to $H$. villosulus Kirby. This pan-palaearctic species distributed from England to Japan is now classified into the carinaless Evylaeus and is quite different from $L$. aulacophorum, with longer hairs, smoother and shiner mesoscutum with sparse and coarse $\mathrm{PP}$, shorter and coarsely sculptured propodeal dorsum, and larger ventral retrose lobe. 
The collected specimens are arranged seasonally as follows: ii, 5 females ( 1 female with pollen loads, 1 female, same and relatively worn) 2 males; iii. 1 male; iv. 1 male; vi, 3 females (1 female relatively worn), 1 male; vii, 1 female (holotype); x, 1 relatively worn female. It is still difficult to know the life cycle sequence of this high altitude species under the local climate.

\section{Lasioglossum (Sudila) jacobsoni (Friese, 1914)}

(Figs. 2, 3, 8, 9, 10, 11, 36)

Halictus jacobsoni Friese, 1914, Tijdschr. Ent., 57: 20 [female, Gunung Gedah, type in Forschungsinstitut Senckenberg, Frankfurt, a. M.]; Bliithgen, 1926, Zool. Jb., Syst., 5 1: 569 [female, redescription].

Diagnosis: Known by the unique type female from Java. Although distributed remotely L. aulacophorum and $L$. jacobsoni are morphologically 2 sister species distinguished clearly only by the sculpture of propodeal dorsum (Fig. $10 \mathrm{~B}, \mathrm{E}$ ).

Description: Female. Only the differences from L. aulacophorum are given below. BL $8.3 \mathrm{~mm}$, WL $8.0 \mathrm{~mm}$. Metric values in Tables 1 and 4. 1- Wing and head slightly longer in ja>al (Figs. 8, 9). 2- Propodeal dorsum sculptured more coarsely in ja>al (Fig. $10 \mathrm{~B}$, E), $\phi$ of 20-40 $\mu$ not less than $10 \mu .3$ - Teeth of inner hind tibial spur longer in ja>au (Fig. 2). 4- Hairs on $T_{1.2}$ sparser in ja >au.5-Punctures and striation on $T_{1.2}$ sparser and weaker in $j a>a u$.

Among these differences item 2 is very distinct, being out of individual variation. Otherwise the 2 species are nearly identical from each other, including wing venation and mesepistemal tubercle (Fig. 3).

Length of hairs on some body parts in $\mu$ : vertex 250 , face and paraocular area 150 , supraclypeus 150, gena anteriorly (and posteriorly) 175 (250), mesoscutum long hairs 200, short hairs 100, mesoscutellum and metanotal apex 140, mesepistemum above (and below) 250(350), propodeal side above (plumose) and below (simple), 275-300 and 375, propodeal shield 275-300. Punctures on mesoscutum $\varnothing 20-55 \mu$, IS linear.

Specimen examined (Fig. 36): 1 female, labeled from above downward, "25/69", "E. Jacobson, Goenoeng Gedeh, Java, Mrt. 191 1", "Collectio A. Weis", "Type (orange color paper)", "Hulictus jacobsoni 1911, Friese det. female", and deposited in Forschungsinstitut Senckenberg, Frankfurt a. M. The type is a female rather more brownish than $L$. uulucophorum.

In the same institute a specimen labelled "Halictus jacobsoni male, Typus" written by Friese is deposited. This specimen, apparently not undescribed, was not a "Halictus" but a Thrinchostomu. In the same paper Friese (1914) described a new species of Thrinchosromu as "Hulictus (Rostrutilupis) mucrognuthus (male). His "Hulictus jacobsoni, male" is different from "H. mucrognuthus". It seems similar to Th. (Thrinchostomu) tonkinense (Blüthgen) but a different, probably undescribed species.

Both Friese and Bliithgen overlooked the mesepisternal tubercle. Redescription by Bliithgen is much better than the original description by Friese but Bliithgen erroneously placed jacobsoni in the Halictus ulbipes group, that belongs to the carinate Evylaeus in the recent usage, nevertheless the apex of the propodeal dorsum is not carinate. He also described "Mesonotum vom buckelartig vorgezogen, der Buckeldurch eine tiefe Furche 
langsgeteilt." Actually the projection is not so strong, rather similar to mesoscutum in females of other consubgeners (Fig. 29).

\section{Lasioglossum (Sudila) kandiense (Cockerell, 1913)}

(Figs. 2, 3, 6, 7, 8, 9, 14, 1.5, 16, 17, 29, 36)

Halictus (Evylaeus) kandiensis Cockerell, 1913, Entomologist, 46: 34 [female, Kandy, Ceylon; type in Nat. Hist. Museum, London]; Blüthgen, 1931, Zool. Jb. Syst., 61: 330 [female, redescription].

Diagnosis: Black, non metallic. Hairs sparse. Sculpture weak. Distinctly smaller and head longer than the other 5 consubgeners. Propodeal dorsum with fine, narrowly spaced longitudinal ridges. $\mathrm{T}_{2-4}$ of female with postmarginal fimbriae of white bristles, not of plumose hairs. Male head normal, not gigantic. Ventral retrose lobe short and apically truncate.

Description: Female. 1- Small sized, BL 5.5-5.8 mm, WL $\pm 5.0 \mathrm{~mm}$ (Fig. 8). 2- MsW and MtW slightly wider than HW. 3- Body black without metallic tint. Tegula brown.

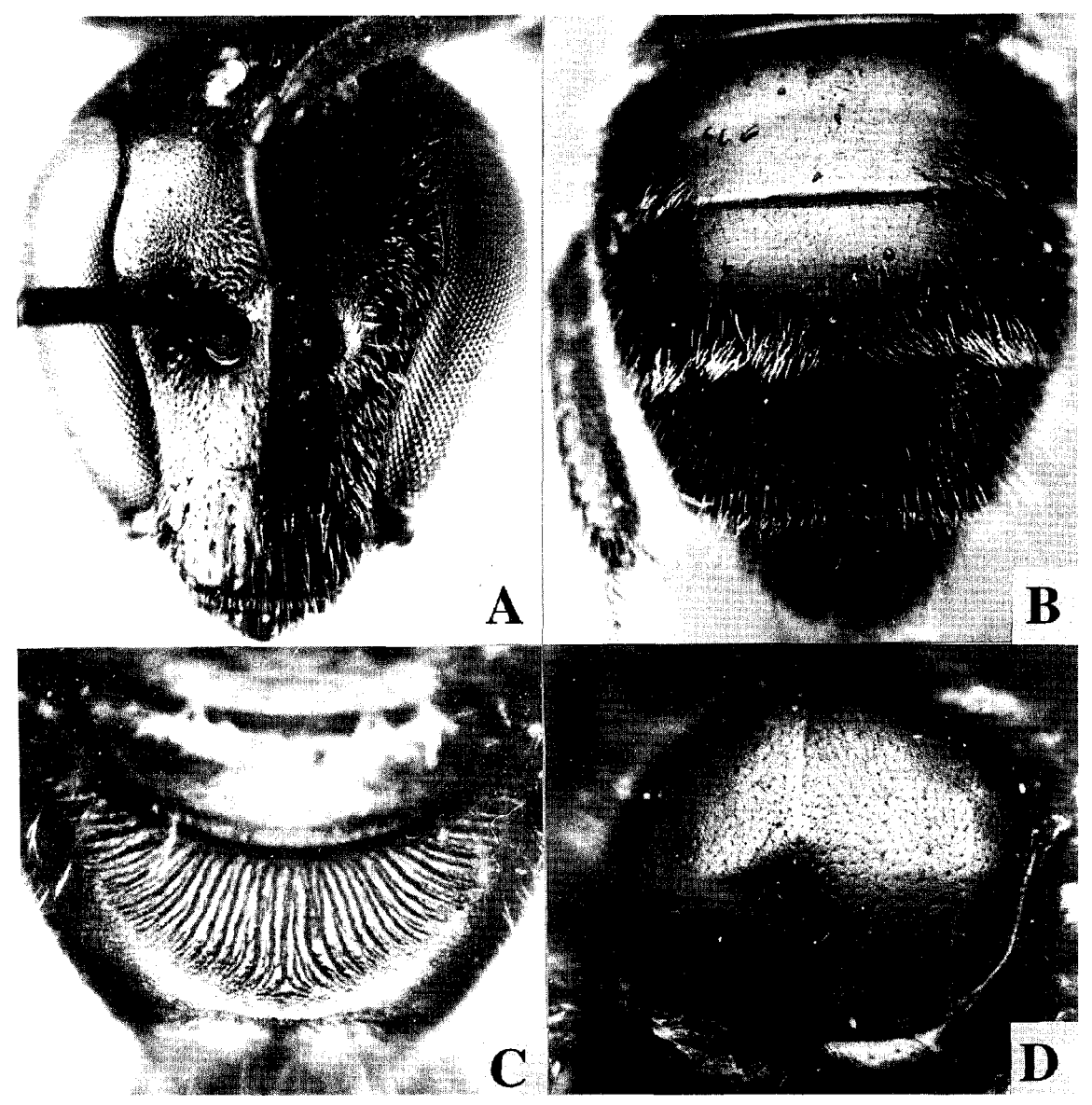

Fig. 14. Lasioglossum (Sudila) kandiense, female. A: Head seen frontally; B: Metasomal pilosity; C: Propodeal dorsum; D: Mesoscutum. 
Metasoma not tending reddish. 4- Hairs more whitish than in the other consubgeners, sparser than in L. aulacophorum, as sparse as in L. alphenrtm. 5- Hairs on head 125-200 $\mu$ on vertex, face and paraocular area. Supraclypeus with hairs $(75 \mu)$, rather homogeneously sparse, slightly denser peripherally. 6- Mesosomal hairs sparser than in L. aulacophorum; mesoscutal hairs $50-75 \mu$, sparse, semierect, simple; some ones inconspicuously plumose. Hairs on mesoscutellum apically and metanotum postlaterally $\pm 175 \mu$, inconspicuously plumose; metanotal tomentum confined to anterior 1/3 but distinct. 7- Propodeal side apically not covered with tomentum, with sparse hairs $( \pm 250 \mu)$, simple or sparsely plumose, issuing from not immediately below lateral slope of dorsum, mesad not attaining near lateral margin of propodeal shield. Shield covered with both tomentum and erect, poorly plumose hairs $(200 \mu)$ (Fig. $14 \mathrm{C}$ ), both sparser than in L. aulacophorum, as dense as in L. alphenrtm and denser than in L.bidentatum; predominantly white. 9- $\mathrm{T}_{1}$ on slope with sparse poorly plumose hairs, sublateral hair patch absent; disc laterally with sparse, fine, outward-directing hairs; postmarginal hairs absent except for some fine hairs on lateral corner. 10- $\mathrm{T}_{2}$ with lateral patch confined to lateral corner; disc laterally with outward-directing hairs slightly denser than on $\mathrm{T}_{1}$. Apically with sparse submarginal hairs and laterally with white postmarginal fimbria (Fig. 14 B) superficially similar to that in Halictus s. lat., and in some Evylaeus, e. g., many species of $L$. (E.) sexstrigatum group, but not consisting of plumose hairs as in these groups but of white bristles as in $L$. (E.) marginatum (Brullé). $11-T_{3,4}$ as on $T_{2}$ but basal patch hidden by $T_{n \cdot 1}$. Hairs generally denser and postmarginal fimbria more extending mesad.12- Head distinctly elongate (Figs. 9, 14). HW : HL = $1: 1.13$. UOD distinctly longer than LOD. 13- Seen frontally vertex raised and medially transverse; lateral ocellus distant from vertex more than own transverse axis; seen laterally slightly depressed, posteriorly raised. OOD and OOcD longer, while VOD shorter than IOD. 14Seen laterally gena distinctly narrower than eye; EW : GW $=1: 0.69$, above finely and minutely punctate, IS $\fallingdotseq \varnothing \mathrm{P}$, smooth and shiny. Malar space linear. 15- Postocellar and ocellocular areas minutely etched and dimly shining, with rather sparse, minute PP ( $\phi$ P 12$15 \mu \ll$ IS). Face granular and mat with weak PP $(\phi \mathrm{P}<10 \mu$, IS mostly $\fallingdotseq \varnothing \mathrm{P})$. Paraocular area above similar. Epistomal lobe sculptured more coarsely and superficially, and dimly shining. 16- Supraclypeus medially mildly raised, homogeneously granular or rather finely net-worked, dimly shining. 17- CAL fairly long and ACL short relative to clypeus (Table 42). 18-Scape attaining lower rim of mid ocellus (Fig. 14 A). 19- Pronotal lateral angle obtuse, apex not pointed forward, and outer margin straight (Fig. 29 D). 20- Mesoscutum finely and homogeneously net-worked as in Nomioides though more mat, with sparse, finest and very shallow PP, $\varnothing \mathrm{P} 10-15 \mu$, IS $=1.5$ or more (Fig. 14 D). Mesoscutellum flat, sculptured as on mesoscutum but more superficially; IS more shiny, PP sparser and weaker though some ones coarser ( $\phi 20-25 \mu) .21$ - Hypoepimeron with finest PP, IS granular and dimly shining. Mesepisternum homogeneously and superficially granular, dimly shining with minute ( $\phi \mathrm{P} 10 \mu$ or less) and sparse PP (IS $\gg \gg \phi$ P) and very weak transverse striation; mesepistemal tubercle distinct. 22- Propodeal dorsum slightly shorter than mesoscutellum. PDL : MTL : MCL = $1: 0.72: 1.17$; mildly descending postward and gently concave; with \pm 40 beautiful, longitudinally radiate ridges, $\pm 25 \mu$ distant from each other, medially not attaining posterior margin, while laterally reaching boundary with lateral slope (Fig. 14 C); posterior margin semilunar, represented by mild flexion; area between ridged part and posterior margin finely granular; lateral slope finely striate. Shield finely granular. 23Teeth of inner hind tibial spur thin and short (5 and 6 in 2 females, Fig. 2). 


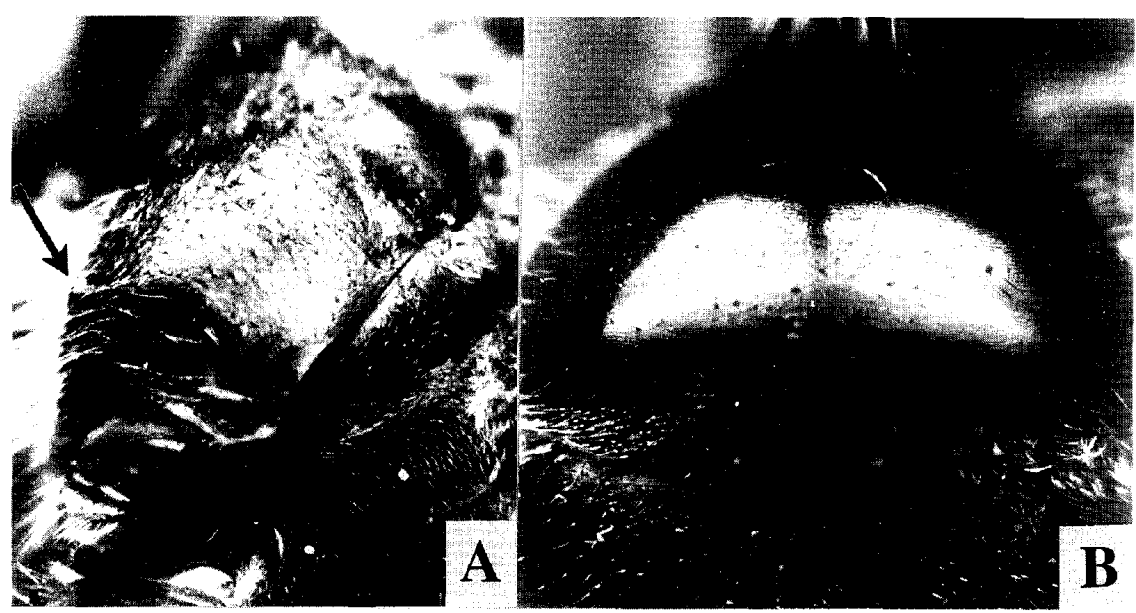

Fig. 15. Lasioglossum (Sudila) kandiense, female. A: Mesepisternal tubercle; B: Sculpture and pilosity of $\mathrm{T} 1$ and 2 .

Male (new to science). 1- Slightly smaller than female. BL $5.6 \mathrm{~mm}$, WL $4.5 \mathrm{~mm}$ in the unique specimen examined (Fig. 8). 2- MsW and MtW about as wide as HW. 3 to 11 - As in female but basal patches on T2.3 and postmarginal fimbriae on T3.4 (Fig. 14 B) absent. 12 to 17 - As in female (Fig. $14 \mathrm{~A}$ ). HW : HL $=1: 1.16$. Vertex as in female but flatter, not depressed and less projecting postward (Fig. $16 \mathrm{~B}$ ). IOD : OOD :OOcD: VOD (see Table $4-2$ ). VOD longer relative to OOcD. $\mathrm{EW}: \mathrm{GW}=1: 1.07$. $\mathrm{CPL}: \mathrm{CAL}: \mathrm{ACL}$ is slightly different from female [but $\mathrm{N}$ of specimens insufficient]. 18-Scape attaining lower rim of mid ocellus (Fig. 16 A). Basal flagellomeres short. F/ below not outcurved (Fig. 7). F2L: $\mathrm{F}_{2} \mathrm{~W}=1: 1.42$. Labrum not examined. Mandible normally short and slender (Fig. $16 \mathrm{C}$ ). 19 to $22-$ As in female including mesepisternal tubercle and wing venation. PDL : MTD : MCL $=1: 0.69: 1.25$. PDL slightly shorter relative to MCL. Median part of longitudinal ridges of propodeal dorsum relatively shorter. 23- Mid trochanter and mid femur below not angulate (cf. Fig. 22 F). Teeth of inner hind tibial spur shorter, 6 in number (Fig. 2). 24- s7 (Fig.17 A) with median process triangular, apically pointed. Apical margin of S8 mildly outcurved. 25 (Fig. 17 B, C)- Gonobase short, about 1/2 of width. Gonocoxite slender, outer margin mildly angulate, inner margin mildly concave, apically roundly projecting, dorsal contour gently outcurved. Volsella medium sized. Penis valve dorsoventrally narrow, dorsal surface with sparse bristles. Gonostylus small, spherical. Ventral retrose lobe about as wide as long, densely haired, apically truncate (Fig. $17 \mathrm{~B}, \mathrm{C}$ ).

Specimens examined (Fig. 36): All from Sri Lanka. 1 female, Gal. Distr., Udugama, Kanneliya Jungle, 400 ft, 6-12. x. 1973 (KVK, PB, PF, J. Ferdinando); 1 male, Gal. Distr., Kanneliya Section, Sinhara Jungle, 2-5. x. 1980 (KVK, PB, TW, LJ, VK); 1 female, Keg. Distr., Kitulaga Jungle, 180-210 m, 25-26. x. 1977 (KVK, TW, MJ, PA).

This seemingly rare species has a curious combination of some features. It shares dentate inner spur of the male and, except for L. paralphenum, mesepisternal tubercle (in both sexes) with the other consubgeners, but much smaller and looks like a small 'carinaless' Evylaeus, particularly some species of L. (Evylaeus) leiosoma group (Ebmer \& Sakagami, 1985b) principally distributed in S. E. Asia, in elongate head, fine sculpture and relatively 


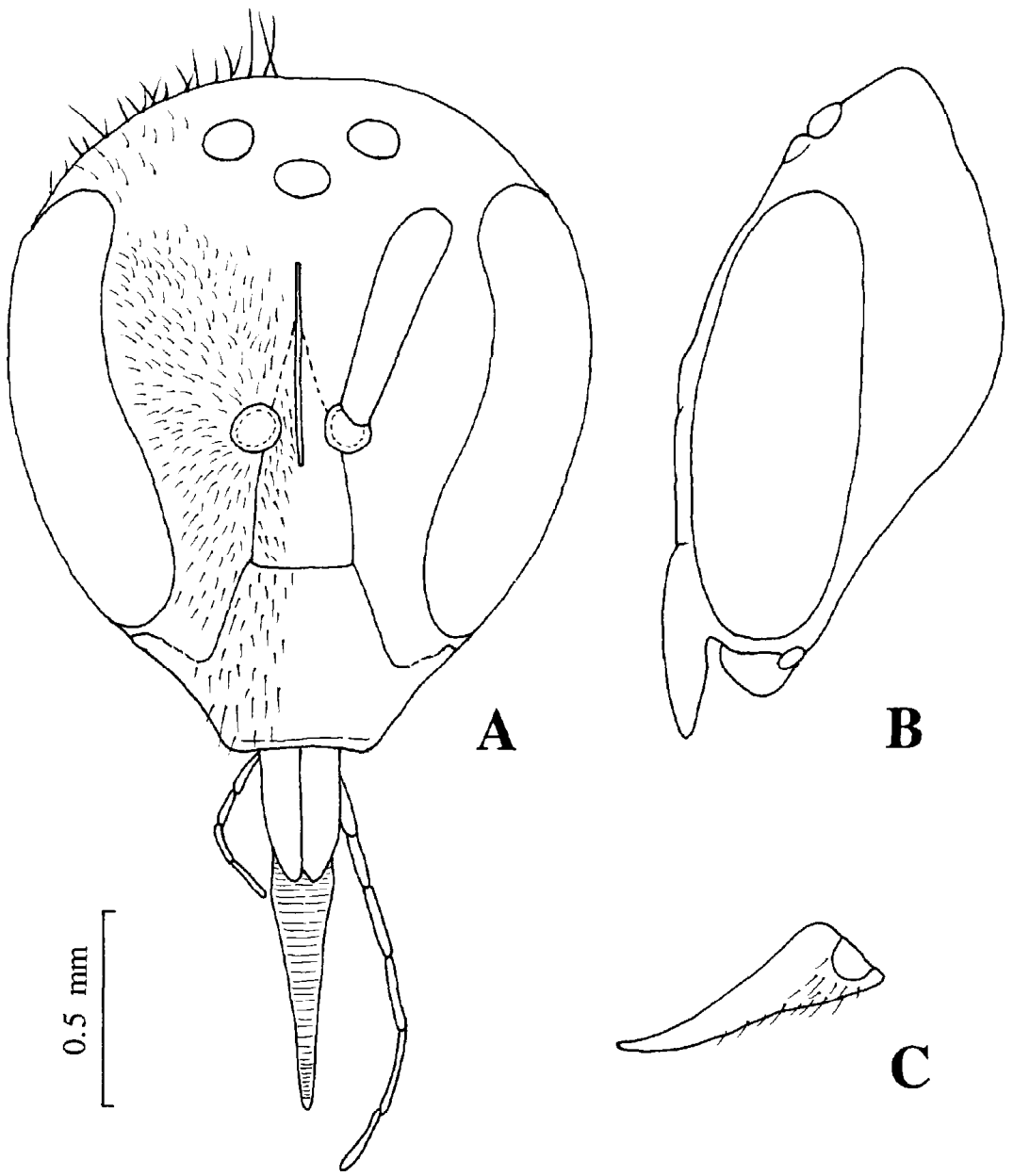

Fig. 16. Lasioglossum (Sudila) kandiense, male. A: Head seen frontally; B: Head seen laterally; C: Left mandible.

long propodeal dorsum. On the other hand, L. kandiense shares the postmarginal fimbria of metasoma with Halictus (both Halictus s. str. and Seladonia, and also their African counterparts, e.g., Patellapis, Michener, 1978), further with some isolately in some species of Lasioglossum (Evylaeus), e.g., L. matianense Blüthgen (Ebmer \& Sakagami, 1985a) and most species of L. sexstrigatum group (Ebmer et al., 1994). In L. kandiense, however, the metasomal fimbriae consist of white bristles as in L. (carinate Evylaeus) marginatum (Brullé), not of proper plumose hairs as in the above mentioned groups. Further, this species is recorded from the altitudes lower than other consubgeners (Fig. 36), except Kandy, the type locality. It is possible that the holotype was collected from a lower outskirt of Kandy city. 


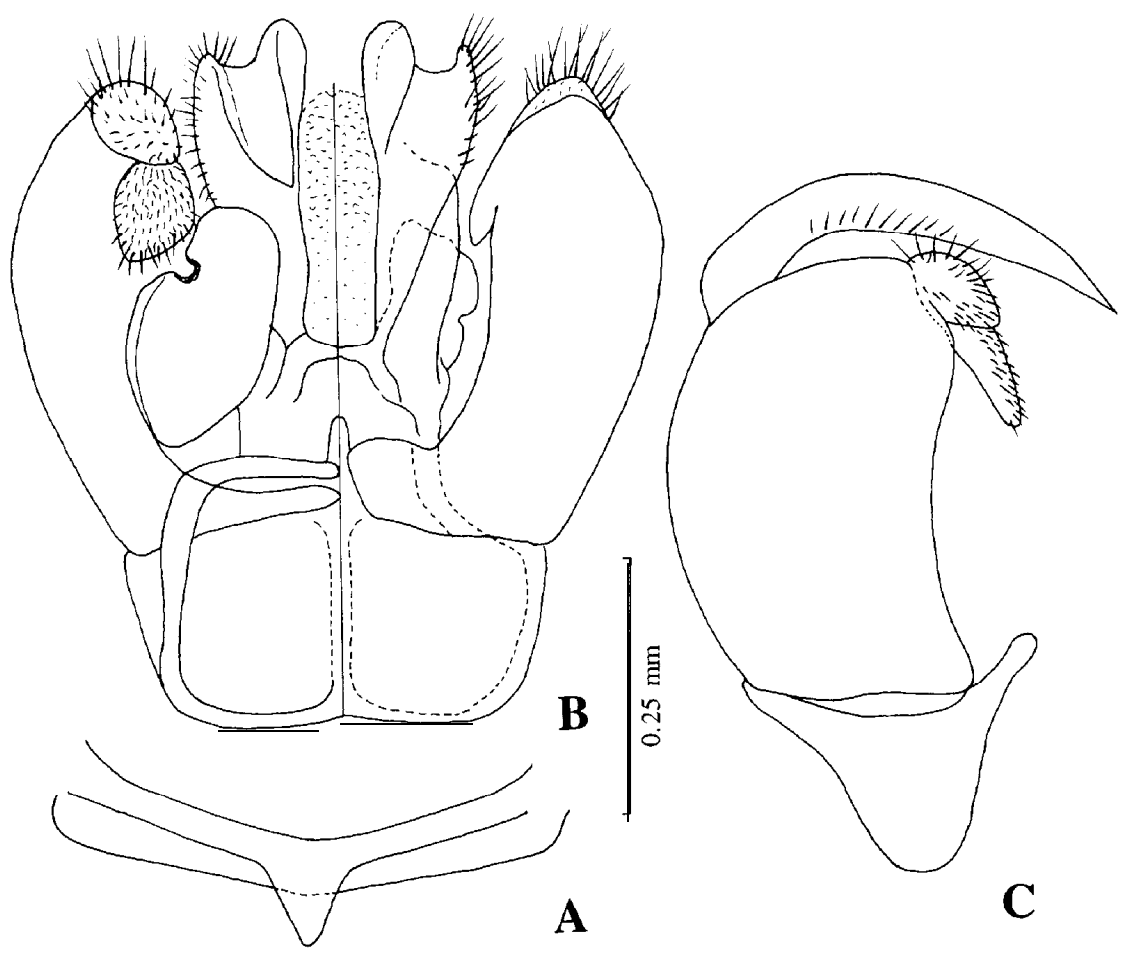

Fig. 17. Lasioglossum (Sudila) kandiense, male. A: Metasomal sterna 7 and 8; B: Genitalia, ventral (left) and dorsal (right) views; C: Genitalia, lateral view.

\section{B. Species with male gigantism}

\section{Lasioglossum (Sudila) alphenum (Cameron, 1897)}

(Figs. 2, 3, 4, 5, 6, 7, 8, 9, 18, 19, 20, 21, 22, 23, 25, 29)

Halictus alphenum Cameron 1897, Mem. Manchester Soc., 41 (4): 108 [male, Mussouri, type in Oxford]; Bliithgen, 1930, Mitt. deutsch. entom. Gesell., 73 (= H. ceylonicus Cameron, 1902); 1931, Zool. Jb. Syst., 61: 301.

Halictus ceylonicus Cameron, 1902, Ann. Mag. Nat. Hist., 9 (7): 253 [female, Ceylon, type in Oxford].

Ceylonicola submicans Friese, 19 18, 2001. Jb. Syst., 41: 504 [male, Ceylon, type in Berlin]; Bliithgen, 1926, Zool. Jb. Syst., 51: 546 (= H. ceylonicus, Cameron, 1902, nec 1898, cf. L. (S.) bidentatum p. 17.5).

Diagnosis: Head and mesosoma dull metallic green. Hairs sparse, sculpture weak. Propodeal dorsum only basally weakly ridged. Male head mildly polymorphic, larger males with basally widened mandible but without genal process. Ventral retrose lobe as in $\mathbf{L}$. kandiense.

Description: Female. 1- Medium sized. BL 7.1-8.2 mm, WL 6.4-6.9 mm (Fig. 8). 2MsW and MtW only slightly wider than head. 3- Body black. Head and mesosoma dully metallic green or blue green. Tegulae dark brown to blackish. Metasoma without reddish 


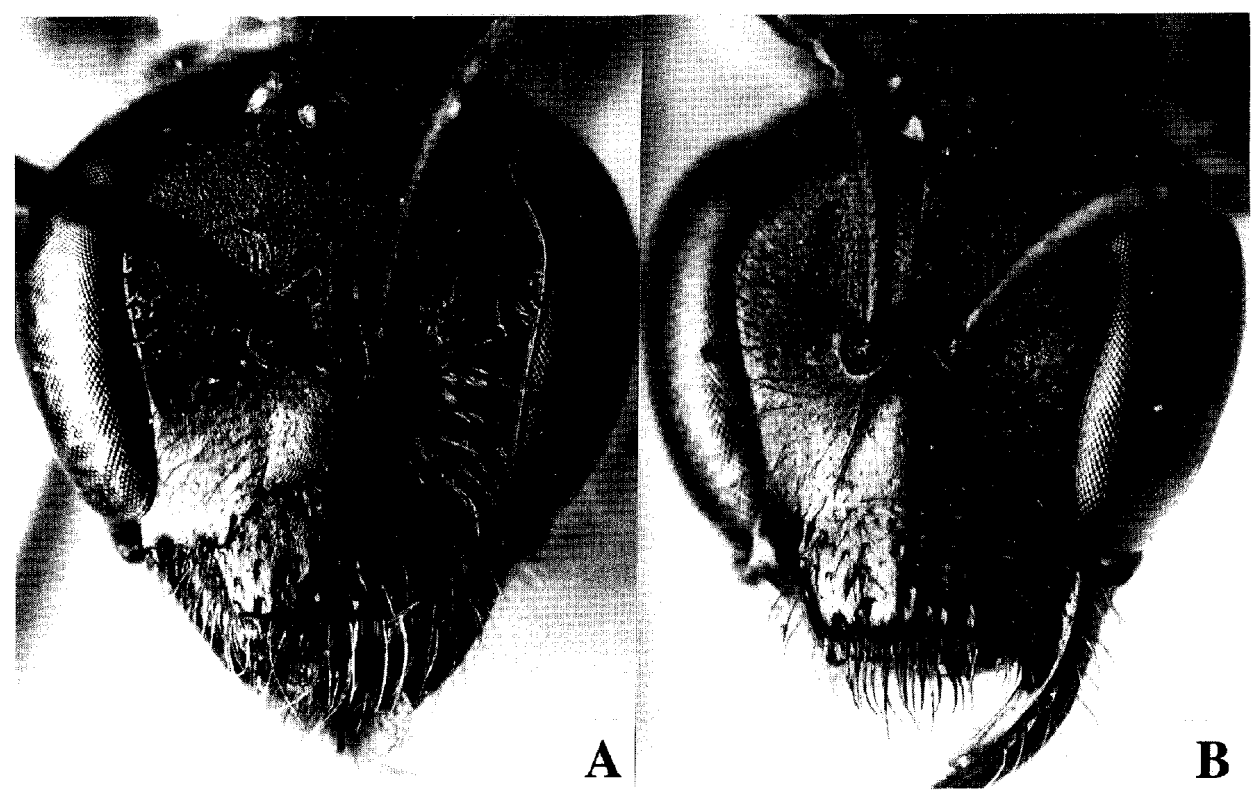

Fig. 18. Head of Lasioglossum (Sudila) alphenum (A) and L. (S.) bidentatum (B), female, seen frontally.
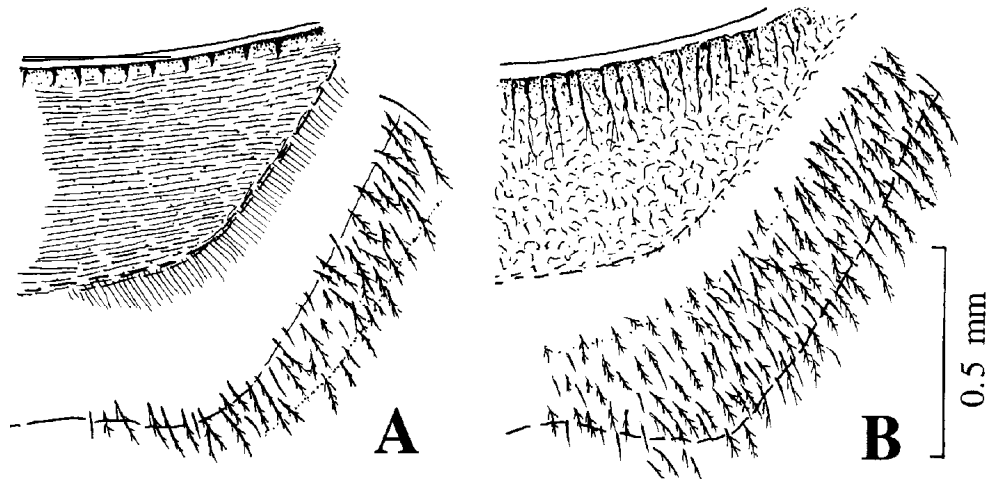

Fig. 19. Sculpture and lateral hairs on propodeal dorsum of Lasioglossum (Sudila) alphenum (A) and L. (S.) aulacophorum (B) female.

tint. 4- Hairs as sparse as in L. kandiense. Whitish to pale yellowish with slight admixture of dark hairs on vertex, frons, face, scape, paraocular area, clypeus and mesosomal dorsum. 5Hairs on head (Fig. 18 A) 225-250 $\mu$ on vertex, 300-350 $\mu$ or more on face; supraclypeus medially glabrous. Genal hairs sparse, not hiding surface, anteriorly simple $(150 \mu)$, postward plumose and longer, to $250 \mu$.6- Mesosomal hairs generally as dense as in $L$. kandiense. Mesoscutal and mesoscutellar hairs respectively 225-275 $\mu$ and 400-500 $\mu$, predominantly dark brown except peripheral white hairs; metanotal tomentum confined to anterior 1/3 but distinct. 7- Propodeal side apically not lined with tomentum; longer erect hairs as in L. kandiense, sparser, less plumose and issuing more distant from dorsum and shield than in L. aulacophorum (Fig. 19 A vs. B). Shield not tomented, erect hairs white, 
plumose, $\pm 250 \mu .8$ - Metasomal hairs as sparse as in $L$. kandiense, longer hairs predominantly white, sparsely admixed with darker ones. 9- $T_{1}$ as in $L$. kandiense but slightly sparser; basal sublateral hair patch and postmarginal hairs absent. 10- T2 with basal plumose patch usually continuous, although narrowed medially; submarginal hairs present behind lateral convexity but sparse; postmarginal hairs confined to lateral part, sparse, fine

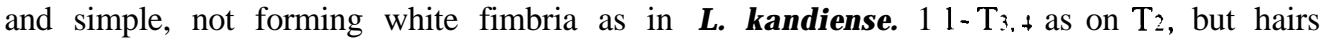
denser; postmarginal hairs extending mesad on $T_{3}$ and continuous on $T_{4}$, but not forming proper white fimbria.

12- Seen frontally head a trifle shorter than wide (Fig. 18 A). HW : HL $=1: 0.94$. UOD distinctly narrower than LOD. 13- Seen frontally (Fig. 18 A) vertex mildly convex; lateral ocellus distant from vertex less than own longitudinal axis; seen laterally (Fig. $25 \mathrm{D}$ ) not much raised postward. OOD and OOcD distinctly longer and VOD slightly shorter than IOD (Table 4 -2). 14- Seen laterally gena a trifle wider than eye. EW : GW = $1: 1.08$; homogeneously granular and not shiny, with sparse and obscure PP $(\phi \pm 15-20 \mu)$, along

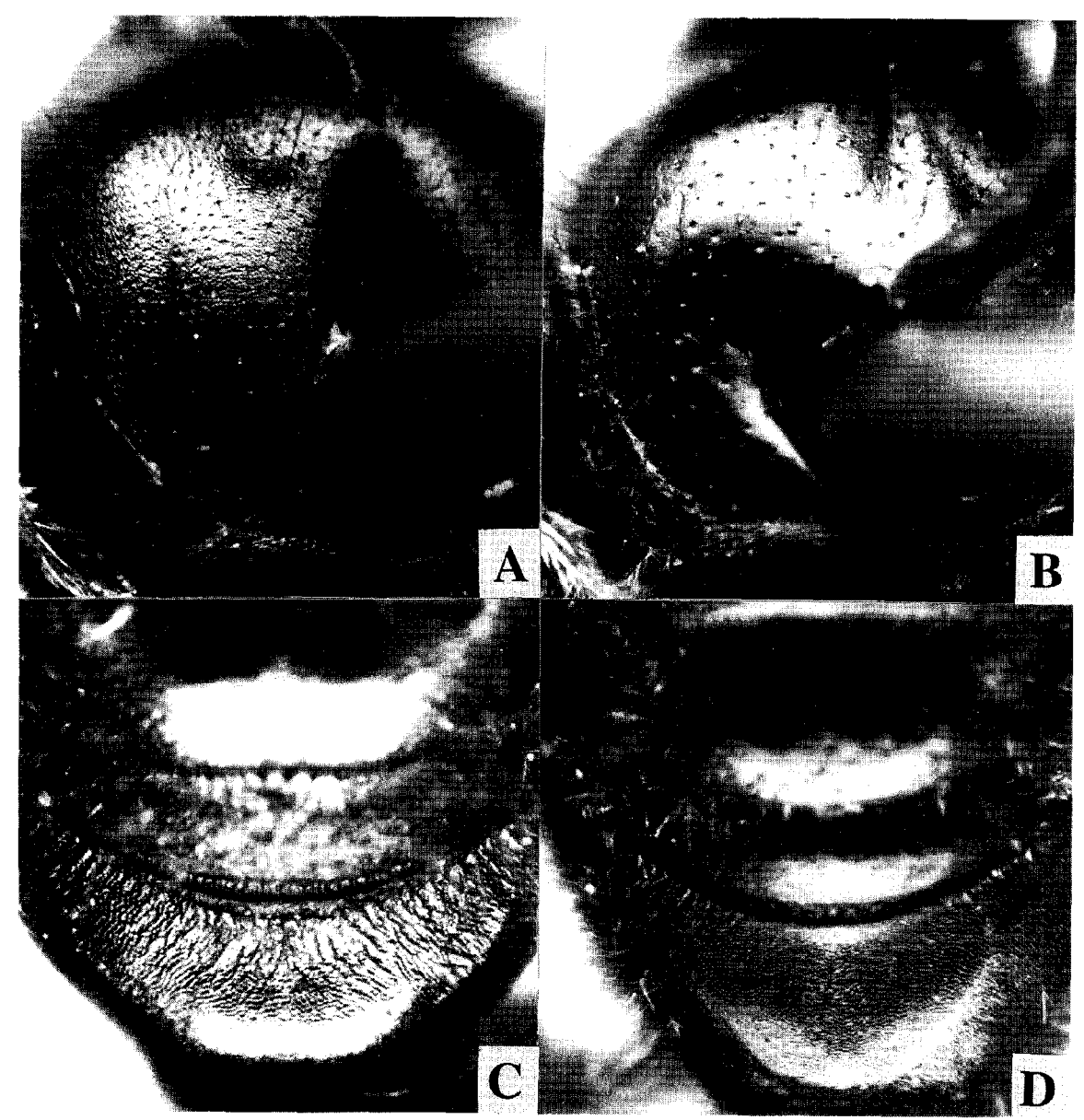

Fig. 20. Sculpture of mesoscutum (A, B) and propodeal dorsum (C, D) in Lasioglossum (Sudila) alphenum (A, C) and L. (S.)bidentatum (B, D) female. 
outer orbit IS smoother and shiner. Malar space very narrow but not linear. 15- Postocellar area granular. Ocellocular area smooth, finely and superficially etched, dimly shining; with sparse, finest PP ( $\phi 10-20 \mu$, Fig. $25 \mathrm{E})$. Face and paraocular area granular and mat, the latter with sparse, weak PP ( $\phi 20 \mu \pm$ ), downward on epistomal lobe sculpture superficial, IS becoming shiner. 16- Supraclypeus very mildly convex, homogeneously finely granular and mat. 17- CAL moderately long and ACL moderately shorter relative to CPL. 18-Scape exceeding mid ocellus.

19- Pronotal lateral angle obtuse, apex imperceptibly projecting, outer margin slightly concave (Fig. 29 B). 20- Mesoscutum homogeneously and finely granular, dully shining, with sparse (IS $=2.0-3.0)$, weak PP $(\phi 10-20 \mu)$ (Fig. 20 A). Mesoscutellum sometimes weakly bigibbous; sculptured peripherally and mediolongitudinally as on mesoscutum or often slightly coarser, whereas on submedian disc more superficially, seen shiner, more contrasting than in L. bidentatum. 21- Hypoepimeron and mesepisternum as on mesoscutum but sculpture on the latter stronger, tending to striate transversely. Mesepistemal tubercle distinct.

22- Propodeal dorsum nearly as long as mesoscutellum. PDL : MTL : MCL $=1: 0.66$ : 1.02, inclined postward, rather steep anteriorly; posterior margin roundly flexing; basally with sparse and weak longitudinal unbranched ridges, 20-25 $\mu$ distant from each other (Fig. $20 \mathrm{C}$ ); median ridges attaining anterior $2 / 5$ of dorsum, lateral ridges attaining

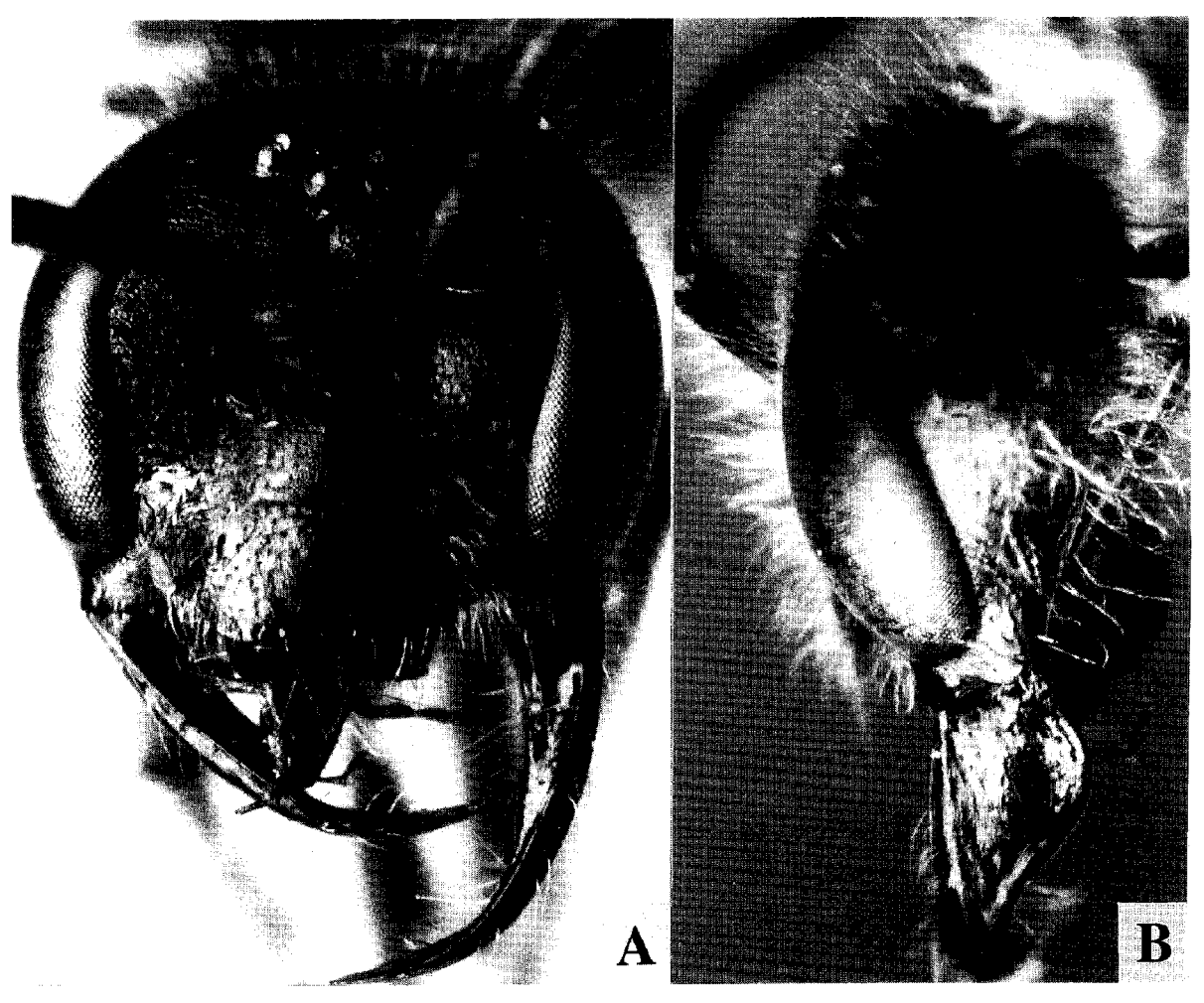

Fig. 21. Head of Lasioglossum(Sudila) alphenum male, seen frontally (A) and laterally (B). 
boundary between lateral slope; entire surface of dorsum finely striate, on anterior slope either longitudinally or obliquely, on apical part transversely. Shield granular, with some obscure and irregularly longitudinal ridges. 23- Inner hind tibia1 spur with teeth strong but seen slenderer than in L. bidentatum (Fig. 2). Number of teeth $5.8 \pm 0.6$, range 4-6, mode 6 , $n=51$.

Male. 1- Size variable (Figs. 8, 9), slightly to very smaller than female. BL 6.0-7.4 mm, WL 5.5-6.7 mm. 2- MsW narrower than HW and MtW narrower than MsW.3-1 1 as in female except for some items. 5- Hairs to $375 \mu$ on vertex and face. Unlike in many halictines, hairs of face below sparser and not appressed. Scape with hairs longer, to $375 \mu$ (250 $\mu$ in female), without admixture of dark ones. 6- Hairs on mesoscutum medially to $275 \mu$ and of mesoscutellum apically to $475 \mu$.

12- Seen frontally head transverse (Fị̣. 21A). HW:HL variable but on average $1: 0.83$. LOD nearly as wide as IOD in large male. 13- Seen frontally vertex flat; lateral ocellus distant from vertex up to twice own longitudinal axis in large macrocephalic male. OOD and $\mathrm{OOcD}$ on average 1.5 times longer than, and VOD slightly longer than IOD. 14- Gena slightly to distinctly wider than eye (Fig. 22 A, B), below rounded, neither angulate nor projecting. $\mathrm{EW}: \mathrm{GW}=$ (on average) $1: 1.03$; along outer orbit coarsely granular with some shiny interspaces, the rest longitudinally striate down to hypostoma. Seen dorsally, gena as wide as eye. Malar space distinctly longer than in female. 15 to 17- Head sculpture as in female. Paraocular area below wider, supraclypeus flatter. Clypeus flatter, epistomal angle obtuse; lateral arm longer, apical margin straight. 18- Scape attaining upper rim of mid ocellus. Basal flagellomeres relatively long (Fig. 7, al. male). $F_{2} L: F_{2} W=1: 0.89$. $F_{1}$ below slightly swollen (Fig. 7). Mandible elongate and sickle-like (Figs. 21 A, B, 22C, D), basally below conspicuously widened; basal surface rather homogeneously granular and mat in small males; smoother and shiner with sculpture more superficial in larger male. Labrum (Fig. 22 G) with basal part transverse subapically depressed; apical margin triangularly pointed medially. 19 to 21 - Mesosomal sculpture and mesepistemal tubercle as in female, mesoscutellum more granular with PP denser and IS less shiner than in female. 22- PDL : MTL : MCL = $1: 0.64: 1.00$ ( $\fallingdotseq$ female), basal ridges of dorsum longer and more acute. 23- Mid trochanter and femur below angulate (Fig. 22 E). Inner hind tibia1 spur with teeth shorter, thinner and denser; number of teeth in 14 males (1 male if not mentioned): 5+a ( $\mathrm{a}=$ incomplete tooth), 6 (6 males), 6+a, 7 (3 males), 8, 9, 10+2a.24Metasoma more slender. 24- S7 with median process short, apex roundly pointed. S8 with apical margin medially roundly outcurved (Fig. 22 I). 25- Gonobase relatively long, length $=4 / 5$ width. Gonocoxite relatively wide, outer margin homogeneously outcurved; inner margin rather straight; apical margin rounded; dorsal contour rather flat. Volsella medium sized. Penis valve dorsoventrally of medium width, dorsally with few hairs. Gonostylus small, spheroid. Ventral retrose lobe short, about as wide as long, densely haired, apically rounded (Fig. 23).

One male from Kanda-ela had only 2 submarginal cells in left fore wing.

Specimens examined (Fig. 36): all from Sri Lanka: [NE. Distr.]: Kanda-ela Reservoir, 5.6 mi SW Nuwara, Eliya, 6200 ft; 55 females 2 males 10-21. ii. 1970 (DR); 2 females, 1-5. x. 1970 (OS); 1 female, Horton Plains 6000 ft, 7 mi SSE Kanda-ela, 2. vi. 1976 (KVK, SK, DW); 3 males, Horton Plains, 7000 ft, 24 mi S. Pattipola Roadside pool, 20. ii. 1970; 1 male, World's End, 6800 ft, Horton Plains, 21. ii. 1970 (DR); 1 male, Small World's End, Horton Plains, 7000 ft, 4. x. 1970 (OS); 1 male, Galway Native Reserve, 5. iii. 1972 (KVK \& PB); 1 


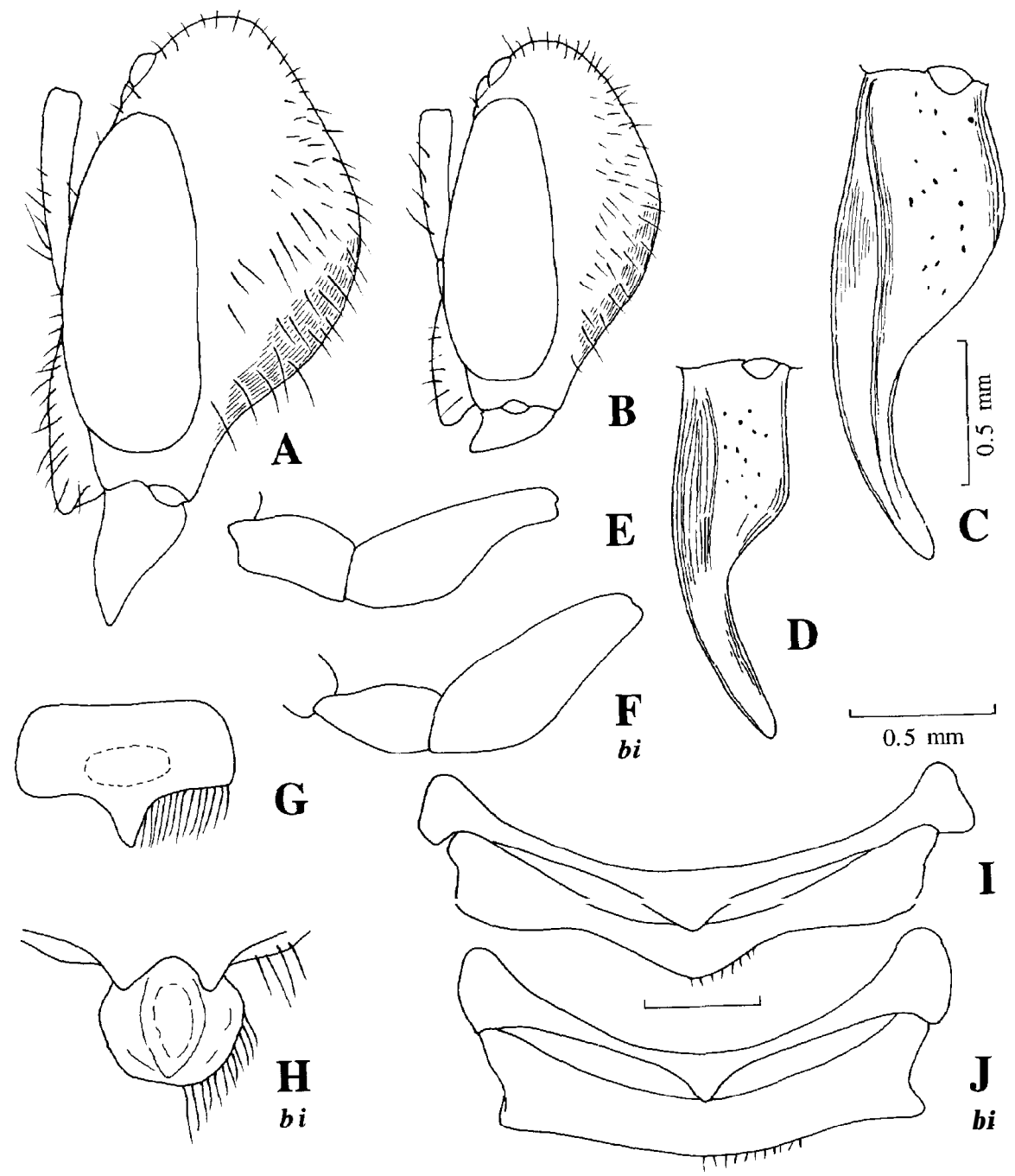

Fig. 22. Some male features in Lasioglossum (Sudila)bidentatum (= bi) and L. (S.) alphenum (all others). A, B: Head seen laterally of large and small males; C, D: Left mandible of large and small males; E, F: Hind trochanter and femur; G, H: Labrum; I, J: Sterna 7 and 8 . Scale $=0.125 \mathrm{~mm}$ in I, J. $=0.5 \mathrm{~mm}$ in all others.

female, Mt. Pidurutalagala, 6500-7500 ft, 8. x. 1976 (GF, RE, SK, DW); 1 female, Hakagala, 6000 ft, 2. vi. 1976 (KVK, SK, DW); Hakagala National Reserve: 2 females, 1650-1800m, 23-25. ii. 1977 (KVK, PB, PK, DW); 1 female, 1790-1830 m, 7. ii. 1979 (KVK) (red label, 2779A, nest excavation); 1 female, $6000 \mathrm{ft}, 2$. vi. 1976 (KVK, PB, DW); 3 females (1 female Malaise), 6-7. ii. 1979 (KVK, SS, TG); 1 female, Hakagala Botanic Garden, 23-25. ii. 1977 (KVK, PB, PF, DW). [Kan. Distr.]: 2 females, Kabaragala, Nillomala, 22-23. iii. 1975 (SK \& PB); 4 females Adams Peak Trail, 4.5 mi W, Maskeliya, 1690-1770 m, 20-21. x. 1977 (KVK, TW, MJ, PA). 
Appendix : Notes on the type specimen of L. (S.) alphenum (Cameron, 1897) deposited in Hope Entomological Collections, University Museum, Oxford.

No. 1 (male). (n) means labels attached numbered from the top downward. Abbreviations of measured body parts are BL (body length), WL (wing length including tegula), $(10=1 \mathrm{~mm})$, WDL (wing diagonal length), HW, HL (head width and length), EL (eye length), MsW and MtW (mesosoma and metasoma width $(25=1 \mathrm{~mm})$. (1) Halictus alphenum Cameron, type; (2) MUSSOORIE, ROTHNEY (printed with red capital letters); (3) 1010 (typewritten). Morphologically identical with the other specimens from Sri Lanka examined by S. F. S (never with $L$. paralphenum described subsequently) including mesepistemal tubercle, labrum, mid leg etc. Inner hind tibia1 spur with teeth $7 / 7$. BL $(10=$ lmm) 63, WL 60, WDL 69, HW 54, HL 46, EL 33, MsW 51, MtW 44. Very probably the printed red label "Mussoorie, Rothney" was misattached to a Ceylonese specimen.

No. 2 (female). (1) Halictusceylonicus Cam., type, Ceylon; (2) 990 (typewritten). Morphologically same to the other Ceylonese specimens compared by S. F. S. BL 81, WL 70, WDL 73, I-JW 57, HL 56, MsW 63, MtW 56.

No. 3 (female). (1) = No. 2; (2) 991 (typewritten), morphologically = No. 2; (3) BL 77, WL 65, WDL 73, HW 55, HL 54, MsW 61, MtW 55.

No. 4 (female). (1) Rothney coll., $H$. ceylonicus, the type, R. C. L. P.; (2) Cotype of $H$. ceylonicus Cameron, submicans Friese is a synonym; (3) Blüthgen, synonym, "otherwise unreadable". Blüthgen in handwritten, morphologically as in Nos. 2, 3, but better preserved. BL 80, WL \pm 66 , WDL \pm 74 , HW 54, HL 53, MsW 59, MtW 55.

It is enigmatic that the type locality of this species is Mussouri, N. India. As explained in L. paralphenum sp. nov., this might have been caused by mislabelling, not meaning the real occurrence of isolate local populations as often known in some boreoalpine insects.

The numbers of specimens collected in various months are February $55+7$ females 6 males; March 2 females 1 male, June 2 females October 7 females 2 males. Most females were unworn and without pollen loads. Pollen carrying females were collected in February (10 females), June ( 2 females) and October ( 3 females). This species was most abundantly collected within the examined consubgeners, but the number of specimens is particularly concentrated on 20-21. ii. 1970 in Kanda-ela Reservoir. As in L. aulacophorum, it is still difficult to know the life cycle of this species exactly under the local climate.

Two records on the bionomics of this species are available both taken at the same site in Hakagala National Reserve (1790-1830 m) by K. V. Krombein (7. ii. 1979) and B. B. Norden (16. vii. 1993) who kindly sent their observations to S. F. S. as summarized below; 1- Krombein: The entrance tumulus of a closed bee nest was found on a flat road. The nest burrow was $3 \mathrm{~mm} \phi$ and descended first vertically for $7.6 \mathrm{~cm}$ deep, then obliquely $\left( \pm 45^{\circ}\right)$ for $6.9 \mathrm{~cm}$ and again vertically for $2.8 \mathrm{~cm}$. There were no brood cells around the burrow and 1 female of $\mathbf{L}$. alphenum was collected at the bottom. 2-Norden: Four nest entrances were located along an earthen pathway and excavated under the local monsoon rains. Three were into empty burrows but one $(7 \mathrm{~cm}$ deep) contained a female. No cells were found $\pm 12 \mathrm{~cm} \phi$ around the bottom and down to $8 \mathrm{~cm}$ below the burrow bottom. The female examined by S. F. S. had both wings and mandibles heavily worn and the ovaries just at the start of degeneration from the full grown state, i.e., she was indubitably an old post-reproductive female.

Both observations still do not tell us much on the bionomics, particularly on the nest architecture and social structure. The vegetation of the nest site was fairly denser in 1993 

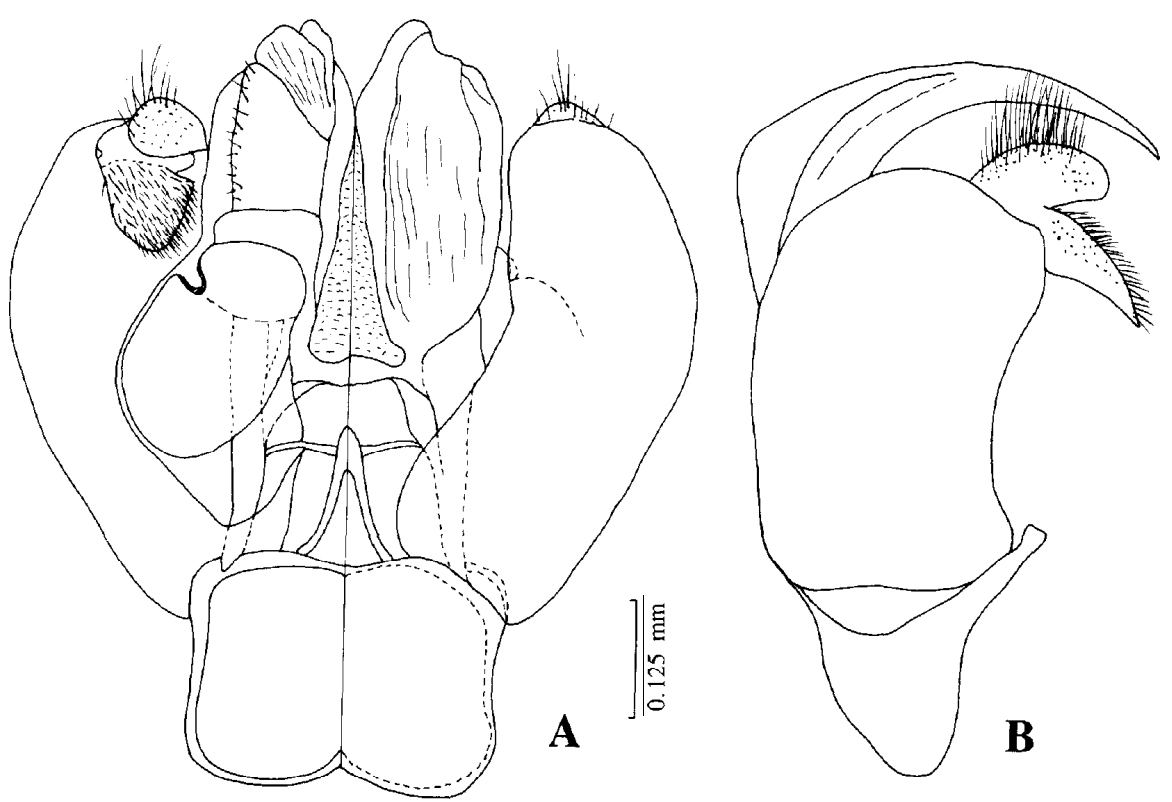

Fig. 23. Male genitalia of Lasioglossum(Studila)alphenum. A: Ventral (left) and dorsal view; B: Lateral view.

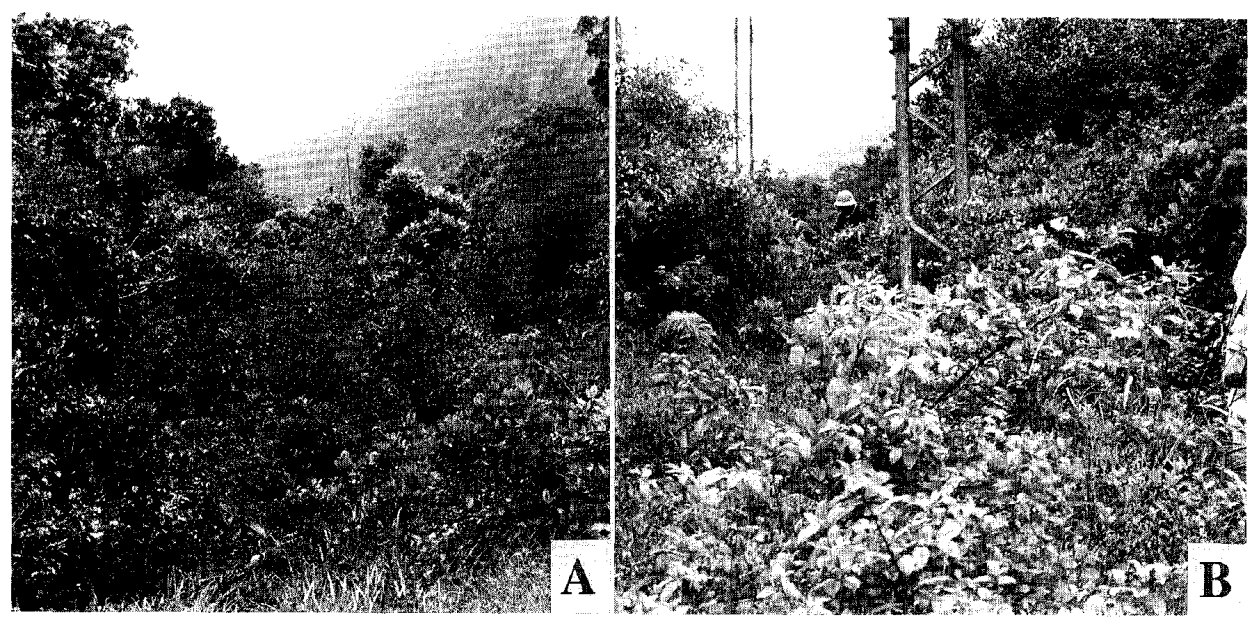

Fig. 24. The nest site found at Hakagala National Reserve $(1790-1830 \mathrm{~m})$. A: Vegetation in general; B: Nest site. Offered by Dr. B. B. Norden.

than 1979 (Fig. 24), unlike at nest sites of many other halictines. Such species distinctly prefer the open earth surface poorly covered with plants, and some ones abandon the nest sites when covered with denser vegetation as known in Lasiogfossum (Evylaeus) duplex (Dalla Torre) in northern Japan, of which nest aggregation survive only when the soil surface was regularly weeded out (Sakagami, 1977). However, there are some species which 
prefer shaded and moderately covered earth surface, e.g., L. (E.) problematicum(Blüthgen) (Sakagami, unpubl.). It is possible that L. alphenum behaves similarly.

\section{Lasioglossum (Sudila) paralphenum sp. nov.}

(Figs. 2, 3, 7, 8, 9, 25, 26, 27, 28)

Diagnosis: Similar to L. alphenum in coloration, pilosity and general habitus, but differing by smaller size, more homogeneous sculpture, and particularly by the absence of mesepistemal tubercles.

Description: 1- Similar to L. alphenum but differs in the following features. Distinctly smaller than alphenum (Figs. 8, 9), BL 6.3-6.8 mm (female), 5.2-5.6 mm (male); WL 5.2$5.7 \mathrm{~mm}$ (female), 5.0-5.5 mm (male). 2- Metanotal tomentum confined to anterior margin as a narrow and sparse band far less developed than in alphenum, the rest of surface with erect hairs as on mesoscutellum. 3- Vertex flatter (Fig. 2.5 C vs. D). Lateral ocellus attaining vertex (female, Fig. 25 A vs. B, male Fig. 27 A vs. Fig. 18 A). 3- Ocellocular punctures denser and more homogeneous, IS more granular, i.e., less shiny. Postocellar

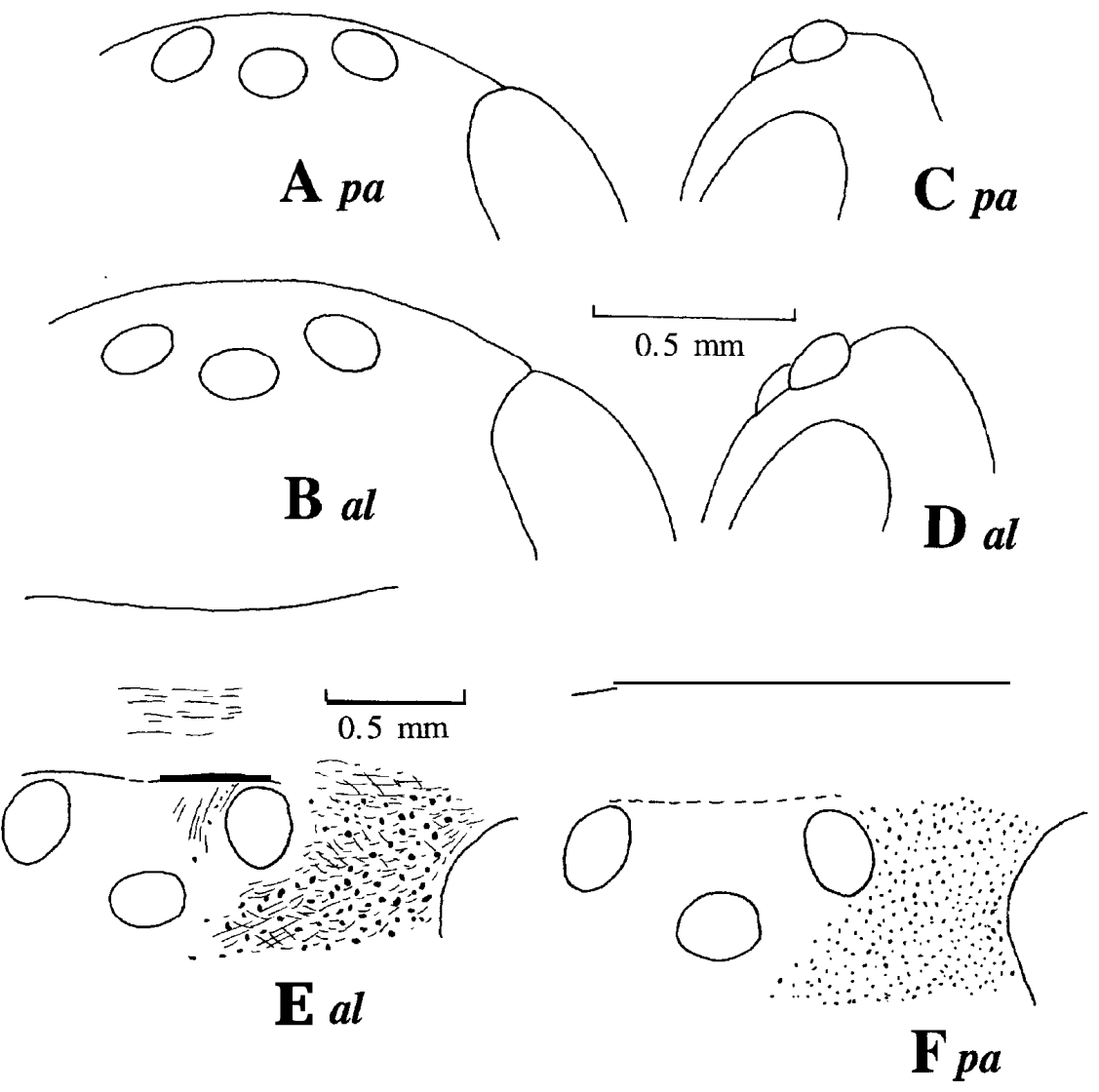

Fig. 25. Comparison of upper part of head between Lasioglossum (Sudila) alphenum (al) and L. (S.) paralphenum (pa) female. A-C: Vertex seen frontally and laterally; E, F: Sculpture on ocellocular area. 
impression weaker (Fig. $25 \mathrm{~F}$ vs. E). 4- Male gena angulate (Fig. 27 B vs. Figs. 21 B, 22 A, B). 5- Male mandible sickle-like but not so developed as in large male of alphenum and basally below not widened (Fig.27 A vs. Fig. 21 B, 22 C, D). 6- Mesoscutal punctures finer and sparser ( $\phi>10 \mu$, IS 3.0 vs. $\phi$ 10-15, IS 1.5-in alphenum). 7- Mesoscutellum less bigibbous, sculpture sexually dimorphic. In female denser and more homogeneous than in alphenum female, while in male far sparser than in alphenum in which sexual difference is weaker (Fig. 26). 8- Mesepistemum homogeneously, coarsely granular, without transverse striation. 9- Mesepisternal tubercle absent (Fig. 3). 10- Male mid trochanter and femur not angulate (as in Fig. 22 F, not E). 11 - Teeth of male inner hind tibial spur shorter (Fig. 2). 12- Apical margin of S7 medially less pointed, and of S8 less projecting (Fig. 28 A vs. Fig. $22 \mathrm{~J}) .13$ - Gonobase and gonocoxite shorter. Gonostylus consisting of apical and basal lobes, the former slender but should be homologous with gonostylus of alphenum. Ventral retrose lobe short as in alphenum but apically rounded, not truncate, and setae sparser, confined to apical part (Fig. 28 B, C vs. Fig. 23 A, B).

Specimens examined (Fig. 36): Holotype female, Nilgiri Hills, Naduvatam, S. India, 6000 ft, v. 1958 (P. S. Nathan). Paratypes: 4 females 3 males, Data same to holotype; 4 females, Tamil Nadu, Nadubattam, Nilgiri, 2000 m, 28. xi. 1978 (Japan-India Coop. Trip); 4 females, Tamil Nadu, Pykara, Nilgiri, 2000 m, 28. xi. 1978 (Japan-India Coop. Trip). Holotype and a male paratype of the same data in A. W. Ebmer's collection, the other 4 females 2 males of the same data in Bee Biology and Systematic Laboratory, Utah State University, Logan, and all 1978 specimens tentatively in Entomological Institute, Hokkaido University, Sapporo.

Some ratios and morphometric values: Ratios see Table 4. Hairs: female, vertex 200-225 $\mu$, face $250-300 \mu$, scape $200 \mu$, gena posteriorly to $225 \mu$, mesoscutum $150-200 \mu$, mesoscutellum $\pm 325 \mu$, erect hairs on propodeal shield $\pm 225 \mu$; male, vertex $250 \mu$, scape $250 \mu$, otherwise $=$ female.
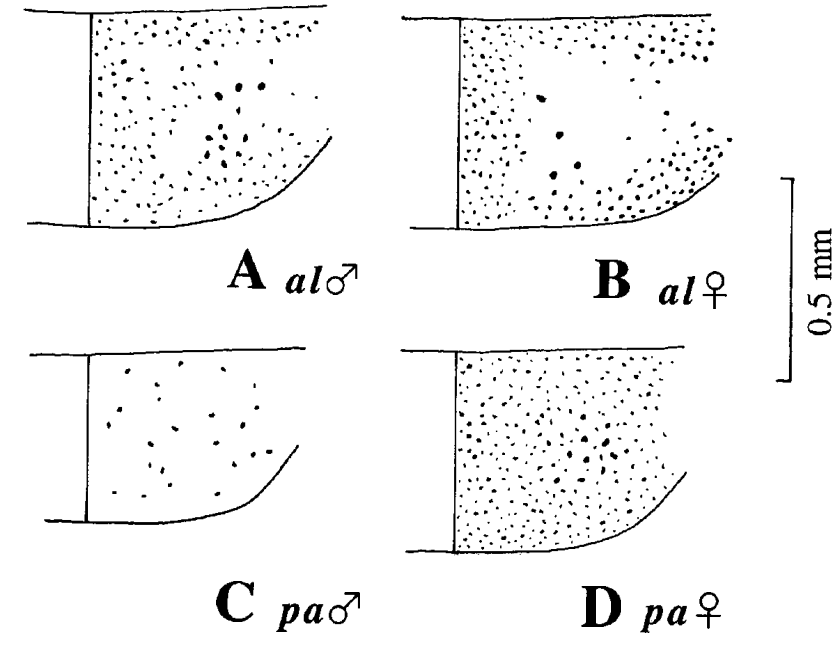

Fig. 26. Mesoscutellar sculpture of Lasioglossum(Sudila) alphenum (al) and L. (S.) paralphenum. 


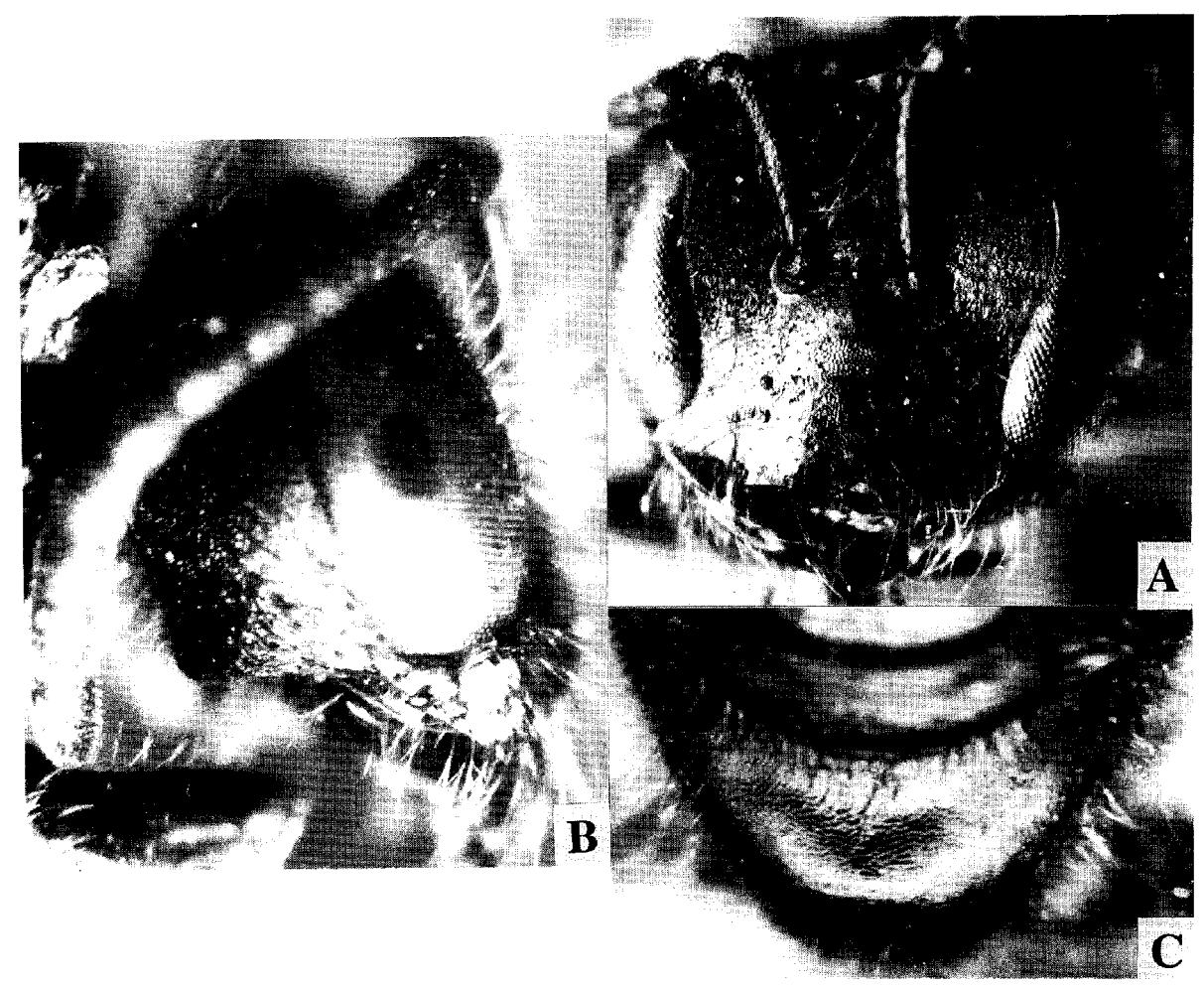

Fig. 27. Lasioglossum (Sudila) paralphenum male. Head seen frontally (A), and laterally (B) and propodeal dorsum (C).

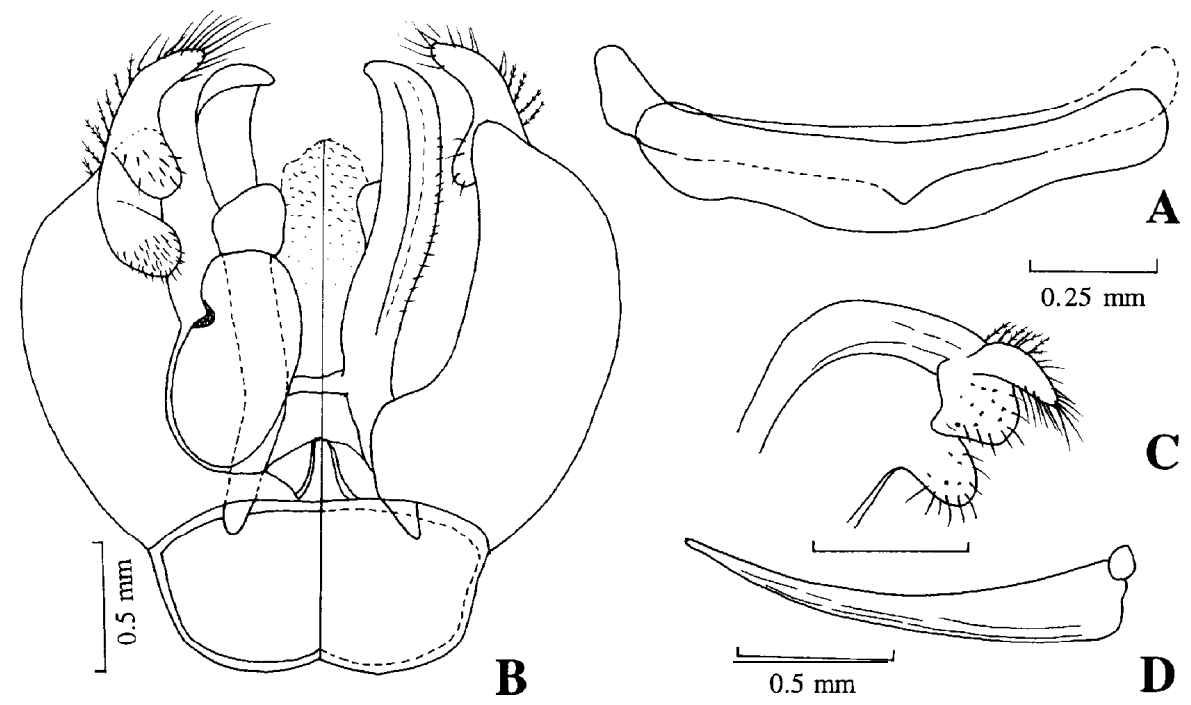

Fig. 28. Lasioglossum (Sudila) paralphenum male. A: Metasomal sterna 7, 8; B: Genitalia, left-ventral, right-dorsal views; C: left mandible. Scale $=0.125 \mathrm{~mm}$ in A, B, and $0.5 \mathrm{~mm}$ in $\mathrm{C}$. 
The resemblance between $L$. alphenum and L. paralphenum strongly suggests that they are cladistic sisters. Then the absence of mesepistemal tubercle in L. paralphenum should be either not yet aquired or already lost. As later explained, the latter hypothesis seems more parsimonious. Whether the cephalic gigantism in the only 3 known males reflects a polymorphism or not is uncertain. Probably such trend is milder than in L. alphenum even if occurs as suggested by the following low ratios of the largest male to the mean of the 2 smaller male in various body parts: HW 1.09, HL 1.01 , MdL 1.13, VOD 1.14, IOD 1.11, OOD 1.20, EW 1.14, GW 1.07 (larger/ smaller).

The discovery of $L$. paralphenum in southern India might suggest that the type specimen of $L$. alphenum, of which type locality is Mussouri, Northern India, was actually $L$. paraiphenrtm than L. alphenum, which is otherwise known only from Sri Lanka. However, examining type specimen from Mussouri, Oxford, Bliithgen (1930) clearly mentioned the possession of mandible and mid trochanter characteristic of L. alphenum. Later, one of us could examine the type in Oxford, and confirmed this. Probably the type was collected in Sri Lanka but mis-labelled as collected in Mussouri. There is another similar case. $L$. (Nesohalictus) serenum (Cameron) is confined to S. India and Sri Lanka, but the type locality is Mussouri (Cameron, 1897).

The female specimens were collected in May, $1958(n=5)$ and November, $1978(n=8)$. The specimens collected in November seem slightly smaller as follows: BL $(10=1 \mathrm{~mm})$ $64.6 \pm 2.0$ ('58), $63.0 \pm 1.9$ ('78), WL ("), $55.3 \pm 1.2$ ('58), $54.4 \pm 1.2$ ("78), WD (25 = 1 mm) $66.0 \pm 1.5,63.9 \pm 1.2$; HW (") $45.0 \pm 1.7,43.1 \pm 0.9$, HL (") $41.6 \pm 1.6,38.9 \pm 1.4$, $\mathrm{MtW}(") 45.6 \pm 1.2,41.9 \pm 1.7$. However, from the SD overlap the difference is insignificant except for body parts. MtW which shows the larger size difference than other parts in many halictines.

The collected locality, Nilgiri Hills are the highest area in S. India. Both 1958 and 1978 bees were collected at the highest point (Pykara) or slightly below (Nadubattam = Naduvatam). According to Prof. S. Takagi, who collected insects there, the original vegetation is evergreen forests in slopes with admixture of Rhododendron, but the primary vegetation was fairly destructed and human habitations were nearby.

\section{Lasioglossum (Sudila) bidentatum (Cameron, 1898)}

(Figs. 1, 2, 3, 4, 6, 7, 8, 9, 18, 20, 22, 29, 30, 3 1, 32, 33, 34, 35)

Sudila bidentata Cameron, 1898, Mem. Manchester Soc., 42 (11): 54 [male, Ceylon, type in Oxford]; Cockerell, 1923, Ann, Mag. Nat. Hist., 9 (11): 267 [male].

Sudila fuscipennis Cameron, 1898, Mem. Manchester Soc., 42 (11): 55 [male, Ceylon, type in Oxford]; Cockerell, 1923, Ann. Mag. Nat. Hist., (9) 11: 268 [male]; Bliithgen, 1930, Mitt. deuts. entom. Gesell., 74; Bliithgen, 2001. Jb., Syst., 61: 301 (= Halictus bidentatus Cameron).

Sudila ceylonica Cameron, 1898, Mem. Manchester Soc., 42 (11): 55 [female, Ceylon, type in Oxford]; Cockerell, 1923, Ann. Mag. Nat. Hist., (9) 11: 267 [female]; Bliithgen, 1930, Mitt. deuts. entom. Gesell., 75; Bliithgen, 1931, Zool. Jb., Syst., 61: 301 (= Halictus bidentatus Cameron).

Ceylonicola atra Friese, 1918, 2001. Jb., Syst., 41: 502 [female \& male, type in Berlin]; Bliithgen, 1930, Mitt. deuts. entom. Gesell., 75; Bliithgen, 1931, Zool. Jb., Syst., 61: 301 (= Halictus bidentatus Cameron). 


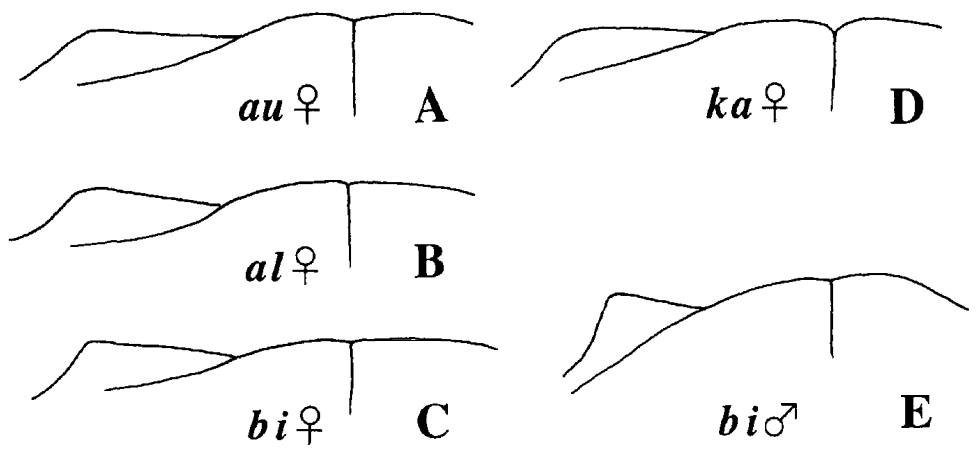

Fig. 29. Pronotum and anterior part of mesoscutum in Lasioglossum(Sudila) aulacophorum female (A), alphenum female (B), kandiense female (D), bidentatum female $(\mathrm{C})$ and large male $(\mathrm{E})$.

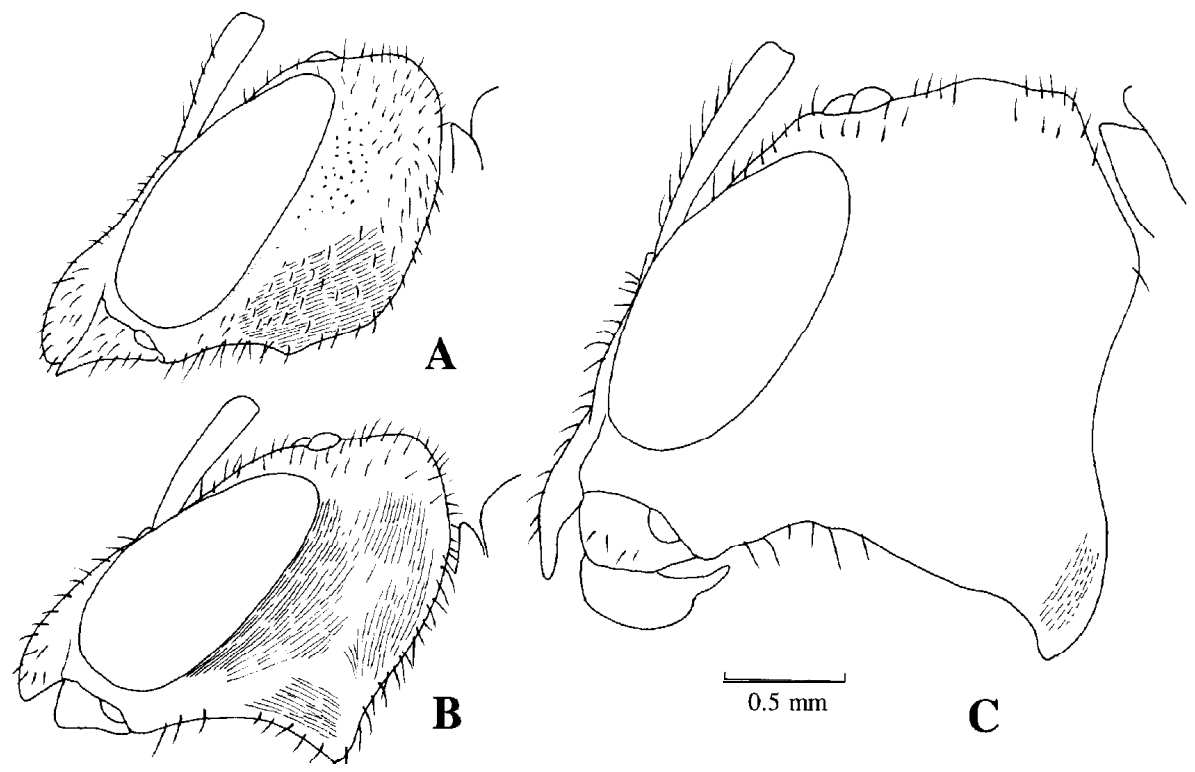

Fig. 30. Lasioglossum (Sudila) bidentatum. Head seen laterally of small (A), medium (B) and large (C) males.

Ceylonicola rubrivenrris Friese, 1918, Zool. Jb., Syst., 19: 503 [female, Ceylon, type in Berlin]; Bliithgen, 1931, Zool. Jb., Syst., 51: 58.5.

Halictus (Sudila) bidentatus: Bliithgen, 1931, Zool. Jb., Syst., 61: 301 (= Sudila fuscipennis Cameron, S.ceylonica Cameron, Ceylonicoln atra Friese).

Diagnosis: Black. Metasoma in some females tending reddish to completely reddish brown. Hairs very sparse, sculpture superficial. Basal ridges of propodeal dorsum evanescent. Male head strongly polymorphic, larger males with very prolonged medially widened mandible and developed genal process. Ventral retrose lobe twice longer than wide. 
Description: Female. 1- Medium sized, slightly larger than L. alphenum, nearly as large as L. aulacophorum (Fig. 8). BL 7.4-8.8 mm, WL 7.3-7.8 mm. 2- MsW and MtW only slightly wider than HW. 3- Body black without metallic tint. Tegula black. Metasoma black, either partially or entirely reddish brown except black on apex of T6.4- Hairs much sparser than in L. alphenrrm and L. kandiense, with denser admixture of dark hairs. 5- Hairs on head (Fig. 18 B) 300-350 $\mu$ on vertex, 350-450 $\mu$ on face, predominantly or exclusively

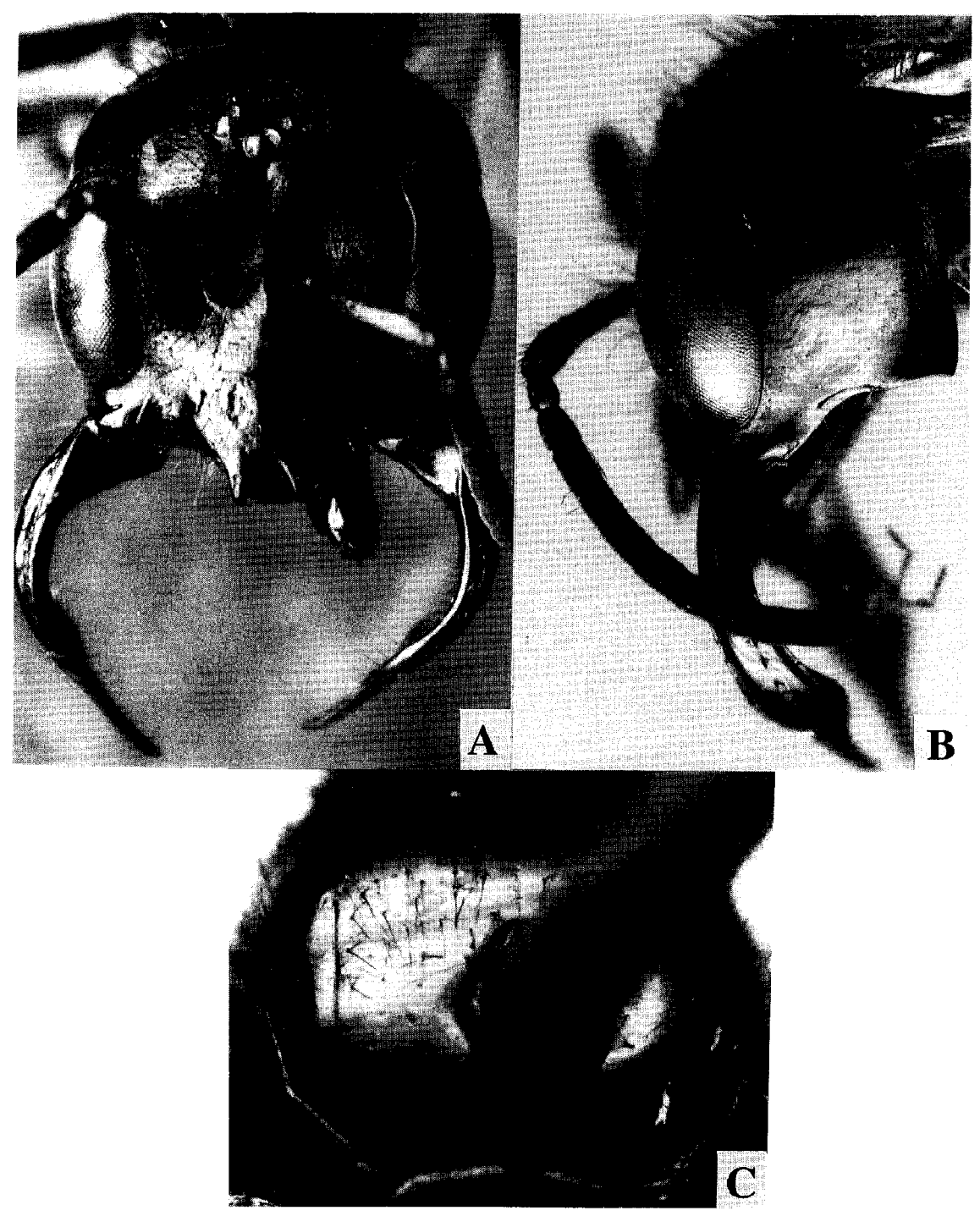

Fig. 31. Lasioglossum (Sudila) bidentatum. Head seen frontally (A) and laterally (B), and mesoscutum of medium male $(\mathrm{C})$. 
dark with little plumosity, sparse, not hiding surface even on paraocular area. Hairs on supraclypeus and gena sparser than in L. alphenum (Fig. 18 B vs. A). 6- Mesosomal hairs unusually sparse as a halictine species, virtually monopolized with simple, dark brown hairs; mesoscutal hairs $(200-300 \mu)$, erect or semierect. Mesoscutellar hairs to $500 \mu$. Metanotal tomentum confined to the anterior margin, occasionally vestigial. 7-Propodeal pilosity as in L. alphenum. Metasomal hairs very sparse, predominantly dark. 9- Except sparse, poorly plumose hairs on slope, $T_{1}$ virtually glabrous, postmarginal hairs absent. 10- $T_{2}$ with basal fimbria usually hidden by $T_{1}$; disc virtually glabrous except very fine and sparse hairs; submarginal hairs forming inconspicuous row confined to postlateral corner; postmarginal hairs absent. 1 1- T3.4 with basal fimbria invisibly narrow, lateral and submarginal hairs denser than on T2, the latter more extending mesad but far sparser than in L. alphenum.

12- Seen frontally head slightly shorter than wide (Fig. 18 B). HW : HL = 1: 0.98. 13Seen frontally vertex mildly convex but slightly more than in L. alphenum. Lateral ocellus distant from vertex about its own vertical axis; seen laterally not much raised postward, OOD and OOcD distinctly, and VOD slightly longer than IOD. 14- Seen laterally gena as wide as eye; EW : GW = $1: 1.02$, homogeneously granular. Malar space narrow but not linear. 15Postocellar area finely granular and mat, posteriorly with obscure transverse reticulation, with fine ( $\varnothing \mathrm{P} 10-15 \mu)$, sparse (IS $\geq \varnothing \mathrm{P}$ ) punctures. Ocellocular area similar but IS more superficially granular, dimly shining. Face and paraocular area mat and homogeneously granular, with sparse, obscure PP ( $\phi$ P 20-25 $\mu$, IS = 2.0-3.0), smoother and shiner downward on epistomal lobe. 16- Supraclypeus mildly convex, homogeneously, finely granular with very sparse and obscure PP ( $\phi$ P 15-20 $\mu$ Fig. 18 B). 17- Clypeal proportion similar to that in L. alphenum (Table 4). 18-Scape exceeding upper rim of mid ocellus.

19- Pronotal shape as in L. alphenum (Fig. 29 C). 20- Mesoscutum homogeneously and very finely tessellate, seen shiny with ill-defined PP ( $\phi 18-25 \mu$, IS $=2.0-3.0$ or more); medially sculpture so superficial that seen as if smooth and shiny (Fig. $20 \mathrm{~B}$ ). Mesoscutellum flat, occasionally weakly depressed mediolongitudinally, sculptured as on mesoscutum, submedially less granular and shiner. 21- Hypoepimeron and mesepistemum sculptured as on mesoscutum, the latter with some coarse (to $25 \mu$ ), sparse (IS $=2.0$ or more), obscure PP without transverse striation. Mesostemal tubercle distinct to weak (Fig. 3). 22- Propodeal dorsum slightly shorter than mesoscutellum. PDL : MTL : MCL = 1 : 0.66 : 1.10. Dorsum (Fig. 20 D), steeper and boundaries with lateral slope and shield more rounded than in L. ulphenum; finely homogeneously, and mainly transversely tessellostriate, mat and dully shining; basilaterally with short, very inconspicuous ridges. Shield similarly tessello-striate. 23- Inner hind tibial spur mostly with 6 long teeth, 1st tooth longest, longer than spur width (Fig. 2) ( $\mathrm{N}$ of teeth $5.6 \pm 1.1, n=25$, range 4-7, mode 6).

Male. 1- Size extremely variable, from distinctly smaller to distinctly larger than female (Fig. 8). BL 6.5-10.0 mm, WL 6.2-8.3 mm, 2- MsW narrower > HW and MtW narrower > MsW.3- Color as in female but metasoma usually darker, not completely reddish in all examined male. 4- Hairs as in female, much sparser and more admixed with dark hairs than in $L$. alphenum. On face to $275 \mu$ vertex to $376 \mu$, mesoscutum to $200 \mu$, mesoscutellum to $375 \mu .5$ - Head as in female, but vertex nearly exclusively dark-haired. Facial (Fig. 32 A, B) and vertex $(\mathrm{C}, \mathrm{E}, \mathrm{D})$ hairs also varying from dense to sparse from small $(\mathrm{A}, \mathrm{C})$ via medium (E) to large (B, D). Gena in S female (small male) with short $(125 \mu)$ and longer $( \pm 275 \mu)$ fringing hairs (maximally to $300 \mu$ toward hypostoma (Fig. $30 \mathrm{~B}$ ), in $\mathrm{M}$ male (medium male) genal surface nearly glabrous, with only sparse $\pm 300 \mu$ hairs on posterior margin 


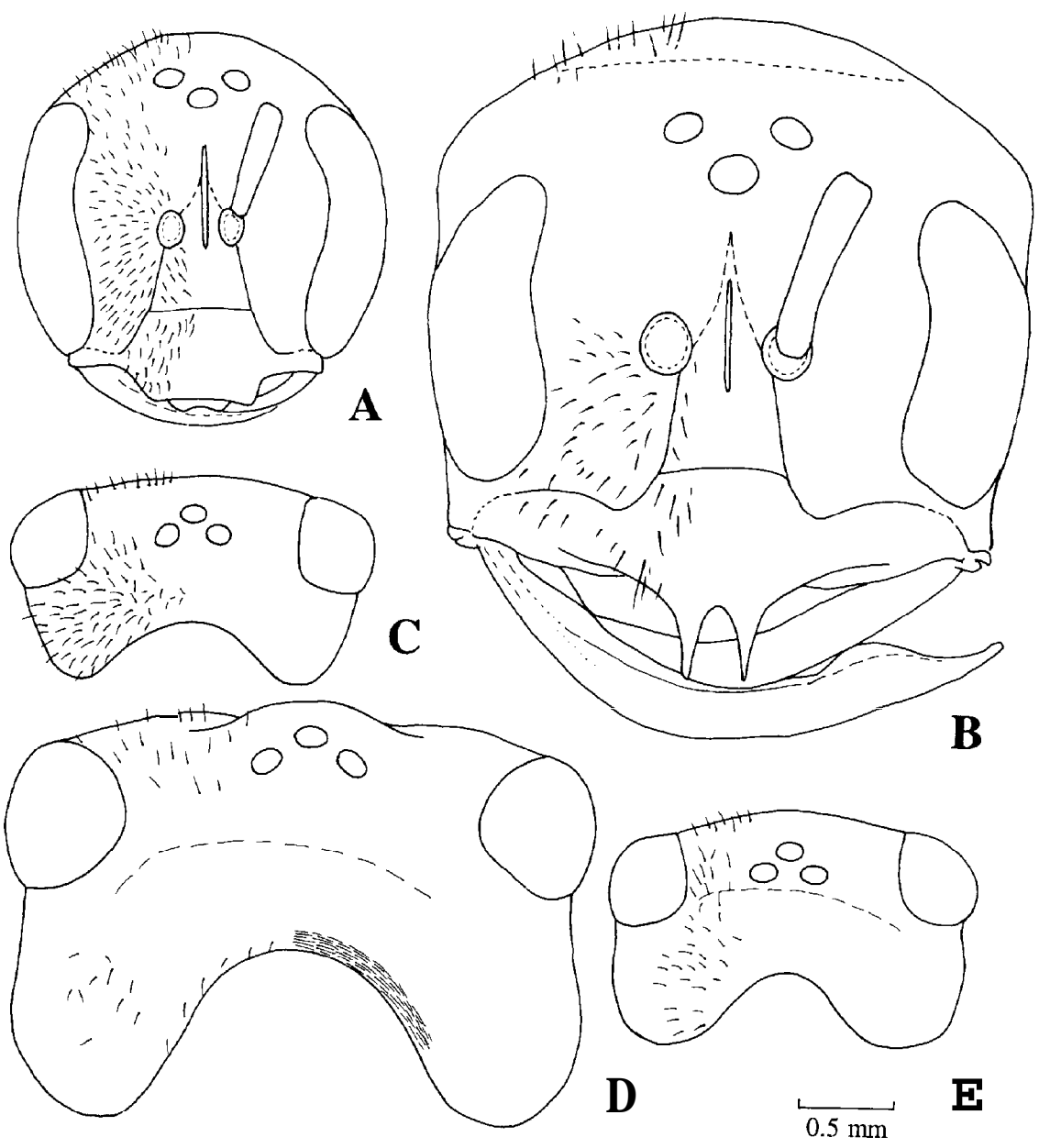

Fig. 32. Lasioglossum (Sudila) bidentatum male. A, B: Head seen frontally; C, D, E: seen dorsally. A, C: Small male, E: Medium male; B, D: Large male.

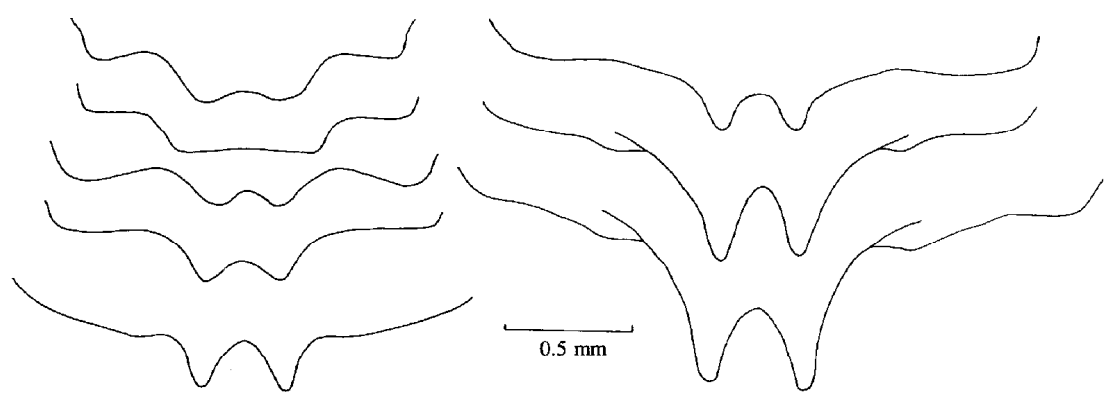

Fig. 33. Lasioglossum (Sudila) bidentatum male. Correlation between body size and length of clypeal teeth. The length approximately (not exactly) corresponds to the size of clypeus. 
(Fig. $30 \mathrm{C}, 31 \mathrm{~B}$ ), and in L male (large male) even fringing hairs absent, with only sparse hairs (300-375 $\mu$ ) on hypostoma (Fig. 30 C). 6 to 11 - Mesosomal dorsum and terga slightly sparser than in female (Fig. $31 \mathrm{C}$ vs. $20 \mathrm{~B}$ ) and very sparser than in L. alphenum male. Tergal hairs arranged as in female.

12- Seen frontally head weakly transverse (Figs. 31 A, 32 A, B). HW : HL on average 1 : 0.92 but variable. 13- Seen frontally lateral ocellus distant from vertex nearly twice own vertical axis even in $\mathrm{S}$ male, far much in $\mathrm{L}$ male. Vertex roundly convex in $\mathrm{S}$ male, very raised, laterally angulate in L male (Fig. 32 A, B). IOD : OOD :OOcD: VOD (on average) $=1: 1.92: 2.36: 2.04$. The last $3 \mathrm{DD}$ much longer than IOD compared with the other consubgeners and the difference much exaggerated in L male (Figs. $30 \mathrm{C}, 32 \mathrm{~B}, \mathrm{D}$ ).

14- Seen dorsally gena wider to very wider than eye (Fig. 30). Seen laterally EW : GW = $1: 1.58$ on average. Gena nearly as wide as eye even in $\mathrm{S}$ male and nearly thrice wider in $\mathrm{L}$ male (Fig. $30 \mathrm{C}$ ); below not projecting in $\mathrm{S}$ male, projecting in $\mathrm{M}$ male and strongly projecting in L male (Fig. 30). In S male gena smooth and shiny with sparse, fine PP (IS = 2.0-3.0) along eye and the remainder area longitudinally granulo-striate (Fig. $30 \mathrm{~A}$ ), in $\mathrm{M}$ male homogeneously striate and dully shining (Fig. $30 \mathrm{~B}$ ) and in L male surface homogeneously smooth (Fig. $30 \mathrm{C}$ ). Malar space not linear, and gradually longer in parallel with enlargement of mandible (Fig. 30, A $\rightarrow$ B $\rightarrow$ C). 15- Postocellar area, ocellocular area and face sculptured as in female in $\mathrm{S}$ male, sometimes even slightly more granular and less shiny with obscure PP $(\phi \mathrm{P} \pm 10 \mu)$, far sparser and surface far smoother in L male. Paraocular area sculptured as in female in $S$ male, homogeneously net-like granular with very obscure PP, except on epistomal lobe where smoother with sparse PP $(\phi 10-20 \mu$, IS 1.0-2.0). In L male smooth area becoming larger and PP sparser. 16 to 17-Supraclypeus $\fallingdotseq$ female.

Clypeus sculptured as in female and males of consubgeners. In L male gradually becoming flatter with longer lateral arm (Fig. $32 \mathrm{~B}$ vs. A), and smoother and shiner with few or no PP. In S male lower margin straight or weakly bidentate; in L male gradually more distinctly bidentate (Figs. 32 A, B, 33).

18-Scape slightly exceeding mid ocellus (Fig. 31 A). Basal flagellomeres relatively long (Fig. 7). $F_{2} L: F_{2} W=1: 0.78 . F_{1}$ below slightly swollen (Fig. 7). Labrum somewhat hexagonal, median convexity longitudinally elliptical, apical margin very gently outcurved (Fig. $22 \mathrm{H}$ ). Mandible varying from normally short and slender to very elongate and sicklelike, with conspicuous subapical widening (Figs. 1, 31 A, B, 32 A, B, 34). 19 to 21- Seen frontally and laterally, pronotal lateral angle much pointed above (Fig. 29 E), outer margin concave; lateral ridge sharply carinate; lateral surface less granular and shiner; these tendencies more acute in L male. 20- Mesoscutum more convex than in female, surface from granular (S male) to smoother and shiner in L male (Fig. $31 \mathrm{C}$ ). Mesoscutellum flatter, smoother and shiner, with very sparse, fine PP (10-15 $\mu$ ), granular only peripherally; median depression weak to absent. Mesepistemal tubercle weak to obsolete (Fig. 3). 22- Propodeal dorsum sculptured as in female. PDL : MTL : MCL $=1: 0.58: 1.11 .23$ - Mid trochanter and femur below not angulate (Fig. $22 \mathrm{~F}$ ). Inner hind tibial spur with teeth shorter and thinner (Fig. 2). $\mathrm{N}$ of teeth in 10 examined male: $5.5 \pm 0.5$, ranging 5-6.

24- Metasoma more slender; tergal sculpture less granular, giving smoother and shiner appearance. 25- S7 (Fig. $22 \mathrm{~J}$ ) with medial process slightly more pointed >alphenum; Ss homogeneously "long" and apical margin uniformly outcurved (Fig. 22 J). 26 (Fig. 35) Gonobase short, about 1.6 times wider than long. Gonocoxite relatively wide, outer margin 


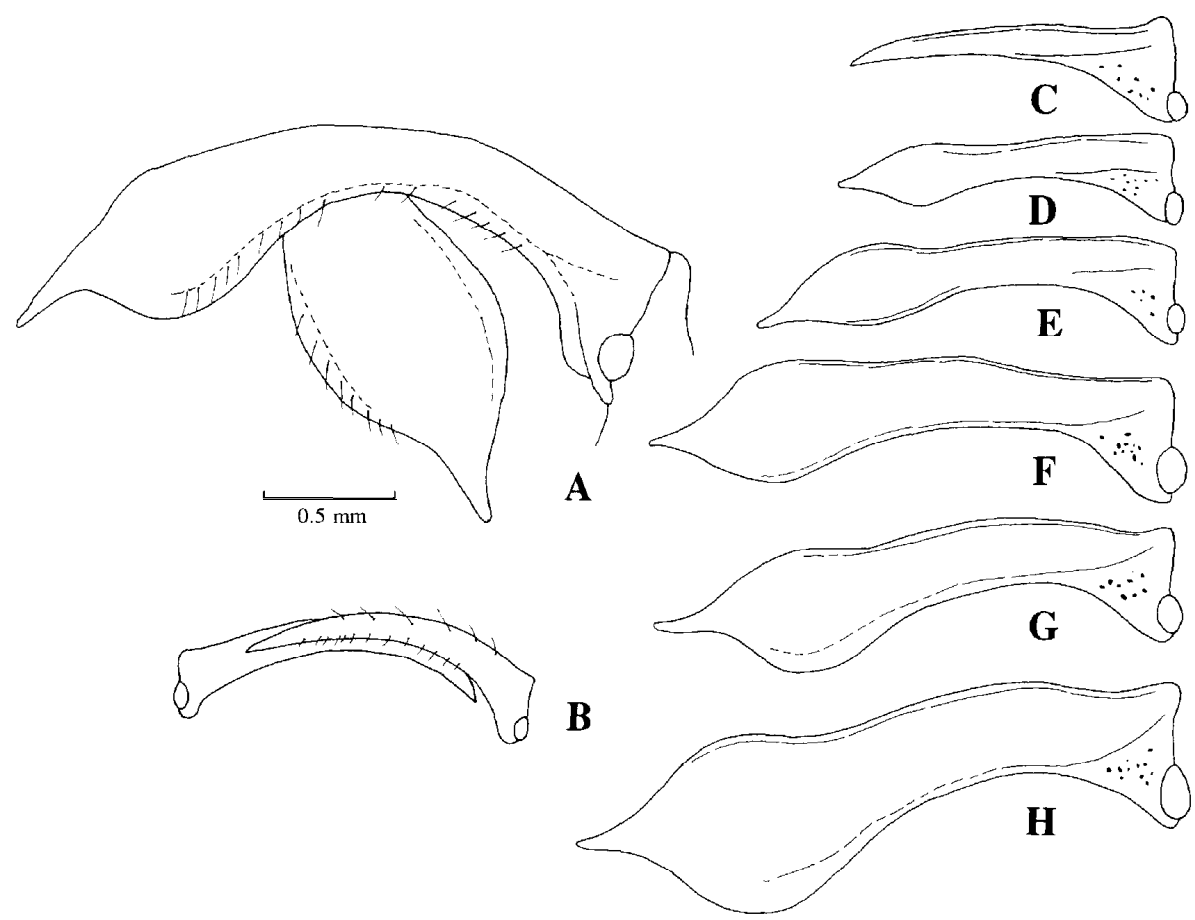

Fig. 34. Lasioglossum (Sudila) bidentatum male. Size and form variation in male mandible. A, B: Maximum and minimum cases shown at the position of the maximum curvature of the lower margin; C-H: Left mandibles arranged in the ascending size order.

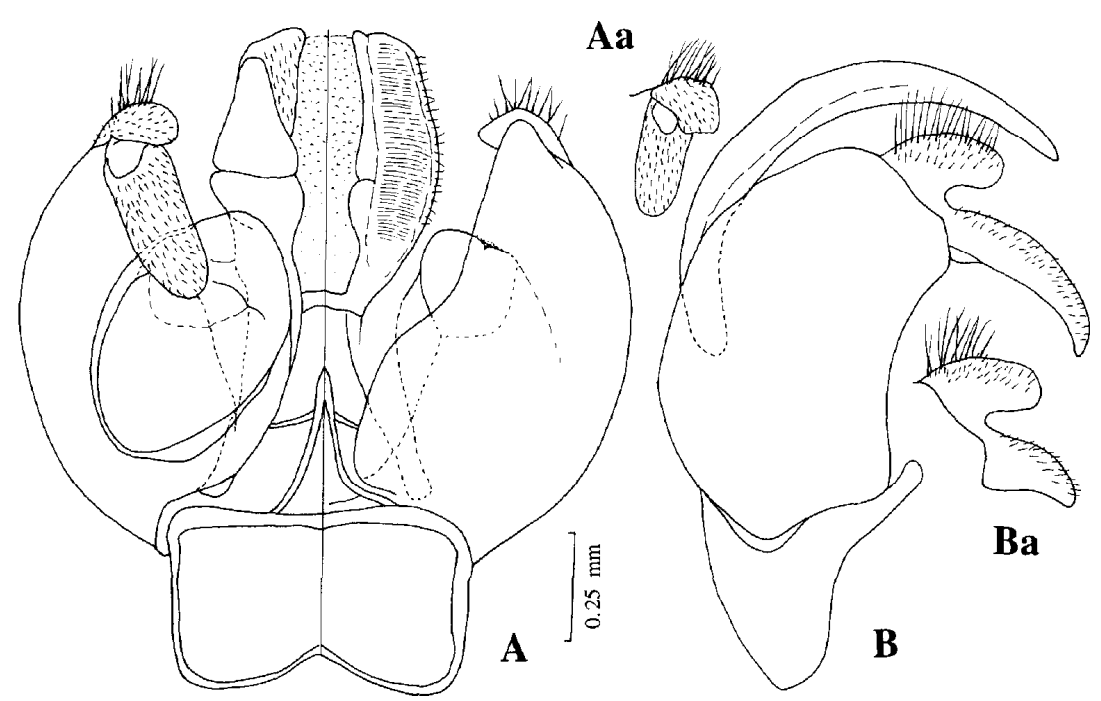

Fig. 35. Male genitalia of Lasioglossum (Sudila) bidentatum. A: Ventral (left) and dorsal (right) views; B: Lateral view; $\mathrm{Aa}, \mathrm{Bb}$ : Gonostylus of another male (Retrose lobe shorter. This male has no transverse stripes on penis valve shown in Fig A). 
basally dilated, apex pointed, dorsal contour roundly outcurved. Volsella large. Penis valve dorsoventrally narrow; dorsally only sparsely haired, transversely striate in 1 male (Fig. 35 A), not in other male. Gonostylus spheroid. Ventral retrose lobe short, tongue-like but longer than in other species, twice longer than wide in 1 male (Fig. 35 Aa) and more in other male (Fig. 35 A).

Specimens examined (Fig. 36): all from Sri Lanka: [NE. Distr.]: Kanda-ela Reservoir, 5.6 mi SW Nuwara, Eliya, 6200 ft: 13 females, 10-21. ii. 1970 (DR); 2 females, 1-5. x. 1970 (OS); Pidurutalagala, $1 \mathrm{~m} \mathrm{~N}$, Nuwara, Eliya: 1 female 2 males, 6500-7500 ft, 14. ii. 1970 (DR); 4 females, 8. x. 1976 (GF, RE, SK, DW); 1 female, World's End, 6800 ft, Horton Plains, 21. ii. 1970 (DR); Hakagala Natural Reserve, 1650-1800 m: 1 female, 23-25. ii.

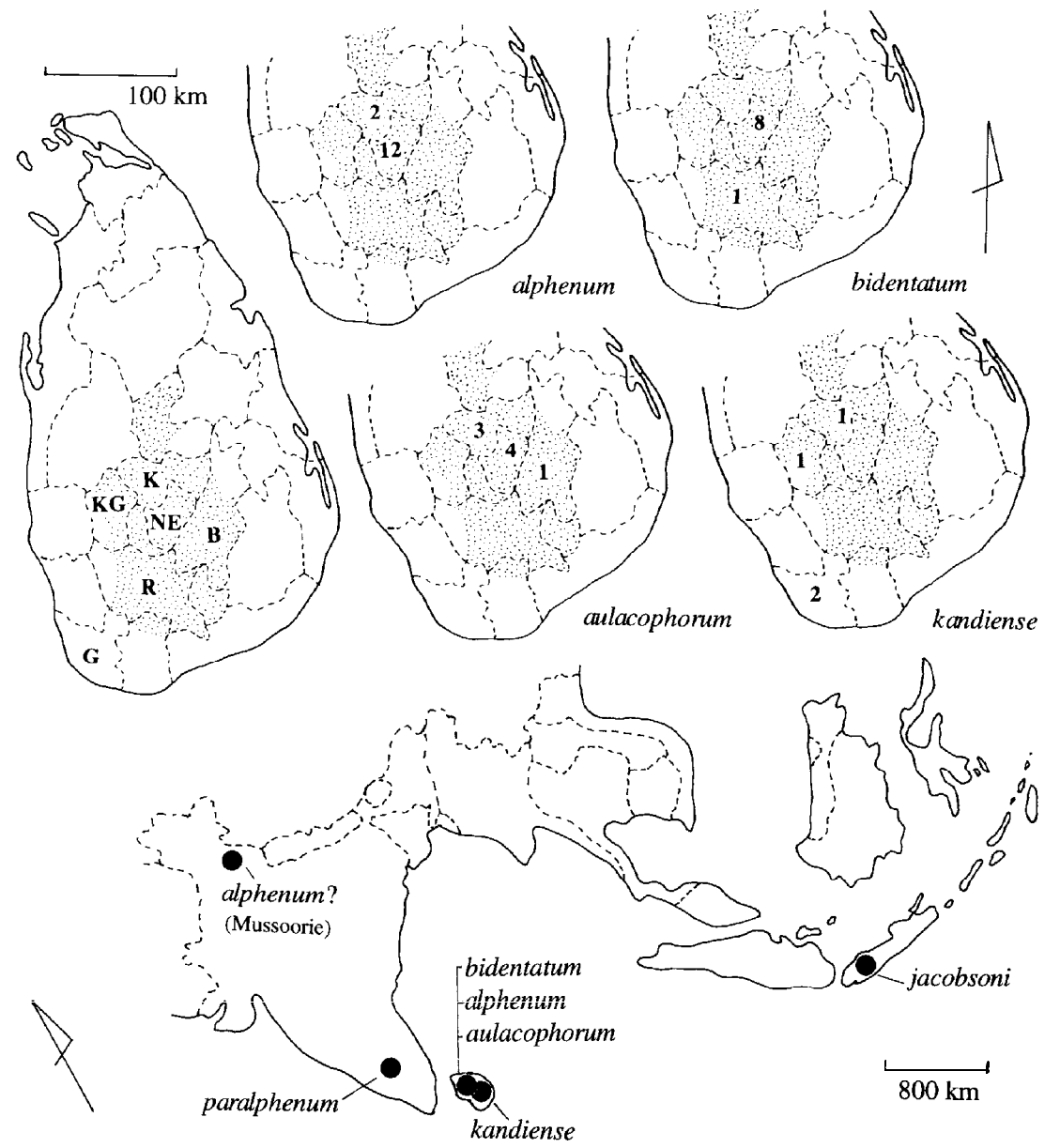

Fig. 36. Geographical distribution of Sudila species. Top: Distribution of 4 Singhalese species. Dotted = Mountainous areas, KG (Kegalla Distr.), K (Kandy Distr.), NE (Nuwara Eliya Distr.), $\mathrm{G}$ (Galle Distr.). $N$ in each district $=$ Number of collection records (each unit record $=$ record at same locality, on same date(s) and by same collector(s)). Bottom: Distribution of all 6 species in India, Sri Lanka and Java. 
1972 (KVK, PB, PF, DW); 1 female, 6-7, ii. 1979 (KVK, PB, TW, SS, TG); 1 female 1 male Hakagala Sanctuary, 23-24. iv. 1981 (KVK, TW, LW). [Bad. Distr.]: 1 male, Ohiya, $5500 \mathrm{ft}$, 1. vi. 1976 (KVK, DW). [Rat. Distr.]: 1 female 1 male, Adams Peak Camey Trail, 7000 ft, 21. x. 1976 (KVK, SK, DW); 1 male, Hakagala Botanic Garden, 6000 ft, black light, 6-8. x. 1976 (C. E. Hevel, RE, SK, DW).

Appendix: Note on the type specimen of L. (S.) bidentatum (Cameron, 1898) female, deposited in Hope Entomological Collections, University Museum, Oxford. As in $L$. alphenum(n) means labels attached, numbered from the top downward, (1) Sudila ceylonica Cam., type, Ceylon, (2) Nov. 1929 sent to P. Bliithgen, (3) Halictus (Sudila) bidentatus Cam. female (syn. Ceylonicola atra Friese, 1918, female and male) [probably handwritten by Bliithgen, S. F. S.], (4) 1017 (typewritten). Mouthparts preserved in a separate slide grass. Morphological identical with the other Singhalese specimens examined by S. F. S: measurements: BL 85, WL \pm 77 , WDL 91, HW 57, HL unmeasurable, MsW 65, MtW 60 (abbreviations see in the appendix in L. alphenump. 29).

\section{Key to the species of Sudila}

1. Antenna 12 segmented.

female 2

Antenna 13 segmented.

male 7

2. Head and mesosoma black with metallic green tint. .......................................... 3

- Head and mesosoma black without metallic green tint. .................................. 4

3. Mesepisternal tubercle present (Fig. 3); sculptures on ocellocular area and mesoscutellum uneven (Figs. 25 E, 26 B); Sri Lanka. ............. alphenım (Cameron)

- Mesepisternal tubercle absent (Fig. 3); sculpture on ocellocular area and mesoscutellum even (Figs. 25 F, 26 D); S. India. .................. paralphenum sp. nov.

4. Small species (5.5 mm, Fig. 8); head longer than wide (Figs. 9, 14 A); metasomal terga 2-4 with white apical fimbriae (Fig. 14 B); Sri Lanka.

kandiense (Cockerell)

- Larger, over $6.5 \mathrm{~mm}$; head as long as or slightly shorter than wide (Figs.9, 10, 18); tergal fimbriae absent.

5. Mesoscutum and propodeal dorsum with fine and weak microreticulation, (Figs. $20 \mathrm{~B}$, D), the former seen as if smooth and shining; propodeal side without dense plumose hairs (as in Fig. 19 A); metasoma often partly or even mostly reddish; Sri Lanka.

bidentatum (Cameron)

- Mesoscutum and propodeal dorsum more coarsely sculptured (Figs. 10 B, C, E, F); hairs on propodeal side dewer (Fig. 19 B); metasoma black.

6. Reticulation of propodeal dorsum finer and denser (Fig. 10 B); Sri Lanka.

ardacophorum (Strand)

- Reticulation of propodeal dorsum coarser; Java. ........................jacobsoni (Friese)

7. Head and mesosoma black with metallic green tint. ........................................ 8

- Head and mesosoma black without metallic tint. ................................................ 9

8. Mesepistemal tubercle present (Fig. 3); gena not angulate (Fig. 21 B, 22 A, B); mandible basally below widened (Fig. 21 B, 22 C, D); mid trochanter and femur below angulate (Fig. 22 E); Sri Lanka. alphenum (Cameron)

- Mesepistemal tubercle absent (Fig. 3); gena angulate (Fig. 2 7B); mid trochanter and femur normal (as in Fig. 22 F); S. India. paralphenum sp. nov. 
9. Small species (5.5 mm, Fig. 8); head longer than wide (Fig. 16 A); Sri Lanka. ................ kandiense (Cockerell)

- Larger (over $4.5 \mathrm{~mm}$, Fig. 8); head as long as or slightly shorter than wide (Figs. 12 A, 31 A, 32 A, B).

10. Mesoscutum and propodeal dorsum sculptured as in female; head not polymorphic; mandible normally slender and short; Sri Lanka........... aulacophorum (Strand)

- Mesoscutum and propodeal dorsum sculptured as in female; head polymorphic (Figs. 31-34); mandible slender in small male, but usually lengthened and subapically widened; clypeus with conspicuous teeth excet for small male; Sri Lanka.

bidentatum (Cameron)

Part II of this study will contain the following sections: Phylogenetic notes and Notes on cephalic polymorphism.

Tables 1 to 4 show some measured values of Sudila species. Abbreviations of measured parts with some explanations (see Sakagami, 1989; Sakagami \& Tadauchi, 1995): L, W = maximum length and width; $\mathrm{D}=$ minimum distance; $\mathrm{BL}=$ body $\mathrm{L}$ (from antennal base to metasomal tip, when the body is bent, fore body and metasoma were separately measured and summed up); WL = L of forewing including tegula; HW = head $\mathbf{W} ; \mathbf{H L}=$ head $\mathrm{L}$, from top of vertex to lower margin of clypeus excluding clypeal tooth (not including tooth); Ms $\mathrm{W}=$ mesosomal $\mathrm{W}$ (between outer rims of tegulae); $\mathbf{M t} \mathbf{W}=$ metasomal $\mathrm{W}$; UOD:MOD:LOD = upper, maximum and lower interorbital $\mathrm{W} ; \mathrm{EL}=$ eye $\mathrm{L} ; \mathrm{CAL}=$ clypealveolar $\mathrm{L} ; \mathrm{CPL}=$ clypeal $\mathrm{L} ; \mathrm{ACL}=\mathrm{L}$ of apical part of clypeus exceeding lower orbital line (in all 3 cases, excluding clypeal tooth as in HL); E W, GW = eye and gena W seen laterally, keeping both antenna1 bases at the same plane); $\mathbf{M d L}=$ mandible L; SPL = scape L; MCL, MTL, PDL = mesoscutellum, metanotum and propodeal dorsum L (first the last 2 parts are measured, both anterior and posterior margins of propodeum are kept at the same place, so that anterior margin of mesoscutellum is seen slightly inclined downward. After the measurement of propodeal and metanotal lengths, the focus is adjusted without moving the specimen to have clearer image of the anterior margin of mesoscutellum); WD = wing diagonal $\mathrm{L}$ (from $M-C u$ bifurcation to inner tip of marginal cell); OOD = ocellocular D; IOD = interocellar D; VOD = verticorbital D (tangential D between summit of vertex and supraorbital line); OOcD = Ocellocipital D; ML = Malar L; F $\boldsymbol{n} \mathbf{L}, \mathbf{F} \boldsymbol{n} \mathbf{W}=\mathrm{L}$ and $\mathrm{W}$ of flagellomere $n$ 
Table 1. Values $(\overline{\mathrm{x}} \pm \mathrm{SD} / \mathrm{n}$ ) of some morphometric characters (shown with abbreviations explained separatelty) in Sudila species (female).

\begin{tabular}{|c|c|c|c|c|c|c|}
\hline Characters & bidentatum & alphenum & paralphenum & kandiense & aulacophorum & jacobsoni \\
\hline \multicolumn{7}{|c|}{10 units $=1 \mathrm{~mm}$} \\
\hline BL & $81.1 \pm 4.4 / 10$ & $75.5 \pm 3.3 / 10$ & $63.6 \pm 2.1 / 13$ & $56.5 \pm 1.5 / 2$ & $80.3 \pm 3.0 / 10$ & $83 / 1$ \\
\hline WL & $75.5 \pm 1.6 / 10$ & $67.3 \pm 1.6 / 10$ & $54.7 \pm 1.3 / 13$ & $50.0 \pm 0.0 / 2$ & $76.9 \pm 4.2 / 9$ & $80 / 1$ \\
\hline \multicolumn{7}{|c|}{25 units $=1 \mathrm{~mm}$} \\
\hline WD & $87.7 \pm 2.5 / 10$ & $73.7 \pm 1.7 / 10$ & $64.7 \pm 1.7 / 13$ & $54.5 \pm 0.5 / 2$ & $86.8 \pm 1.6 / 9$ & $95 / 1$ \\
\hline HW & $55.1 \pm 1.8 / 10$ & $55.1 \pm 1.8 / 10$ & $43.8 \pm 1.6 / 13$ & $41.0 \pm 0.0 / 2$ & $55.7 \pm 1.1 / 10$ & $57 / 1$ \\
\hline $\mathrm{HL}$ & $54.1 \pm 1.8 / 10$ & $54.1 \pm 1.8 / 10$ & $39.9 \pm 2.0 / 13$ & $46.5 \pm 0.5 / 2$ & $53.4 \pm 1.3 / 10$ & $56 / 1$ \\
\hline $\mathrm{MsW}$ & $62.1 \pm 2.9 / 10$ & $61.8 \pm 2.4 / 10$ & $46.6 \pm 2.2 / 13$ & $45.0 \pm 0.5 / 2$ & $65.4 \pm 2.9 / 10$ & $74 / 1$ \\
\hline $\mathrm{MtW}$ & $57.4 \pm 2.1 / 10$ & $57.7 \pm 1.6 / 10$ & $43.3 \pm 2.3 / 13$ & $48.0 \pm 0.0 / 2$ & $64.8 \pm 2.3 / 10$ & $71 / 1$ \\
\hline UOD & $29.6 \pm 1.2 / 10$ & $32.1 \pm 1.0 / 10$ & $25.9 \pm 0.8 / 13$ & $24.5 \pm 0.5 / 2$ & $29.7 \pm 1.1 / 10$ & $31 / 1$ \\
\hline MOD & $35.7 \pm 1.1 / 10$ & $38.5 \pm 1.1 / 10$ & $30.0 \pm 1.3 / 13$ & $26.5 \pm 0.5 / 2$ & $35.3 \pm 1.3 / 10$ & $36 / 1$ \\
\hline LOD & $29.4 \pm 1.4 / 10$ & $31.6 \pm 0.9 / 10$ & $24.6 \pm 1.4 / 13$ & $17.2 \pm 0.2 / 2$ & $27.4 \pm 1.3 / 10$ & $29 / 1$ \\
\hline EL & $37.6 \pm 1.2 / 10$ & $36.2 \pm 1.1 / 10$ & $28.1 \pm 0.7 / 13$ & $31.0 \pm 0.0 / 2$ & $38.4 \pm 0.8 / 10$ & $41 / 1$ \\
\hline CAL & $25.3 \pm 1.1 / 10$ & $24.1 \pm 0.8 / 10$ & $16.9 \pm 1.1 / 13$ & $11.9 \pm 0.0 / 2$ & $22.5 \pm 0.8 / 10$ & $25 / 1$ \\
\hline CPL & $14.1 \pm 0.9 / 10$ & $13.8 \pm 0.4 / 10$ & $9.6 \pm 0.8 / 13$ & $6.2 \pm 0.0 / 2$ & $12.4 \pm 1.0 / 10$ & $13 / 1$ \\
\hline ACL & $10.2 \pm 1.0 / 10$ & $10.4 \pm 0.6 / 10$ & $6.5 \pm 0.5 / 13$ & $4.2 \pm 0.1 / 2$ & $9.0 \pm 0.4 / 10$ & $10 / 1$ \\
\hline $\mathrm{EW}$ & $13.9 \pm 0.5 / 10$ & $12.5 \pm 0.6 / 10$ & $10.7 \pm 0.4 / 13$ & $11.2 \pm 0.3 / 2$ & $15.3 \pm 0.3 / 5$ & $15.5 / 1$ \\
\hline $\mathrm{GW}$ & $14.2 \pm 0.8 / 10$ & $13.4 \pm 0.3 / 10$ & $10.0 \pm 0.5 / 13$ & $7.8 \pm 0.3 / 2$ & $10.9 \pm 0.5 / 5$ & $11.8 / 1$ \\
\hline SPL & $24.1 \pm 0.5 / 5$ & $22.1 \pm 0.6 / 5$ & $19.1 \pm 0.9 / 13$ & $10.3 \pm 0.3 / 2$ & $22.7 \pm 0.4 / 10$ & $26 / 1$ \\
\hline MCL & $14.1 \pm 0.9 / 10$ & $12.6 \pm 0.4 / 10$ & $10.0 \pm 0.5 / 13$ & $10.5 \pm 0.5 / 2$ & $13.2 \pm 0.4 / 5$ & $14 / 1$ \\
\hline MTL & $8.4 \pm 0.6 / 10$ & $8.5 \pm 0.6 / 10$ & $6.1 \pm 0.5 / 13$ & $6.5 \pm 0.5 / 2$ & $8.8 \pm 0.4 / 5$ & $9 / 1$ \\
\hline PDL & $12.8 \pm 0.4 / 10$ & $12.8 \pm 0.4 / 10$ & $9.6 \pm 0.7 / 13$ & $9.0 \pm 0.0 / 2$ & $12.8 \pm 0.4 / 5$ & $15 / 1$ \\
\hline \multicolumn{7}{|c|}{40 units $=1 \mathrm{~mm}$} \\
\hline OOD & $12.7 \pm 0.6 / 10$ & $14.6 \pm 0.9 / 10$ & $11.1 \pm 0.7 / 13$ & $10.0 \pm 0.0 / 2$ & $11.0 \pm 0.3 / 10$ & $12 / 1$ \\
\hline IOD & $9.3 \pm 0.5 / 10$ & $10.9 \pm 0.5 / 10$ & $9.3 \pm 0.8 / 13$ & $8.5 \pm 0.0 / 2$ & $11.1 \pm 0.7 / 10$ & $12 / 1$ \\
\hline VOD & $10.0 \pm 0.8 / 10$ & $9.8 \pm 0.9 / 10$ & $7.8 \pm 0.7 / 13$ & $8.0 \pm 0.0 / 2$ & $8.8 \pm 0.6 / 9$ & $11 / 1$ \\
\hline OOCD & $12.8 \pm 1.4 / 10$ & $13.3 \pm 0.6 / 10$ & $8.0 \pm 1.0 / 13$ & $10.5 \pm 0.5 / 2$ & $11.2 \pm 0.4 / 10$ & $12 / 1$ \\
\hline ML & $2.3 \pm 0.4 / 5$ & $2.1 \pm 0.4 / 5$ & linear & linear & linear & linear \\
\hline $\mathrm{F}_{2} \mathrm{~L}$ & $5.5 \pm 0.4 / 5$ & $5.2 \pm 0.4 / 5$ & $4.0 \pm 0.0$ & $3.0 \pm 0.0 / 2$ & $5.0 \pm 0.6 / 6$ & $5 / 1$ \\
\hline $\mathrm{F}_{2} \mathrm{~W}$ & $6.6 \pm 0.5 / 5$ & $6.4 \pm 0.5 / 5$ & $5.6 \pm 0.2$ & $5.0 \pm 0.0 / 2$ & $6.9 \pm 0.2 / 6$ & $7 / 1$ \\
\hline
\end{tabular}


Table 2. Values ( $\overline{\mathrm{x}} \pm \mathrm{SD} / \mathrm{n})$ of some morphometric characters in Sudila species (male).

\begin{tabular}{|c|c|c|c|c|c|}
\hline Characters & bidentatum & alphenum & paralphenum & kandiense & aulacophorum \\
\hline \multicolumn{6}{|c|}{10 units $=1 \mathrm{~mm}$} \\
\hline $\mathrm{BL}$ & $82.1 \pm 10.5 / 18$ & $67.4 \pm 4.8 / 15$ & $54.0 \pm 1.6 / 3$ & $56 / 1$ & $71.8 \pm 2.1 / 5$ \\
\hline WL & $71.6 \pm 6.6 / 18$ & $62.8 \pm 2.9 / 14$ & $51.7 \pm 2.4 / 3$ & $45 / 1$ & $63.6 \pm 2.0 / 5$ \\
\hline \multicolumn{6}{|c|}{25 units $=1 \mathrm{~mm}$} \\
\hline WD & $86.6 \pm 8.0 / 17$ & $69.5 \pm 3.4 / 23$ & $61.0 \pm 2.2 / 3$ & $52 / 1$ & $76.6 \pm 1.6 / 5$ \\
\hline HW & $61.8 \pm 9.2 / 18$ & $55.2 \pm 3.1 / 25$ & $45.3 \pm 1.9 / 3$ & $38 / 1$ & $47.6 \pm 0.8 / 5$ \\
\hline $\mathrm{HL}$ & $57.3 \pm 10.2 / 18^{*}$ & $45.8 \pm 2.8 / 25$ & $38.7 \pm 0.5 / 3$ & $44 / 1$ & $48.7 \pm 0.9 / 5$ \\
\hline MsW & $57.8 \pm 6.1 / 18$ & $53.0 \pm 3.6 / 25$ & $43.7 \pm 1.7 / 3$ & $41 / 1$ & $55.0 \pm 0.9 / 5$ \\
\hline MtW & $46.9 \pm 5.0 / 18$ & $44.8 \pm 3.0125$ & $35.7 \pm 2.3 / 3$ & $36.5 / 1$ & $51.6 \pm 2.2 / 5$ \\
\hline UOD & $36.8 \pm 5.6 / 18$ & $32.8 \pm 2.7 / 25$ & $27.7 \pm 1.2 / 3$ & $23 / 1$ & $27.0 \pm 1.1 / 5$ \\
\hline MOD & $40.6 \pm 5.9 / 18$ & $34.6 \pm 4.2 / 25$ & $31.1 \pm 1.2 / 3$ & $26 / 1$ & $31.0 \pm 1.3 / 5$ \\
\hline LOD & $36.3 \pm 6.7 / 18$ & $32.6 \pm 2.3 / 25$ & $25.3 \pm 1.2 / 3$ & $16 / 1$ & $21.4 \pm 0.5 / 5$ \\
\hline EL & $33.9 \pm 2.7 / 18$ & $32.0 \pm 1.6 / 25$ & $26.7 \pm 0.9 / 3$ & $30 / 1$ & $33.4 \pm 0.5 / 5$ \\
\hline CAL & $34.6 \pm 5.1 / 10^{*}$ & $30.8 \pm 1.9 / 10$ & $15.0 \pm 0.0 / 3$ & $11 / 1$ & $13.0 \pm 0.2 / 5$ \\
\hline CPL & $21.1 \pm 5.8 / 18^{*}$ & $11.9 \pm 0.8 / 15$ & $9.0 \pm 0.0 / 3$ & $6 / 1$ & $7.1 \pm 0.3 / 5$ \\
\hline ACL & $15.7 \pm 5.7 / 10^{*}$ & $7.5 \pm 1.4 / 10$ & $5.0 \pm 0.0 / 3$ & $3 / 1$ & $4.9 \pm 0.2 / 5$ \\
\hline EW & $24.4 \pm 1.7 / 18$ & $21.1 \pm 0.8 / 25$ & $11.0 \pm 0.8 / 3$ & $11 / 1$ & $14.0 \pm 0.3 / 5$ \\
\hline GW & $38.6 \pm 10.7 / 18^{* *}$ & $21.8 \pm 1.7 / 25$ & $14.3 \pm 0.5 / 3$ & $8 / 1$ & $9.2 \pm 0.2 / 5$ \\
\hline $\mathrm{MdL}$ & $51.6 \pm 14.2 / 18$ & $38.7 \pm 2.9 / 25$ & $32.3 \pm 1.913$ & $16 / 1$ & $20.2 \pm 0.7 / 5$ \\
\hline SPL & $23.2 \pm 3.2 / 16$ & $18.9 \pm 0.8 / 10$ & $16.3 \pm 0.5 / 3$ & $8 / 1$ & $16.0 \pm 0.6 / 5$ \\
\hline MCL & $13.4 \pm 1.6 / 10$ & $11.2 \pm 0.7 / 10$ & $9.7 \pm 0.5 / 3$ & $10 / 1$ & $11.2 \pm 0.4 / 5$ \\
\hline MTL & $7.0 \pm 0.5 / 10$ & $7.2 \pm 0.5 / 10$ & $6.0 \pm 0.8 / 3$ & $5.5 / 1$ & $6.6 \pm 0.5 / 5$ \\
\hline PDL & $12.1 \pm 1.4 / 10$ & $11.2 \pm 0.9 / 10$ & $10.0 \pm 0.0 / 3$ & $8 / 1$ & $12.8 \pm 0.8 / 5$ \\
\hline \multicolumn{6}{|c|}{40 units $=1 \mathrm{~mm}$} \\
\hline OOD & $18.6 \pm 4.2 / 18$ & $16.4 \pm 1.3125$ & $13.3-\mathrm{t} 1.2 / 3$ & $10 / 1$ & $11.0 \pm / 5$ \\
\hline IOD & $9.7 \pm 1.3 / 18$ & $10.6 \pm 0.9 / 25$ & $9.3 \pm 0.5 / 3$ & $9 / 1$ & $10.0 \pm / 5$ \\
\hline VOD & $19.7 \pm 5.8 / 12$ & $11.2 \pm 1.0 / 10$ & $7.2 \pm 0.6 / 3$ & $12 / 1$ & $10.8 \pm / 5$ \\
\hline $\mathrm{OOcD}$ & $23.0 \pm 6.4 / 6$ & $15.3 \pm 1.2 / 15$ & $8.7 \pm 0.5 / 3$ & $10 / 1$ & $10.2-\mathrm{t} / 5$ \\
\hline ML & $6.3 \pm 2.7 / 18$ & $4.6 \pm 0.7 / 19$ & $1.0 \pm 0.1 / 3$ & linear/ 1 & linear \\
\hline$F_{1 L}$ & $8.2 \pm 1.0 / 10$ & $6.9 \pm 0.4 / 6$ & $5.5 \pm 0.4 / 3$ & $3.5 / 1$ & $5.1 \pm / 5$ \\
\hline $\mathrm{F}_{2} \mathrm{~L}$ & $8.7 \pm 0.9 / 10$ & $7.5 \pm 0.5 / 6$ & $6.5 \pm 0.4 / 3$ & $3.5 / 1$ & $6.2 \pm / 5$ \\
\hline $\mathrm{F}_{3} \mathrm{~L}$ & $8.4 \pm 0.7 / 10$ & $7.6 \pm 0.4 / 6$ & $6.5 \pm 0.4 / 3$ & $5 / 1$ & $6.8 \pm / 5$ \\
\hline $\mathrm{F}_{2} \mathrm{~W}$ & $6.8 \pm 0.2 / 10$ & $6.8 \pm 0.2 / 6$ & $6.0 \pm 0.0 / 3$ & $5 / 1$ & $7.1 \pm / 5$ \\
\hline
\end{tabular}

** Downward to the middle of clypeus, not to the tip of clypeal tooth.

Excluding genal process. 
Table 3. Coefficients of variation of morphometric characters in Sudila species.

\begin{tabular}{lrrrrrrrr}
\hline Characters & \multicolumn{2}{c}{ bidentatum } & \multicolumn{2}{c}{ alphenum } & \multicolumn{2}{c}{ aulacophorum } & \multicolumn{2}{c}{ paraphenum } \\
(abbrev.) & female & male & female & male & female & male & female & male \\
\hline BL & 5.4 & 12.8 & 4.4 & 7.1 & 3.0 & 2.9 & 3.3 & 3.0 \\
WL & 2.1 & 9.2 & 2.4 & 4.6 & 5.5 & 3.1 & 2.4 & 4.6 \\
WD & 2.8 & 9.2 & 2.3 & 4.9 & 1.8 & 2.1 & 2.6 & 3.6 \\
HW & 3.3 & 14.9 & 3.1 & 5.6 & 1.9 & 1.7 & 3.6 & 4.2 \\
HL & 2.4 & 17.8 & 1.7 & 6.1 & 2.4 & 1.8 & 5.0 & 1.2 \\
MsW & 4.7 & 10.5 & 3.9 & 6.8 & 4.4 & 1.6 & 4.7 & 3.9 \\
MtW & 3.6 & 10.7 & 2.8 & 6.7 & 3.5 & 4.3 & 5.3 & 6.4 \\
UOD & 4.0 & 15.2 & 3.1 & 8.2 & 3.7 & 4.1 & 3.1 & 4.3 \\
MOD & 3.1 & 14.5 & 2.8 & 12.1 & 3.7 & 4.2 & 4.3 & 3.8 \\
LOD & 4.8 & 18.4 & 2.8 & 7.1 & 4.7 & 2.3 & 5.7 & 4.7 \\
EL & 3.2 & 8.0 & 3.0 & 5.0 & 2.1 & 1.5 & 2.5 & 3.4 \\
CAL & 4.3 & 14.7 & 3.3 & 6.2 & 3.5 & 1.5 & 6.5 & 0.0 \\
CPL & 6.4 & 27.4 & 2.9 & 5.7 & 8.0 & 4.2 & 8.3 & 0.0 \\
ACL & 9.8 & 36.3 & 5.8 & 18.6 & 4.4 & 4.1 & 7.7 & 0.0 \\
EW & 3.6 & 7.0 & 4.8 & 3.8 & 2.0 & 2.1 & 3.7 & 7.2 \\
GW & 5.6 & 29.2 & 2.2 & 7.8 & 4.6 & 2.2 & 5.0 & 3.5 \\
MdL & & 27.5 & & 7.5 & & 3.5 & & 5.9 \\
SPL & 2.1 & 14.0 & 2.7 & 4.6 & 1.7 & 3.8 & 4.7 & 3.1 \\
MCL & 6.7 & 11.6 & 3.5 & 6.1 & 3.0 & 3.6 & 5.0 & 5.7 \\
MTL & 6.7 & 7.1 & 7.3 & 6.9 & 4.5 & 7.6 & 8.2 & 13.3 \\
PDL & 3.4 & 11.3 & 2.4 & 7.8 & 3.1 & 6.2 & 7.3 & 0.0 \\
OOD & 4.7 & 22.6 & 6.2 & 7.9 & 2.7 & 0.0 & 6.3 & 9.0 \\
IOD & 5.4 & 13.4 & 4.6 & 8.5 & 6.3 & 0.0 & 8.6 & 5.4 \\
VOD & 8.0 & 29.4 & 9.2 & 8.9 & 6.8 & 3.7 & 9.0 & 6.5 \\
00CD & 10.9 & 27.8 & 4.5 & 7.8 & 3.5 & 3.9 & 1.2 & 5.7 \\
ML & 17.4 & 42.8 & 16.6 & 15.2 & - & - & - & 10.0 \\
F1L & & 12.1 & & 5.8 & & 3.9 & & 7.2 \\
F2L & 7.2 & 10.3 & 7.7 & 6.7 & 1.2 & 6.4 & 0.0 & 6.1 \\
F3L & & 8.3 & & 5.3 & & 5.9 & & 6.1 \\
F2W & 7.8 & 2.9 & 7.8 & 2.9 & 2.8 & 2.8 & 3.6 & 0.0 \\
\hline & & & & & & & & \\
\hline
\end{tabular}


Table 4 -1. Some ratios between /among morphometric characters in Sudila.

\begin{tabular}{|c|c|c|c|}
\hline Characters/Ratios & Species & Female & Male \\
\hline \multirow[t]{6}{*}{ HW:MsW:MtW } & paralphenum & 1:1.06:0.99 & $1: 0.96: 0.79$ \\
\hline & alphenum & $1: 1.11: 1.04$ & $1: 0.96: 0.81$ \\
\hline & bidentatum & $1: 1.12: 1.04$ & 1:0.93:0.76 \\
\hline & kandiense & $1: 1.10: 1.17$ & $1: 1.08: 0.96$ \\
\hline & aulacophorum & $1: 1.17: 1.16$ & $1: 1.15: 1.08$ \\
\hline & jacobsoni & 1: $1.03: 1.77$ & \\
\hline \multirow[t]{6}{*}{ HW:HL } & paralphenum & $1: 0.91$ & $1: 0.85$ \\
\hline & alphenum & $1: 0.94$ & $1: 0.83$ \\
\hline & bidentatum & $1: 0.98$ & $1: 0.92$ \\
\hline & kandiense & $1: 1.13$ & $1: 1.16$ \\
\hline & aulacophorum & $1: 0.96$ & $1: 1.02$ \\
\hline & jacobsoni & $1: 0.98$ & \\
\hline \multirow[t]{6}{*}{ UOD:MOD:LOD } & paralphenum & $1: 1.15: 0.95$ & 1:1.13:0.91 \\
\hline & alphenum & $1: 1.20: 0.78$ & $1: 1.05: 0.99$ \\
\hline & bidentatum & $1: 1.21: 0.99$ & $1: 1.10: 0.99$ \\
\hline & kandiense & $1: 1.08: 0.70$ & $1: 1.08: 0.70$ \\
\hline & aulacophorum & 1:1.19:0.94 & $1: 1.15: 0.79$ \\
\hline & jacobsoni & $1: 1.16: 0.93$ & \\
\hline \multirow[t]{6}{*}{ CPL:CAL:ACL } & paralphenum & 1: $1.76: 0.68$ & $1: 1.67: 0.55$ \\
\hline & alphenum & $1: 1.75: 0.75$ & 1:1.60:0.39 \\
\hline & bidentatum & $1: 1.79: 0.72$ & $1: 1.63: 0.74$ \\
\hline & kandiense & $1: 1.90: 0.68$ & $1: 1.83: 0.55$ \\
\hline & aulacophorum & $1: 1.81: 0.72$ & $1: 1.82: 0.68$ \\
\hline & jacobsoni & $1: 1.92: 0.78$ & \\
\hline
\end{tabular}

- Continued - 
Table 4 -2. Some ratios between /among morphometric characters in Sudila.

\begin{tabular}{llll}
\hline Characters/Ratios & Species & Female & Male \\
\hline EW:GW & paral phenum & $1: 0.93$ & $1: 1.30$ \\
& alphenum & $1: 1.08$ & $1: 1.03$ \\
& bidentatum & $1: 1.02$ & $1: 1.58$ \\
& kandiense & $1: 0.69$ & $1: 0.72$ \\
& aulacophorum & $1: 0.71$ & $1: 0.66$ \\
& jacobsoni & $1: 0.76$ & \\
\hline IOD:OOD:OOcD:VOD & paralphenum & $1: 1.19: 0.86: 0.84$ & $1: 1.43: 0.93: 0.99$ \\
& alphenum & $1: 1.34: 1.22: 0.90$ & $1: 1.55: 1.44: 1.06$ \\
& bidentatum & $1: 1.36: 1.38: 1.07$ & $1: 1.92: 2.36: 2.04$ \\
& kandiense & $1: 1.18: 1.23: 0.94$ & $1: 1.11: 1.11: 1.20$ \\
& aulacophorum & $1: 0.99: 0.99: 0.79$ & $1: 1.10: 1.02: 1.08$ \\
& jacobsoni & $1: 1.00: 1.00: 0.97$ & \\
\hline F2L:F2W & paralphenum & & $1: 1.08$ \\
& alphenum & & $1: 0.89$ \\
& bidentatum & & $1: 0.78$ \\
& kandiense & & $1: 1.42$ \\
& aulacophorum & & $1: 1.14$ \\
\hline PDL:MTL:MCL & paralphenum & $1: 0.61: 0.96$ & $1: 0.60: 0.97$ \\
& alphenum & $1: 0.66: 1.02$ & $1: 0.64: 1.00$ \\
& bidentatum & $1: 0.66: 1.10$ & $1: 0.58: 1.11$ \\
& kandiense & $1: 0.72: 1.17$ & $1: 0.69: 1.25$ \\
& aulacophorum & $1: 0.69: 1.03$ & $1: 0.52: 0.88$ \\
& iacobsoni & $1: 0.60: 1.07$ & \\
\hline & &
\end{tabular}

